MORALES, Ana María. "Vigilancia en la modernidad tardía:

El monitoreo telemático de infractores".

Polít. crim. Vol. 8, № 16 (Diciembre 2013), Art. 3, pp. 408-471.

[http://www.politicacriminal.cl/Vol_08/n_16/Vol8N16A3.pdf]

\title{
Vigilancia en la modernidad tardía: El monitoreo telemático de infractores
}

\author{
Ana María Morales Peillard \\ Abogado Universidad de Chile, \\ Magíster en Política Criminal, London School of Economics and Political Science, \\ Directora del Área de Justicia y Reinserción de la Fundación Paz Ciudadana, \\ Docente en criminología y política criminal UAH. \\ amorales@pazciudadana.cl
}

\section{Resumen}

El presente artículo busca entregar antecedentes para un debate acerca de lo que se puede esperar con la implementación del monitoreo telemático en nuestro país. Para esto, se realiza un recorrido, comenzando con los orígenes de su utilización en otras legislaciones, analizando sus principales características y aplicaciones en el sistema penal. Además, se realiza un breve examen de su regulación en la Ley $\mathrm{N}^{\circ} 20.603$.

Junto con lo anterior, y siendo éste el propósito principal, el presente trabajo intenta sistematizar algunas preguntas vinculadas al cumplimiento de los objetivos trazados con su implementación, además de abordar algunos debates que se han suscitado en la experiencia comparada. De esta forma, busca entregar respuestas en base a las evaluaciones e investigaciones realizadas hasta la fecha, apuntando fundamentalmente a entender la utilidad del monitoreo telemático en relación a los objetivos asociados a la reducción de la población recluida, a la entrega de una alternativa costo-eficiente al encarcelamiento u otros programas en la comunidad, y a la reducción de la reincidencia de los sujetos a control. A esto se suman, algunos análisis en relación a la aplicación de este mecanismo de control respecto de determinados delitos y ofensores, de sus efectos en los infractores y sus familias, de la afectación de la garantía constitucional a la privacidad y de otros derechos, y la promoción de una sociedad vigilante.

\section{Palabras clave}

Monitoreo telemático, control telemático, monitoreo electrónico, sanciones intermedias, penas sustitutivas, Ley $\mathrm{N}^{\circ} 20.603$.

\begin{abstract}
This article seeks to provide background for a discussion of what can be expected with the implementation of electronic monitoring in Chile. For that purpose a general review regarding electronic monitoring is carried out, beginning with the origins of its implementation in other legislations, analyzing their main features and applications in the penal system. In addition, there is a brief review of its regulation under the Law $\mathrm{N}^{\circ} 20.603$.
\end{abstract}


MORALES, Ana María. "Vigilancia en la modernidad tardía:

El monitoreo telemático de infractores".

Along with the above, and as its main purpose, the article also seeks to systematize some questions relating to the achievement of the objectives outlined in the implementation of electronic monitoring, together with addressing some debates that have arisen concerning international experiences in its use. Thus, it seeks to provide answers based on the evaluations and research to date, mainly pointing to understand the utility of electronic monitoring in relation to the objectives associated with the reduction of prison population, to deliver a cost-effective alternative to imprisonment or to other programs in the community, and the reduction of recidivism of the persons subject to it. Also, an analysis is carried out regarding the application of this control mechanism for certain offenses and offenders, the effects on offenders and their families, the affectation of the constitutional guarantee of privacy and other rights, and the promotion of a surveillance society.

\section{Key words}

Telematic monitoring, telematic control, electronic monitoring, intermediate sanctions, substitutive sanctions, Law 20.603.

\section{Introducción}

El monitoreo telemático de infractores ha sido introducido en diversas legislaciones a partir de los años 80, formando parte del catálogo punitivo del cual disponen los estados para hacer frente a la delincuencia. Entre los objetivos usualmente citados por los gobiernos, encontramos desde aquellos instrumentales, que apuntan a disminuir la población encarcelada, reducir los costos del Estado, y plasmar más control a las penas en libertad; aquéllos asociados a la prevención especial positiva, evitando los efectos nocivos del encarcelamiento, ofreciendo más posibilidades de reinserción, y buscando controlar la asistencia a programas de intervención en la comunidad; hasta algunos más bien simbólicos, en orden a aparecer más enérgicos en sus respuestas contra el delito, y a demostrar que los avances tecnológicos y la modernización, también alcanzan al sistema penal.

Como se observa, los objetivos perseguidos con su implementación han sido variados, y por lo tanto surge la interrogante de si efectivamente éstos han sido logrados. Considerando lo anterior, en la literatura comparada es posible encontrar investigaciones que han buscado hacerse cargo de evaluar el cumplimiento de algunos de dichos propósitos, en base a evidencia empírica. En ese contexto, el presente artículo busca sistematizar ciertas preguntas vinculadas al cumplimiento de dichos objetivos, junto con abordar algunos debates que se han suscitado en otros países a propósito de la implementación. De esta forma, se busca otorgar respuestas en base a las evaluaciones realizadas hasta la fecha, apuntando fundamentalmente a entender la utilidad del monitoreo telemático en relación a los objetivos asociados a la reducción de la población recluida, de entregar una alternativa costo-eficiente al encarcelamiento u otros programas en la comunidad, y de reducir la reincidencia de los sujetos a control. A aquello, se suman algunos análisis en relación a la aplicación de este mecanismo de control respecto de determinados delitos y ofensores, de 
Polít. crim. Vol. 8, No 16 (Diciembre 2013), Art. 3, pp. 408-471.

[http://www.politicacriminal.cl/Vol_08/n_16/Vol8N16A3.pdf]

los efectos en los infractores y sus familias, de la afectación de la garantía constitucional a la privacidad, y de la creación de una sociedad vigilante.

Como marco conceptual de dicho debate, el primer capítulo repasará lo que ha sido la implementación del monitoreo telemático en otras legislaciones, enmarcando su análisis dentro de lo que la criminología ha denominado "sanciones intermedias". Luego, se efectuará una descripción de las distintas tecnologías que lo componen y sus diferentes usos en el sistema penal.

El segundo capítulo efectuará un breve repaso de los principales contenidos de la ley $\mathrm{N}^{\circ} 20.603$, recientemente promulgada, en relación a la utilización del monitoreo telemático en el contexto de las penas sustitutivas, analizando a su vez algunos aspectos particulares de su implementación.

Finalmente, el tercer capítulo, y coincidiendo con el objetivo principal del presente análisis, contendrá una sistematización de los estudios y la evidencia criminológica internacional, en relación a los cuestionamientos antes descritos, con el propósito de aportar a futuros debates que se susciten en su aplicación en nuestro país. En ese sentido, una de las principales finalidades de este artículo es debatir empíricamente acerca de sus consecuencias y despejar los mitos que han rodeado su implementación en otros países, de manera de aportar con antecedentes para un debate realista de lo que se puede esperar con su próxima utilización, junto con develar aquellas áreas respecto de las cuales aún es necesario seguir investigando, considerando el reciente desarrollo de este tipo de tecnologías.

\section{Introducción a las sanciones intermedias y a la utilización del monitoreo telemático como tecnología de supervisión.}

\subsection{Antecedentes históricos sobre el uso de alternativas al encarcelamiento.}

La implementación del monitoreo electrónico en diversas legislaciones, surge junto a la búsqueda de respuestas sancionatorias distintas a la privación de la libertad en recintos carcelarios.

Fue en el seno del movimiento desencarcelatorio de los años 70, surgido al alero de la criminología crítica, que utilizando el análisis desarrollado por la teoría del etiquetamiento sobre el papel que juega la prisión en la desviación secundaria, se propuso la derivación de los conflictos sociales fuera del sistema penal. Como señala Larrauri, durante esta época abundaron las críticas a las instituciones totales, como la prisión, y se abogó por la solución de los conflictos de manera autónoma, sin intervención del derecho penal. En ese mismo contexto, para aquellas personas cuya entrada al sistema penal se tornaba inevitable, se buscó alternativas tendientes a evitar su paso por la cárcel. De esta forma, la discusión sobre las alternativas en dicha época, buscaba no sólo acortar el tiempo de privación de la 
MORALES, Ana María. "Vigilancia en la modernidad tardía:

El monitoreo telemático de infractores".

libertad para evitar la sobrepoblación, si no también evitar la entrada a la prisión, considerando su efecto estigmatizador y su carácter desocializador. ${ }^{1}$

Sin embargo, esta reivindicación de los años 70 fue cuestionada en la década siguiente, considerando que la introducción de las sanciones alternativas a la pena privativa de la libertad, no fueron concebidas en las distintas legislaciones como un producto del triunfo de los movimientos desencarcelatorios, sino como consecuencia del interés de desarrollar un sistema penal más eficaz, de aumentar el control social, y de reducir el gasto público debido a la crisis fiscal. ${ }^{2}$ En ese contexto, autores como Cohen, advirtieron que la introducción de alternativas a la cárcel había implicado más bien ampliar las redes de control penal a hechos que antes no eran captados por su órbita, a través del fenómeno del "netwidening". 3

Esto implicó en muchos casos la generación de una política penal expansiva, donde las alternativas en definitiva no operaron "en vez" de la cárcel, si no como complemento de ésta, especialmente para aquellos casos de menor lesividad, que no lograban ser divertidos del sistema penal. Como señala Bottoms, la cárcel seguía repleta con los infractores más peligrosos, y las alternativas iban dirigidas a sectores como los jóvenes, los infractores primerizos, y los de cuello blanco, que tampoco tradicionalmente eran condenados a la cárcel. ${ }^{4}$ Así, las alternativas se "configuraban como alternativas a la puesta en libertad". 5 En ese contexto, como plantea Larrauri, se llegó a la paradoja de que el retorno a la pena privativa de libertad parecía ser la única solución viable, lo que claramente fue rechazado por su inconveniencia tanto por el progresismo como por los sectores más conservadores, por lo que en los años 80 se produce, como señala la citada autora, una "reafirmación cautelosa" de las alternativas, intentando aseverar sus valores propios y reducir sus inconvenientes. ${ }^{6}$

Es así como surge una postura intermedia, basada en el principio de especificidad, que defendía la aplicación de las alternativas para aquellos casos en que "el encierro en prisión parecía innecesariamente severo y para los cuales la probation, parecía una sanción inapropiadamente leve". 7 Es en ese contexto que surge con fuerza la necesidad de generar sanciones "intermedias", "comunitarias" o "alternativas", como las conocemos en la actualidad, ${ }^{8}$ que pudieran dar respuesta a esta necesidad política criminal.

${ }^{1}$ LARRAURI, Elena y CID, José, "Uso expansionista de la prisión y políticas reduccionistas", en: LARRAURI, Elena y CID, José, (Coords.) Las Penas alternativas a la prisión, Barcelona: Bosch, 1997.

${ }^{2}$ LARRAURI, Elena, "Las paradojas de importar alternativas a la cárcel en el Derecho Penal español", Anuario de Derecho Penal y Ciencias Penales, 1991, 1 pp. 45-62.

${ }^{3}$ COHEN, Stanley, "The punitive city: Notes on the dispersal of social control", Contemporary Crises, 1979, 3 (4), pp. 339-363.

${ }^{4}$ BOTTOMS, Anthony, "Neglected features of contemporary penal systems", en: GARLAND, David; YOUNG, Peter (Eds.) The power to punish, Londres: Heinemann, 1983. Cit.: LARRAURI, "Las paradojas", cit. nota $\mathrm{n}^{\circ} 2$.

${ }^{5}$ LARRAURI, "Las paradojas", cit. nota ${ }^{\circ} 2$, p. 47.

${ }^{6}$ LARRAURI, "Las paradojas", cit. nota ${ }^{\circ}$ 2, p. 52.

${ }^{7}$ PETERSILIA, Joan, "A decade of experimenting with intermediate sanctions: what have we learned?", Journal of the Justice Research and Statistics Association, 1999, 1 (1), p.10. La traducción es de la autora.

${ }^{8}$ ALBRECHT, Hans-Joerg, "Imprisonment and alternatives to prisons: Changes and prospects in comparative perspective", Revista Académica, 3 (6), UNAM-Instituto de Investigaciones Jurídicas, 2006, p. 7. La traducción es de la autora. 
Polit. crim. Vol. 8, № 16 (Diciembre 2013), Art. 3, pp. 408-471.

[http://www.politicacriminal.cl/Vol_08/n_16/Vol8N16A3.pdf]

En particular, de acuerdo a Petersilia, tres eventos habrían colaborado con fuerza en la generación de las sanciones intermedias en el caso de Estados Unidos. El primero de ellos se vinculó a la existencia de sobrepoblación penal al sur del país, frente a lo cual, al no contar los estados con presupuesto para construir nuevos recintos, se tuvo que buscar nuevas intervenciones en los infractores. La idea era que éstas fueran vistas por los votantes, no como programas sociales "indulgentes" aplicables a quienes violaban la ley, sino como intervenciones "punitivas" más que "rehabilitadoras". Fue así, como en esos estados se generaron los denominados "intensive supervision programs" (programas de supervisión intensiva), que supusieron un mayor control de los condenados a penas en libertad. ${ }^{9}$

Un segundo evento, se habría producido de la mano de algunas evaluaciones de programas de ofensores federales condenados al cumplimiento de penas en libertad, los que de acuerdo a estudios, como el realizado por Petersilia y sus colaboradores, ${ }^{10}$ habrían concluido que la supervisión de estos infractores a través de la probation ${ }^{11}$ había sido inefectiva, acarreando serias consecuencias para la seguridad pública.

Finalmente, un tercer elemento estuvo unido al surgimiento del movimiento del just deserts (justo merecimiento), que destacó la necesidad de crear nuevas alternativas entre la probation y la cárcel, que permitiesen una graduación de la pena en función del ilícito cometido, representada entre otros autores por Von Hirsch y Wasik; ${ }^{12}$ junto con otras versiones proporcionalistas más matizadas y permeables los criterios asociados a la prevención especial, como la expuesta por Morris y Tonry. ${ }^{13}$ En efecto, estos últimos autores argumentaron que la existencia de "sanciones intermedias" rigurosamente implementadas, servirían de mejor forma a las víctimas y al sistema de justicia. Así, la existencia de un abanico de sanciones que pudieran ser aplicadas, considerando la gravedad del hecho, resultaba esencial para la creación de un sistema de aplicación de sanción racional. En ese contexto, las propuestas proporcionalistas buscaron dejar de lado el enfoque rehabilitador que sólo apuntaba sus críticas al uso de la privación de la libertad en el caso de las penas cortas, fundadas en el contagio criminógeno y la imposibilidad de realizar un adecuado tratamiento. De esta forma, en el ámbito continental, considerando

\footnotetext{
${ }^{9}$ PETERSILIA, "A decade of experimenting with intermediate sanctions", cit. nota $n^{\circ} 7, p .10$. La traducción es de la autora.

${ }^{10}$ PETERSILIA, Joan; TURNER, Susan; KAHAN, James y PETERSON, Joyce, Granting felons probation: public risks and alternatives, Washington: National Institute of Justice y RAND Corporation, 1985.

${ }^{11}$ Dependiendo de la legislación, la probation puede abarcar fórmulas de suspensión de la condena o de la imposición de una pena privativa de la libertad, la sustitución de ésta última, o la imposición de sanciones comunitarias como penas principales; que generalmente supone la supervisión directa a través de un funcionario y la intervención de la conducta infractora a través de programas psico-socio laborales. En el contexto jurídico nacional, suele asimilarse a la libertad vigilada regulada en la Ley $\mathrm{N}^{\circ} 18.216$, que pasó a ser una pena sustitutiva después de la reforma a la Ley $\mathrm{N}^{\circ} 20.603$, aun cuando la homologación supondría también abordar hipótesis de suspensión como la contemplada en el artículo 398 del Código Procesal Penal, pero que en nuestro contexto no suponen una supervisión directa o la intervención de la conducta infractora. Por eso, su traducción estricta bajo el concepto de "libertad vigilada", debe ser tomada con precaución.

${ }^{12}$ VON HIRSCH, Andrew, Censurar y castigar, Madrid: Trotta, 1998; VON HIRSCH, Andrew; WASIK, Martin, "Non-custodial penalties and the principles of Desert", The Criminal Law Review, 1988, pp.554-572.

${ }^{13}$ MORRIS, Norval y TONRY, Michael, Between Prison and Probation. Intermediate Punishments in a rational Sentencing System, New York: Oxford University Press, 1990.
} 
MORALES, Ana María. "Vigilancia en la modernidad tardía:

El monitoreo telemático de infractores".

que la ley es la que se limita a establecer las penas para los delitos, que el juez tradicionalmente no cuenta con la flexibilidad para imponer la sanción, como en el caso anglosajón, es que algunos autores plantearon la necesidad de que las penas en libertad se conciban como sanciones principales, proporcionales a la gravedad del delito. ${ }^{14}$

Dentro de las sanciones intermedias contenidas en las propuestas de algunos de los autores mencionados anteriormente encontramos: los día- multa, el servicio comunitario, el arresto domiciliario, la libertad vigilada intensiva y el monitoreo electrónico. Sin embargo, como precisan Morris y Tonry, si bien este último se inserta dentro de la búsqueda de sanciones intermedias entre la probation y la cárcel, el monitoreo electrónico es realmente una "tecnología" o una "técnica" que no pretende servir como un castigo o sanción en sí mismo. $^{15}$

\subsection{Surgimiento del monitoreo electrónico.}

La tecnología básica para el desarrollo del monitoreo telemático fue desarrollada en los años 60 por el psicólogo Robert Schwitzgebel de la Universidad de Harvard, quien experimentaba con infractores, libertos condicionales voluntarios, pacientes siquiátricos y estudiantes. ${ }^{16}$ En ese contexto, diseñó en conjunto con otros colegas, un dispositivo pequeño de monitorización denominado BehaviorTrasmiter-Reinforcer $(B T-R)$ y estudiaron su aplicación de forma experimental. ${ }^{17}$ En concreto, la propuesta consistía en aplicar la monitorización como alternativa a la prisión a presos reincidentes crónicos en libertad condicional o a condenados a libertad vigilada, considerados peligrosos, como una medida terapéutica y también como una forma de reducir la población penal, patentándolo en 1969. $^{18}$

Como señala Nellis este sistema generó poco interés durante la década de los 70, y no fue sino en la década de los 80, que comenzó a ser utilizado de manera más o menos simultánea en los estados de Nuevo México y de Florida. En particular, el Juez Jack Love, de Albuquerque, fue el primero en decretar su utilización, para lo cual habría persuadido a un experto en electrónica, para que desarrollara un dispositivo de control que pudiera ser utilizado como complemento de la probation, para ofensas menores en las cuales el infractor pudiere estar en riesgo de sufrir violencia carcelaria. ${ }^{19}$ Aparentemente, como lo retrata la literatura, este juez habría tomado la idea de cómic del "Hombre araña" (Spiderman) en el cual el villano ata un brazalete alrededor de la muñeca del superhéroe, para poder seguir sus movimientos. ${ }^{20}$

\footnotetext{
${ }^{14}$ LARRAURI/ CID, “Uso expansionista de la prisión”, cit. nota $\mathrm{n}^{\circ} 1$.

${ }^{15}$ MORRIS/ TONRY, Between Prison and Probation, cit. nota ${ }^{\circ}$ 13, p.7. La traducción es de la autora.

${ }^{16}$ NELLIS, Mike, "The electronic monitoring of offenders in England and Wales: Recent developments and future prospects”, British Journal of Criminology, 1991, 31(2), pp. 165-185.

${ }^{17}$ BURREL, William y GABLE, Robert, "From B.F. Skinner to Spiderman to Martha Stewart: The Past, Present and Future of electronic monitoring of offenders", Probation and Parole, Current Issues, 2008, pp.101-118.

${ }_{18}$ NELLIS, "The electronic monitoring of offenders in England and Wales", cit. nota $\mathrm{n}^{\circ} 16$.

${ }^{19}$ NELLIS, "The electronic monitoring of offenders in England and Wales", cit. nota $\mathrm{n}^{\circ} 16$.

${ }^{20}$ JOHN HOWARD SOCIETY OF ALBERTA (JHSA), “Electronic Monitoring”, The Reporter, 2001,18 (1). Cfr.: BURREL/GABLE, "From B.F. Skinner to Spiderman”, cit. nota n 17.
} 
Polít. crim. Vol. 8, No 16 (Diciembre 2013), Art. 3, pp. 408-471.

[http://www.politicacriminal.cl/Vol_08/n_16/Vol8N16A3.pdf]

El primer programa de monitoreo telemático fue creado formalmente en 1984, en el estado de Florida con el objeto de reducir el hacinamiento carcelario. A partir de ahí, los programas de monitoreo telemático se fueron expandiendo rápidamente, y ya en 1998, de acuerdo al Instituto Nacional de Justicia de Estados Unidos, se encontraba implementada esta tecnología en 32 estados con alrededor de 2.277 infractores sujetos al mismo. ${ }^{21}$ Luego de su introducción en ese país, se produjo su expansión en otros como Inglaterra y Gales, Suecia, Holanda, Bélgica, Francia, Italia, España, Portugal y Australia. Actualmente, el programa más ambicioso se encuentra alojado en el primero de estos países, ${ }^{22}$ el que de acuerdo a Nellis, fue expandido por el gobierno laborista, a fin de reducir los gastos asociados al mantenimiento de personas privadas de su libertad, manejar el crecimiento de la población recluida, materializar el deseo de plasmar más control a las penas en libertad, y comprometerse sustantiva y simbólicamente con la modernización. ${ }^{23}$

A nivel latinoamericano se ha implementado el monitoreo telemático en Panamá, Uruguay, Colombia, Brasil, México y Argentina, aunque en este último país las autoridades decidieron cerrar el piloto radicado en la provincia de Buenos Aires, atendida la ocurrencia de un caso de connotación mediática.

\subsection{Los problemas de definición.}

La palabra "monitoreo" no forma parte de la lengua castellana, pero la expresión usualmente es utilizada como sinónimo de control. Por otro lado, de acuerdo a la Real Academia de la Lengua, la expresión "telemática" se refiere a la aplicación de técnicas de la telecomunicación y de la informática, a la transmisión a larga distancia de información computarizada.

En ese contexto, podríamos definir el monitoreo telemático como "aquella tecnología destinada a localizar a los infractores que se encontraren en libertad, en un espacio y tiempos determinados, mediante la aplicación de técnicas de telecomunicación e informáticas de larga distancia".

En la literatura comparada, se hace referencia a esta forma de control, mediante expresiones tales como "monitoreo electrónico" (electronic monitoring), "etiquetado" (tagging) o control telemático. ${ }^{24}$

\footnotetext{
21 SCHMIDT, Annesley, Discussion Paper 4-88: The use of electronic monitoring by criminal justice agencies, Washington: National Institute of Justice, 1988. Cit.: NELLIS, "The electronic monitoring of offenders in England and Wales", cit. nota $n^{\circ} 16$.

${ }^{22}$ HAVERKAMP, Rita; MAYER, Markus, LÉVY, René, "Electronic monitoring in Europe”, European Journal of Crime, Criminal Law and Criminal Justice, 2004, 12(1), pp. 36-45.

${ }^{23}$ NELLIS, Mike, "Out of this World: The Advent of the Satellite Tracking of Offenders in England and Wales", The Howard Journal of Criminal Justice, 2005, 44(2), pp. 125-150.

24 Para efectos del presente artículo, se utilizaran de manera indistintamente las expresiones "control telemático" o "control electrónico".
} 
MORALES, Ana María. "Vigilancia en la modernidad tardía:

El monitoreo telemático de infractores".

Este mecanismo de control, ha sido conceptualizado bajo variadas definiciones. Así, algunas más genéricas plantean que

"la tecnología de ME [monitoreo electrónico] debe ser entendida, nada más ni nada menos, que como un sistema de vigilancia remoto, y como una forma flexible de regular espacial y temporalmente los horarios de la vida de un infractor". ${ }^{25}$

Sin embargo, otros autores han planteado definiciones más acotadas, y que hacen referencia a las distintas formas en las que se puede materializar este mecanismo de control, concibiéndolo como cualquier tecnología

"que detecta la localización de un infractor en la comunidad en espacios y tiempos determinados sin la observación humana, trasmitiendo electrónicamente esa información a una estación central de control, o en que se usa un dispositivo electrónico para detectar la presencia de una sustancia prohibida en el cuerpo (o para monitorear otras funciones fisiológicas) de un infractor que viven en la comunidad, trasmitiendo dicha información a una estación central". ${ }^{26}$

De la citada definición se desprende las siguientes características:

- Pueden haber múltiples tecnologías de monitoreo electrónico.

- El objetivo se centra en la localización del infractor.

- Supone un control a distancia, sin la observación humana directa.

- La información es trasmitida a una estación central de control.

- También incluye el uso de dispositivos para detectar sustancias prohibidas en el cuerpo o para monitorear otras funciones fisiológicas.

De acuerdo a Rezema y Mayo-Wilson ${ }^{27}$ esta definición excluye el uso de alcohol ignition interlocks, esto es, de dispositivos que suponen el bloqueo en el encendido de un vehículo frente a la presencia de consumo de alcohol por el conductor, e incluye el uso del rastreo satelital o GPS y algunas tecnologías para el testeo de sustancias ilícitas o para controlar algunas funciones fisiológicas.

El uso del monitoreo telemático, se ha venido extendiendo por distintas jurisdicciones, principalmente de Norteamérica y Europa, como una forma de control de infractores en el sistema penal. Como se expondrá más adelante, este sistema presenta variadas utilizaciones en la arena penal, ya sea para el control de medidas cautelares ambulatorias, de penas

\footnotetext{
${ }^{25}$ NELLIS, Mike; TORRES, Nuria, Electronic Monitoring and Probation: Offender rehabilitation and the reduction of prison population - Report on $7^{\text {th }}$ European Electronic Monitoring Conference, 5 al 7 de Mayo, Portugal. Cit.: NELLIS, Mike; BEYENS, Kristel y KAMINSKY, Dan, "Introduction: making sense of electronic monitoring" en: NELLIS, Mike; BEYENS, Kristel y KAMINSKY, Dan, Electronically Monitored Punishment. International and critical perspectives, Oxon: Routledge, 2013, pp. 4-5. La traducción es de la autora.

${ }^{26}$ RENZEMA, Marc, “Electronic Monitoring's Impact on Reoffending”, 2003, p. 10. La traducción es de la autora. Disponible en http://www.correcttechllc.com/articles/13.pdf [visitado el 15.04.2013].

${ }^{27}$ RENZEMA, Marc y MAYO-WILSON, Evan, "Can electronic monitoring reduce crime for moderate to high risk offenders?”, Journal of Experimental Criminology 1 (2005), pp. 215-237.
} 
Polít. crim. Vol. 8, No 16 (Diciembre 2013), Art. 3, pp. 408-471.

[http://www.politicacriminal.cl/Vol_08/n_16/Vol8N16A3.pdf]

sustitutivas, y de los permisos de salida y libertad condicional. Incluso, en ciertos casos, se ha utilizado para controlar algunas medidas de seguridad.

\subsection{Objetivos asociados a la introducción del monitoreo telemático en las distintas legislaciones.}

De acuerdo a Martinovic, ${ }^{28}$ los objetivos asociados a la introducción de distintos programas de control electrónico de infractores, se vinculan con múltiples y ambiciosas metas de los distintos gobiernos orientados a:

- Aliviar el hacinamiento carcelario, buscando alternativas distintas al uso de la prisión.

- Reducir el pago de impuestos de la población, evitando los costos del encarcelamiento, y obligando en el caso de Estados Unidos, que los infractores costeen su supervisión en la comunidad.

- Castigar a los infractores mediante confinamiento en su domicilio y la supervisión de sus movimientos.

- Fomentar la seguridad pública, mediante la supervisión estricta a través del monitoreo telemático.

- Proteger al infractor de los efectos de la corrupción y estigmatización del encarcelamiento institucional, y evitar el corte de los lazos familiares y comunitarios.

Por otro lado, más allá de estos objetivos instrumentales, también encontramos algunos de carácter simbólico, asociados a la introducción de este tipo de tecnología en el sistema penal. Así, de acuerdo a Albrecht, la introducción del monitoreo telemático en distintas legislaciones también se ha asociado simbólicamente a una suerte de mayor conciencia en orden a introducir alternativas costo efectivas y modernas; junto con el potencial simbólico para el mundo político de parecer duros con el control, firmes en la supervisión, y de entregar credibilidad al sistema. ${ }^{29}$

En ese contexto, como señala el mismo autor, el monitoreo telemático, hasta hoy "parece encajar bien dentro del marco teórico de la criminología crítica, que se centra en la comercialización, riesgo, gerenciamiento, [y] privatización", 30 aun cuando agrega, que esta manifestación de la "nueva penología" (new penology), no es más que un pequeño elemento dentro de una tendencia general que involucra una serie de "cambios en el sistema

\footnotetext{
${ }^{28}$ MARTINOVIC, Marietta, "The punitiveness of electronically monitored community based programs". Artículo presentado en la Conferencia de la "Probation and Community Corrections Officers Association Inc.”, Perth, Australia, 2002. Disponible en http://www.aic.gov.au/media_library/conferences/probation/martinovic.pdf [visitado el 12.04.2013].

29 ALBRECHT, Hans-Joerg, Electronic monitoring in Europe. A summary and assessment of recent developments in the legal framework and implementation of electronic monitoring, Max Planck Institute for Foreign and International Criminal Law, 2005. Disponible en
} http://www.mpicc.de/shared/data/pdf/albrecht.pdf [visitado el 12.04.2013].

${ }^{30}$ ALBRECHT, Electronic Monitoring in Europe, cit. nota $n^{\circ} 29$, p. 1. La traducción es de la autora. 
MORALES, Ana María. "Vigilancia en la modernidad tardía:

El monitoreo telemático de infractores".

de sanciones y del control social, y en general una consecuencia de los avances tecnológicos y un paso hacia las sociedades postmodernas". 31

\subsection{Tipos de tecnología que permiten la localización de una persona.}

La definición de monitoreo electrónico, explorada anteriormente, precisa la existencia de distintas tecnologías, que permiten la supervisión remota de infractores. De acuerdo a la experiencia comparada, es posible detectar la existencia de al menos tres tipos de aplicaciones tecnológicas utilizadas bajo esta denominación: la radio frecuencia, el contacto programado y el rastreo satelital. Sin embargo, también existen otras tecnologías más específicas, orientadas a detectar determinados eventos que también serán abordadas de manera sintética en el presente trabajo.

\subsubsection{Radio frecuencia.}

Constituye la tecnología más utilizada a nivel comparado de monitoreo y se utiliza fundamentalmente para el control de las reclusiones domiciliarias.

Para su aplicación, el infractor debe portar todo el tiempo, ya sea en su muñeca o en el tobillo, un dispositivo con la forma de un brazalete, que no puede ser removido por él. Este dispositivo, que debe ser recargado periódicamente con batería, trasmite señales de radio frecuencia dos o más veces por minuto, a una unidad de monitoreo localizada en el mismo domicilio. $^{32}$

La unidad de monitoreo es adjuntada a la línea telefónica, y es la encargada de recibir las señales de radio frecuencia emitidas por el brazalete. Ésta, a su vez, envía un mensaje a través de la línea telefónica a una computadora central, ya sea cuando deja de recibir la radio frecuencia o cuando vuelve a recibirla. Dependiendo del lugar, algunos dispositivos pueden ser programados para detectar la presencia del sujeto en radios de 12 hasta 120 metros, en atención al tipo de equipamiento utilizado. ${ }^{33}$

La mayoría de las entidades encargadas, requieren que el infractor cuente con servicio telefónico de manera de que pueda recibir señales de manera permanente en "tiempo real". En otros casos, en que no se cuente con línea telefónica, la información es almacenada en la unidad de monitoreo y el sujeto debe llevar el dispositivo cada vez que se reporte. ${ }^{34}$

La computadora central cuenta con una programación para cada infractor. Si un sujeto debe abandonar su hogar para trabajar, entonces el dispositivo informará a la central que no detectó al sujeto durante las horas en que estuvo afuera de su domicilio, lo que no generará alerta alguna, en la medida que esto no corresponda a un período sujeto a restricción. En

\footnotetext{
${ }^{31}$ ALBRECHT, Electronic Monitoring in Europe, cit. nota ${ }^{\circ}$ 29, p. 2. La traducción es de la autora.

32 DEMICHELE, Matthew y PAYNE, Brian, Offender supervision with Electronic Technology: Community corrections resource, Washington: Bureau of Justice Assistance, Department of Justice, 2009. Disponible en http://www.appa-net.org/eweb/docs/appa/pubs/oset_2.pdf [visitado el 12.04.2013].

${ }^{33}$ DEMICHELE/ PAYNE, Offender supervision, cit. nota ${ }^{\circ} 32$.

${ }^{34}$ DEMICHELE/ PAYNE, Offender supervision, cit. nota ${ }^{\circ} 32$, p. 29.
} 
Polít. crim. Vol. 8, No 16 (Diciembre 2013), Art. 3, pp. 408-471.

[http://www.politicacriminal.cl/Vol_08/n_16/Vol8N16A3.pdf]

cambio, si la señal se pierde estando el sujeto en período de restricción o recibe información del sujeto en períodos en los cuales éste no debiera encontrarse en el hogar, la computadora generará una alerta que es reportada a la autoridad encargada de controlarlo, informándole de la anormalidad. Luego, la entidad seguirá el procedimiento destinado a determinar las razones detrás de ello. ${ }^{35}$

Uno de los aspectos problemáticos de este sistema, es el hecho de que el sujeto debe portar permanente el brazalete, y no sólo en aquellos momentos en que debiera estar recluido. Esto puede ser sin duda estigmatizante, e importar un control que se extiende más allá de la medida impuesta.

\subsubsection{Contacto programado.}

Esta tecnología no supone que el sujeto porte un dispositivo, sino que sea contactado o deba reportarse telefónicamente. En concreto, supone la existencia de una computadora central que recibe llamadas telefónicas o efectúa llamadas al infractor en una o más locaciones. Estas llamadas pueden ser realizadas de manera aleatoria o en base a una agenda programada. $^{36}$

Existen distintas tecnologías que permiten verificar que es el infractor el que está dando respuesta al llamado, ya sea mediante la verificación de voz, la verificación a través de video, o la introducción de un dispositivo en el receptor que se encuentra en su domicilio. ${ }^{37}$

Como señalan algunos autores, la utilización de sistemas de contacto programado para controlar el arresto domiciliario presenta varias ventajas. Entre ellas, que se requiere sólo de la existencia de un teléfono. Por otro lado, con este sistema, la persona no debe portar un brazalete y por lo tanto, se evita un eventual efecto estigmatizante. ${ }^{38}$ Sin embargo, su aplicación puede generar un ambiente disruptivo para el infractor ${ }^{39}$ y para quienes habitan con él, especialmente cuando las llamadas de realizan de manera aleatoria en la noche.

En el ámbito comparado, este mecanismo se utilizó principalmente en las primeras fases de implementación de la monitorización en el sistema penal, siendo en la actualidad reemplazado por la monitorización mediante radio frecuencia, por considerarse que ésta infringe menos cargas al sujeto monitorizado y a las personas que viven con él. ${ }^{40}$

\footnotetext{
${ }^{35}$ DEMICHELE/ PAYNE, Offender supervision, cit. nota $\mathrm{n}^{\circ} 32$.

${ }^{36}$ CONWAY, Peggy "A basic introduction to electronic monitoring: Remote supervision technologies", Journal of Offender Monitoring, 2001, 14 (1\&2), pp. 6-10.

${ }^{37}$ DEMICHELE/PAYNE, Offender supervision, cit. nota $\mathrm{n}^{\circ} 32$.

${ }^{38}$ GONZÁLEZ, Cristina, El control telemático en el sistema penal, tesis doctoral, Universidad de Barcelona, 2008. Disponible en http://ddd.uab.cat/pub/tesis/2008/tdx-1120108-151704/cgb1de1.txt [visitado el 12.04.2013].

39 RENZEMA, Marc, "State of the art: Part II Programmed contact equipment", Journal of offender monitoring, 1992, 2 (3), pp.18-23.

${ }^{40}$ GONZÁLEZ, El control telemático en el sistema penal, cit. nota $n^{\circ} 38$.
} 
MORALES, Ana María. "Vigilancia en la modernidad tardía:

El monitoreo telemático de infractores".

\subsubsection{Rastreo satelital.}

El rastreo satelital permite realizar un seguimiento de los traslados del infractor, y conocer su ubicación en tiempo casi real. La tecnología de rastreo satelital o GPS (Global Positioning technologies) fue originalmente diseñada para usos militares, sin embargo en la actualidad se utiliza para una serie de otras aplicaciones, incluyendo el seguimiento de vehículos de transporte. $^{41}$

Este sistema, se compone de tres dispositivos básicos. Un trasmisor operado con baterías, con la forma de un brazalete, que usualmente es transportado en la muñeca o el tobillo; un dispositivo de tracking, similar a un teléfono celular, que tiene la función de conectarse con la red de satélites de GPS y con el computador central; y un cargador de la batería del dispositivo de tracking. Tanto el primer como el segundo dispositivo, deben ser trasportados por el individuo permanente, mientras que el tercero debe permanecer en el hogar. ${ }^{42}$ El trasmisor emite una señal de radio frecuencia que es recibida por el dispositivo de tracking lo que permite verificar que ambos permanecen juntos. Lo anterior supone que la persona monitorizada que porta el trasmisor se encuentra, a un máximo de aproximadamente cinco metros del dispositivo de tracking. El trasmisor emite señal de radio dos o más veces por minuto, la que es recibida por el dispositivo de tracking. Este último contiene varios tipos de tecnología: un receptor de las señales del trasmisor, la señal de GPS, un computador, y circuitos de telefonía celular. El computador almacena la información sobre los movimientos del infractor y los circuitos de telefonía celular sirven para comunicar la información acerca de la ubicación del sujeto a la central de monitoreo. ${ }^{43}$

Cuando se utiliza el GPS como control de una determinada medida en el sistema penal, se debe determinar zonas de exclusión e inclusión para cada infractor. Las zonas de exclusión son áreas en las cuales éste no puede ingresar, tales como el hogar de una víctima en el caso de delitos de violencia intrafamiliar, o parques y escuelas en el caso de condenados por la comisión de delitos sexuales contra menores. Dependiendo del equipo, las zonas de exclusión comprenden radios de 91 a 610 metros, pudiendo ser varias de éstas las que se determinan respecto de un sujeto. Por otro lado, en el caso de las áreas de inclusión se espera que el infractor esté en determinados lugares y horarios. Al igual que la anterior, se puede determinar varios perímetros de inclusión respecto de una misma persona. Tanto las zonas de exclusión como las de inclusión, son ingresadas a nivel central, a través de un software de mapeo (mapping), que crea un mapa de ruta del sujeto. El computador entonces es programado para emitir una señal de alerta cada vez que el infractor entre a un perímetro excluido o abandone uno en el que debiera encontrarse en un horario determinado. ${ }^{44}$

\footnotetext{
${ }^{41}$ BURREL/GABLE, "From B.F. Skinner to Spiderman", cit. nota ${ }^{\circ}$ 17. Cfr.: DEMICHELE/PAYNE, Offender supervision, cit. nota $\mathrm{n}^{\circ} 32$.

${ }^{42}$ CROWE, Ann; SYDNEY, Linda, BANCROFT, Pat; LAWRENCE, Beverly, Offenders Supervision with Electronic Technology, Kentucky: American Probation and Parole Association, 2002. Disponible en https://www.ncjrs.gov/pdffiles1/nij/grants/197102.pdf [visitado el 12.04.2013].

${ }^{43}$ CROWE et al., Offenders Supervision with Electronic Technology, cit. nota ${ }^{\circ} 42$. Cfr.: DEMICHELE/ PAYNE, Offender supervision, cit. nota $\mathrm{n}^{\circ} 32$.

${ }^{44}$ CROWE et al., Offenders Supervision with Electronic Technology, cit. nota ${ }^{\circ} 42$. Cfr.: DEMICHELE/ PAYNE, Offender supervision, cit. nota ${ }^{\circ} 32$.
} 
Polít. crim. Vol. 8, № 16 (Diciembre 2013), Art. 3, pp. 408-471.

[http://www.politicacriminal.cl/Vol_08/n_16/Vol8N16A3.pdf]

Asimismo, existen tres tipos de monitorización mediante GPS, dependiendo de cómo la información es trasmitida a la computadora central: la activa, la pasiva y la mixta. El monitoreo activo, permite conocer los movimientos del sujeto casi en el mismo momento en que se producen, desde el computador central. Por su parte, el monitoreo pasivo, permite conocer sus movimientos desde el computador central, unas horas después de que se producen, normalmente al final del día, cuando se envía la información sobre la localización de la persona. A su vez, la mixta funciona como un sistema pasivo de forma general, en que la información es trasmitida a la computadora central cada dos o tres veces al día, y como un sistema activo cuando la persona monitorizada incumple alguna de las restricciones de movimientos que se le han impuesto, pasando a ser controlada casi en tiempo real. $^{45}$

El sistema de GPS presenta bastantes ventajas en relación a los sistemas de monitoreo electrónico analizados anteriormente. La primera de ellas, se vincula a que ofrece mayores posibilidades de protección para las víctimas, ${ }^{46}$ especialmente cuando éstas constituyen el foco especial de interés del infractor. Así, como se examinará en los siguientes acápites, el sistema de rastreo satelital es especialmente útil en los casos de violencia doméstica, pues incluso se ha desarrollado una aplicación tecnológica que permite a la víctima portar un dispositivo que la alerte en caso que el sujeto vulnere la prohibición de acercamiento.

La segunda ventaja dice relación con que otorga una mayor libertad circulatoria del infractor, no encontrándose necesariamente obligado a permanecer en un lugar para efectos de su control. De esta forma, le permite al sujeto monitorizado, desarrollar su rutina diaria sin tantas constricciones de desplazamiento, lo que además supone, que en caso que éste deba participar en determinados programas orientados a su rehabilitación o reinserción, pueda compatibilizar su concurrencia a los mismos, con su trabajo y otros requerimientos de desplazamiento, junto con la posibilidad de ser controlada su asistencia.

Además, el sistema de rastreo satelital puede ser usado aun cuando no se cuente con línea telefónica, pudiendo incluso ser usado en zonas remotas y rurales.

Sin embargo, este sistema también presenta desventajas que deben ser consideradas. Así, al utilizar la tecnología celular para comunicar la información, al igual que en el caso de los teléfonos móviles, pueden producirse problemas asociados a la falta de señal, generándose "puntos muertos". Esto significa que el infractor momentáneamente no podrá ser rastreado. En este caso, el GPS continuará almacenando información con la ubicación del sujeto. Si bien la información puede ser recuperada, está no será enviada al computador central sino cuando la persona salga del área sin cobertura. ${ }^{47}$ Es por esto, que se recomienda previo a su instalación, que se testee su efectividad en determinados ámbitos geográficos.

${ }^{45}$ CROWE et al., Offenders Supervision with Electronic Technology, cit. nota ${ }^{\circ} 42$. Cfr.: DEMICHELE/ PAYNE, Offender supervision, cit. nota $\mathrm{n}^{\circ} 32$.

${ }^{46}$ PETERSILIA, Joan, When prisoners come home. Parole and Prisoner Reentry, Nueva York: Oxford University Press, 2003.

${ }^{47}$ CROWE et al., Offenders Supervision with Electronic Technology, cit. nota $\mathrm{n}^{\circ} 42$. Cfr.: DEMICHELE/PAYNE, Offender supervision, cit. nota ${ }^{\circ} 32$. 
MORALES, Ana María. "Vigilancia en la modernidad tardía:

El monitoreo telemático de infractores".

Por otro lado, a pesar de otorgar mayores posibilidades de movimiento, el sistema de rastreo satelital, es sin duda el que más afecta la vida privada del sujeto, en la medida que con este sistema se puede tener un control casi en tiempo real y las veinticuatro horas del día de sus movimientos, no restringiéndose al control en el domicilio y a determinados horarios, como ocurre usualmente con las tecnologías de radio frecuencia y el contacto programado. En ese contexto, precisamente el sistema de GPS, es el que mayor utilidad presenta para efectos de la persecución penal y el establecimiento de patrones delictivos. Sin embargo, como consecuencia, se produce una afectación de los derechos fundamentales asociados a la protección de la vida privada, como será analizado en las páginas siguientes. En atención a lo anterior, la literatura ha considerado más apropiado el uso de esta aplicación tecnológica, para aquellos casos de infractores que presentan alto riesgo de reincidencia o de causar daño a la víctima, en la medida que constituye el método de supervisión más invasivo de los tres. ${ }^{48}$ Además, la utilización en sujetos de bajo riesgo, como también se analizará, se vincula con el fenómeno del "netwidening", por lo que la utilización en estos casos, puede tener como consecuencia una innecesaria expansión del control penal.

\subsubsection{Otros tipos de tecnologías.}

En la experiencia comparada, también se han desarrollado otras tecnologías que pueden ser enmarcadas dentro del control telemático, y que se ocupan de ciertas particularidades que puedan presentar los infractores, asociadas al uso de sustancias que actúan como gatillantes o móviles de la conducta infractora. Tal es el caso de alcohol y las drogas. Además, en este mismo contexto, se explora la implementación de tecnología destinada a alertar a la víctima acerca de la proximidad de su posible agresor.

\section{a) Detección de alcohol a distancia.}

El equipo remoto de detección de alcohol, puede servir -dependiendo de la tecnología-, para indicar si un individuo ha consumido alcohol o para determinar el nivel de alcohol en la sangre que éste tuviere al momento de tomar la prueba. ${ }^{49}$

Para la aplicación de este sistema, generalmente se requiere de la instalación de un equipo en el domicilio del infractor. Al tomar la prueba, el sujeto debe insuflar el dispositivo. Los resultados de las pruebas remotas de alcohol se trasmiten a través de líneas telefónicas y se procesan a través de computadoras en el centro de monitoreo. Si el sujeto también está siendo supervisado con otros sistemas (p.ej. monitorización de la reclusión domiciliaria), el mismo equipo puede trasmitir la información cuando se realiza la prueba. Si ésta registra contenido de alcohol, por lo menos dos pruebas adicionales deben ser tomadas para configurar una prueba positiva válida. Cuando el resultado es positivo, la información se trasmite al funcionario encargado de la supervisión. ${ }^{50}$

\footnotetext{
${ }^{48}$ CROWE et al., Offenders Supervision with Electronic Technology, cit. nota ${ }^{\circ} 42$.

${ }^{49}$ CONWAY, "A basic introduction to electronic monitoring", cit. nota $\mathrm{n}^{\circ} 36$.

${ }^{50}$ CROWE et al., Offenders Supervision with Electronic Technology, cit. nota ${ }^{\circ} 42$.
} 
Polít. crim. Vol. 8, No 16 (Diciembre 2013), Art. 3, pp. 408-471.

[http://www.politicacriminal.cl/Vol_08/n_16/Vol8N16A3.pdf]

La mayoría de estos dispositivos cuenta con tecnología destinada a garantizar que la persona que toma la prueba corresponde al infractor. Las pruebas pueden solicitarse ya sea mediante llamadas aleatorias o con una combinación de llamadas programadas y otras aleatorias. $^{51}$

También, dentro de las tecnologías de detección a distancia de alcohol, encontramos el alcohol ignition interlock, que puede ser instalado en el vehículo, y que requiere que el conductor insufle un dispositivo localizado al interior de éste, antes de que arranque. El dispositivo a su vez se encuentra conectado al sistema de encendido eléctrico del coche, y en caso que el sujeto presente alcohol o exceda de determinado límite, el sistema procede a bloquear el encendido. Al igual que en los dispositivos revisados anteriormente, éste generalmente cuenta con tecnología, que permite asegurar que el que toma la prueba sea el infractor. ${ }^{52}$

Sin embargo, como se señaló anteriormente, la utilización de dispositivos como el alcohol ignition interlock, de acuerdo a la definición entregada por Renzema y Mayo-Wilson, ${ }^{53}$ no se enmarcaría dentro del concepto de monitoreo electrónico, en la medida que la tecnología usada en esos casos, no supone la trasmisión de la información a una estación central, electrónicamente. No obstante lo anterior, parte de la literatura especializada en materia de conducción bajo los efectos del alcohol, sí considera que el uso de estos dispositivos se enmarca dentro del concepto entregado, en la medida que constituye una tecnología accesoria a otras medidas penales. ${ }^{54}$

Por otro lado, Crowe y sus colaboradores agregan que también se está desarrollando tecnología para monitorizar el consumo de alcohol de infractores a través de bandas adheridas al cuerpo. ${ }^{55}$

\section{b) Detección a distancia del consumo de drogas.}

Al igual que en el caso anterior, para efectos del control del consumo de estupefacientes, se instalan en el domicilio dispositivos tendientes a medir la cantidad de estas sustancias en la orina del infractor, en los cuales éste debe verter una muestra. De la misma forma que los dispositivos anteriormente analizados, existen sistemas tecnológicos que permiten dar fidelidad acerca de la identidad del sujeto que está proveyendo la muestra. Posteriormente, esta información es enviada de manera telefónica.

Al igual que en el caso anterior Crowe y sus colaboradores agregan que se estarían desarrollando tecnología tendiente a medir la cantidad de drogas presente en la sangre de un sujeto monitorizado, mediante un sistema de microchip adherido al cuerpo con parches. ${ }^{56}$

\footnotetext{
${ }^{51}$ CROWE et al., Offenders Supervision with Electronic Technology, cit. nota $\mathrm{n}^{\circ} 42$.

${ }^{52}$ CROWE et al., Offenders Supervision with Electronic Technology, cit. nota ${ }^{\circ} 42$.

${ }^{53}$ RENZEMA/MAYO-WILSON, "Can electronic monitoring reduce crime”, cit. nota $\mathrm{n}^{\circ} 27$.

${ }^{54}$ GONZÁLEZ, "El control telemático en el sistema penal”, cit. nota ${ }^{\circ} 38$.

${ }^{55}$ CROWE et al., Offenders Supervision with Electronic Technology, cit. nota $\mathrm{n}^{\circ} 42$.

${ }^{56}$ CROWE et al., Offenders Supervision with Electronic Technology, cit. nota ${ }^{\circ} 42$.
} 
MORALES, Ana María. "Vigilancia en la modernidad tardía:

El monitoreo telemático de infractores".

c) Sistema de notificación/alerta a la víctima.

El sistema de notificación o alerta de la víctima es particularmente utilizado en la experiencia comparada, en casos de violencia intrafamiliar, para efectos de controlar las condiciones de alejamiento impuestas a un imputado o condenado por delitos de esa naturaleza. ${ }^{57}$ Para llevarla a cabo, es posible la utilización de tecnología de control a través de la radio frecuencia o del mecanismo de rastreo satelital, la que es usada tanto en el infractor como en la víctima, mediante lo que se ha denominado sistema de monitoreo electrónico "bilateral", 58

En el caso de la radiofrecuencia, el supuesto agresor debe contar con un sistema como el descrito anteriormente, que implica la localización de un dispositivo en su domicilio y otro en su muñeca o tobillo, que indicará si éste se encuentra en su hogar en los horarios establecidos en la sentencia. En el caso de la víctima, ésta pude contar con un dispositivo en su hogar, que se encuentra sincronizado con el del supuesto agresor, y que podrá detectar la presencia de éste en su domicilio, en un radio de 152 metros aproximadamente. ${ }^{59}$ Este sistema, actualmente goza de menor popularidad en la experiencia comparada a diferencia del rastreo satelital, considerando que sólo puede detectar la presencia del infractor en el domicilio de la víctima, mas no en otras áreas.

En el caso de la utilización de la tecnología de rastreo satelital, y del mismo modo que en los dispositivos de GPS antes analizados, el supuesto agresor debe llevar continuamente amarrado a su muñeca o tobillo, un aparato que emite señales de radio frecuencia, y que son recibidas por el tracking. Al igual que en los demás casos de utilización del rastreo satelital, el sujeto tiene fijadas zonas de exclusión, como el domicilio de la víctima, su lugar de trabajo u otros lugares frecuentados por ésta como el colegio de los hijos, o el domicilio de sus familiares próximos. Generalmente, el individuo tampoco puede acercarse al ofendido, por lo que se debe establecer previamente un radio de alejamiento respecto de éste, que en algunos casos es de 500 metros. En caso de acercamiento a las zonas de exclusión o hacia la víctima, se generan alertas a nivel central, correspondiendo a los funcionarios encargados del control, dar aviso a las víctimas de eventuales acercamientos del sujeto. ${ }^{60}$ En particular, es necesario tener presente que el sistema está programado para localizar la presencia del infractor en las áreas de exclusión, sin embargo, no detecta aquellos contactos que se producen fuera de las áreas monitorizadas, ni los que se realizan a través de otras vías, como el teléfono, email, u otras vías tecnológicas. ${ }^{61}$

\footnotetext{
${ }^{57}$ EREZ, Edna; IBARRA, Peter, "Making Your Home a Shelter. Electronic Monitoring and Victim Re-entry in Domestic Violence Cases", British Journal of Criminology, 2007, 47 (1) pp.100-120.

${ }^{58}$ IBARRA, Peter y EREZ, Edna, "Victim-centric Diversion? The electronic monitoring of domestic violence cases”, Behavioral Sciences and the Law 23 (2005), pp. 259-276, p. 260. La traducción es de la autora.

${ }^{59}$ Corresponde a una conversión de 500 pies.

${ }^{60}$ GONZÁLEZ, El control telemático en el sistema penal, cit. nota $n^{\circ} 38$.

61 EREZ, Edna; IBARRA, Peter; BALES, William y GUR, Oren, GPS Monitoring Technologies and Domestic Violence: An Evaluation Study, Washington: National Criminal Justice Reference Service, 2012. Disponible en http://www.ncdsv.org/images/GPSMonitoringTechnologiesAndDVandEvaluationStudy_62012.pdf [visitado el 12.04.2013].
} 
Polít. crim. Vol. 8, № 16 (Diciembre 2013), Art. 3, pp. 408-471.

[http://www.politicacriminal.cl/Vol_08/n_16/Vol8N16A3.pdf]

\subsection{Utilización en el sistema penal.}

En la experiencia comparada, variados son los usos que ha tenido el monitoreo telemático en el sistema penal, permitiendo el control en la comunidad de infractores que se encuentran cumpliendo una medida cautelar ambulatoria, o una pena en libertad, o que hubieren accedido a permisos de salida de los recintos penitenciarios o hubieren sido liberados condicionalmente, trascurrido un determinado tiempo de cumplimiento de la condena. También se registra su utilización, como medida de seguridad post delictual, especialmente en el caso de sujetos que hubieren cumplido una pena asociada a la comisión de un delito sexual contra menores.

\subsubsection{Para el control de medidas cautelares ambulatorias.}

El sistema de monitoreo telemático es utilizado en diversas jurisdicciones para efectos del control de las medidas cautelares ambulatorias. En la mayoría de los casos, el control telemático, se ha implementado para efectos de controlar la medida de reclusión domiciliaria y también algunas condiciones de alejamiento decretadas contra el imputado. ${ }^{62}$ En algunos países, el uso de esta tecnología también se ha utilizado como complemento al pago de fianzas, y al control de consumo de drogas. ${ }^{63}$

Las utilizaciones más frecuentes para el control de estas medidas las encontramos en el caso de Estados Unidos, y en Inglaterra y Gales. En el caso del primero de estos países, de acuerdo a un estudio realizado en el estado de Indiana, el objetivo asociado a la utilización como medida cautelar, apunta a asegurar la comparecencia del imputado y aliviar los problemas de sobrepoblación, utilizándose mayormente en los casos de imputados por hurtos, manejo en estado de ebriedad, falsificación, robo con fuerza, delitos de microtráfico, tráfico, y alteración del orden público. ${ }^{64}$ En el caso de Inglaterra y Gales, también el monitoreo electrónico fue introducido como una condición de la fianza, buscando ser aplicado para todas aquellas ofensas que arriesgaran pena de cárcel (imprisonable offences), estableciendo que el tiempo servido bajo fianza con monitoreo telemático, podía ser imputable a la condena privativa de la libertad que se impusiere posteriormente. ${ }^{65}$ En términos de su aplicación, en éstos últimos países, el 34\% corresponde al control de medidas cautelares ambulatorias, frente a otras aplicaciones en el sistema de justicia -ya sea como pena en libertad o liberación anticipada-. ${ }^{66}$

Adicionalmente, en el caso de Estados Unidos, como se analizó anteriormente, las investigaciones desarrolladas por Erez y sus colaboradores, muestran que el monitoreo

\footnotetext{
${ }^{62}$ GONZÁLEZ, El control telemático en el sistema penal, cit. nota n 38.

${ }^{63}$ DEMICHELE/PAYNE, Offender supervision, cit. nota $\mathrm{n}^{\circ} 32$.

${ }^{64}$ GOWDY, Voncile, Intermediate sanctions, Washington: National Institute of Justice, 1993. Cit.: DEMICHELE/PAYNE, Offender supervision, cit. nota ${ }^{\circ} 32$.

${ }^{65}$ NELLIS, Mike, "Electronic monitoring: towards integration into offender management?" en: McNEILL, Fergus; RAYNOR, Peter, y TROTTER, Chris, Offender Supervision. New Directions in theory, research and practice, Oxon: Willan, 2010.

${ }^{66}$ BOOTHER, Mark, "An overview of electronic monitoring", presentación efectuada en seminario "El uso de tecnologías en el sistema penal: Monitoreo Telemático", realizado por la Fundación Paz Ciudadana, 2011. Inédito.
} 
MORALES, Ana María. "Vigilancia en la modernidad tardía:

El monitoreo telemático de infractores".

telemático también es ampliamente utilizado para supervisar el cumplimiento de las prohibiciones de acercamiento, impuestas como medida cautelar en los casos de violencia doméstica. ${ }^{67}$ A nivel europeo continental, en España también encontramos la regulación del monitoreo electrónico como forma de control de la medida cautelar de alejamiento en los supuestos de violencia de género, de acuerdo a lo dispuesto en el artículo 64.3 de la LO 1/2004. Sin embargo, esta aplicación ha sido criticada por algunos autores, en la medida que sólo se llevaría a cabo ante los supuestos de violencia de género, y no frente a otras hipótesis de violencia intrafamiliar. ${ }^{68}$

\subsubsection{Para el control de penas de cumplimiento en libertad.}

En diversas legislaciones, se ha adoptado el monitoreo telemático como una forma de control de sanciones que se decretan en el medio libre, como sucede en Estados Unidos, Inglaterra y Gales, España, Canadá, y Holanda, entre otros. Al igual que en el caso anterior, la mayoría corresponde al control de la reclusión domiciliaria y al control de medidas de alejamiento.

Esta aplicación, como señalan algunos autores, constituye el denominado modelo de front door (puerta de entrada), que supone que el monitoreo telemático sea decretado por la judicatura como parte de la sentencia, ${ }^{69}$ generalmente para el control de reclusiones en el domicilio, o de ciertas medidas de alejamiento que se impongan como condición o como pena propiamente tal.

La utilización del monitoreo telemático como parte de la sentencia decretado para el control de la reclusión domiciliaria, lo encontramos por ejemplo, en el caso de Holanda, donde este sistema puede ser impuesto, cuando la sentencia condenatoria no exceda los 6 meses. Por otro lado, en el caso de Inglaterra y Gales, éste puede ser decretado por el tribunal, para supervisar algunas de las sanciones contendidas en el Criminal Justice Act de 2003, que reguló las órdenes comunitarias con requerimientos simples o múltiples. En el caso de las órdenes comunitarias simples, se establece la posibilidad de decretar "curfews" o reclusión domiciliaria, entre dos a doce horas al día, las que serán controladas a través del sistema de monitoreo electrónico. En general, no se establecen restricciones para su imposición, por lo tanto se puede decretar respecto de la mayoría de los infractores, mientras no interfiera con sus actividades educacionales, de trabajo o religiosas. En el caso de las órdenes comunitarias con múltiples requerimientos, se suma a la reclusión domiciliaria controlada por monitoreo telemático, la supervisión por un delegado, quien es informado de los eventuales incumplimientos y violaciones, así como encargado de reportar a las cortes sobre su cumplimiento. ${ }^{70}$ De esta forma, el monitoreo telemático es utilizado en el contexto de las denominadas community sanctions (sanciones comunitarias), bajo la lógica de la individualización del castigo, especialmente considerando la variedad de sanciones

\footnotetext{
${ }^{67}$ EREZ et al., Monitoring Technologies and Domestic Violence, cit. nota $\mathrm{n}^{\circ} 61$.

${ }^{68}$ GONZÁLEZ, El control telemático en el sistema penal, cit. nota $\mathrm{n}^{\circ} 38$.

${ }^{69}$ JHSA, Electronic (radio frequency) and GPS monitored community based supervision programs, 2006. Disponible en http://www.johnhoward.ab.ca/pub/pdf/monitorupdate.pdf [visitado el 12.04.2013].

${ }^{70}$ BOOTHER, "An overview of electronic monitoring", cit. nota $n^{\circ} 66$.
} 
Polít. crim. Vol. 8, № 16 (Diciembre 2013), Art. 3, pp. 408-471.

[http://www.politicacriminal.cl/Vol_08/n_16/Vol8N16A3.pdf]

comunitarias que son puestas a disposición de la judicatura, que pueden ser combinadas en atención a la necesidad del infractor, la víctima y la sociedad.

Para efectos de determinar cuál sanción es más adecuada -si una orden comunitaria con requerimientos simples o múltiples-, el Servicio de Probación (Probation Trust) debe evacuar al tribunal una evaluación de riesgo del sujeto. ${ }^{71}$ El monitoreo telemático como forma de control del cumplimiento de sanciones comunitarias, constituye la fórmula de aplicación más amplia, abarcado el $52 \%$ de su utilización en el sistema de justicia en comparación con otros de sus usos, como medida cautelar o liberación anticipada. ${ }^{72}$

En el caso de España, el monitoreo telemático es utilizado para el control de la pena de alejamiento, contenida en el artículo 48 del Código Penal, y a la localización permanente regulada en el artículo 37 del mismo. La primera constituye una pena accesoria, privativa de derechos, por la cual se condena al penado a la privación del derecho a residir en determinados lugares o acudir a ellos, o de aproximarse a la víctima y sus familiares, o de comunicarse con ellos. Por su parte, la pena de localización permanente, constituye una sanción privativa de la libertad, en virtud de la cual el penado debe permanecer en su domicilio o en otro lugar especificado en la sentencia, por un período máximo de 6 meses, y cuya ejecución puede ser continua o discontinua en el tiempo. Esta regulación ha sido criticada, en el caso de la primera, por sus eventuales problemas de proporcionalidad dado su carácter accesorio, y en el caso de la segunda, dado su aplicación a casos de escasa lesividad. $^{73}$

\subsubsection{Para control del reemplazo total o parcial del cumplimiento de una pena de prisión.}

El cumplimiento bajo esta modalidad constituye el modelo denominado back door (puerta de salida), que supone que es la administración penitenciaria la que decide sobre la aplicación del monitoreo telemático, en atención al cumplimiento de ciertos requisitos relevantes para el condenado. En este caso, el interno es autorizado a permanecer una determinada cantidad de horas en su domicilio, generalmente en la noche, bajo el control telemático. $^{74}$

La utilización del monitoreo telemático bajo esta modalidad, admite distintas aplicaciones, ya sea en reemplazo de una sentencia de prisión, como condición de una liberación anticipada -similar a un beneficio intrapenitenciario-, o del otorgamiento de la libertad condicional.

La primera aplicación la encontramos en el caso de países como Holanda y Suecia. Así, el primero de ellos, admite el reemplazo total de la pena de prisión impuesta por el arresto

\footnotetext{
71 CRIMINAL JUSTICE JOINT INSPECTION, Thematic report. It's complicated: The management of electronically monitored curfews, 2012. Disponible en http://www.justice.gov.uk/downloads/publications/inspectorate-reports/hmiprobation/jointthematic/electronic-monitoring-report-2012.pdf [visitado el 12.04.2013].

${ }^{72}$ BOOTHER, "An overview of electronic monitoring", cit. nota $\mathrm{n}^{\circ} 66$.

${ }^{73}$ GONZÁLEZ, El control telemático en el sistema penal, cit. nota ${ }^{\circ} 38$.

${ }^{74}$ JHSA, Electronic (radio frequency) and GPS, cit. nota ${ }^{\circ} 69$.
} 
MORALES, Ana María. "Vigilancia en la modernidad tardía:

El monitoreo telemático de infractores".

domiciliario controlado con monitoreo telemático, en condenados a penas de hasta seis meses. En el caso del segundo, se admite el reemplazo total de la pena de prisión por arresto domiciliario, en condenados a penas de hasta 3 meses. ${ }^{75}$

La segunda aplicación, la encontramos en el caso de Inglaterra y Gales, donde el monitoreo electrónico es utilizado para controlar el cumplimiento de una parte de la pena privativa de la libertad, bajo reclusión domiciliaria. De esta forma, son elegibles aquellos condenados a los que les resten hasta cuatro meses y medio para ser liberados, luego de su evaluación de riesgo y la de sus hogares, a cargo de los entes encargados de su control, pertenecientes a los Servicios de Probación. La restricción se aplica todos los días y se debe extender al menos a nueve horas. La mayoría de los condenados que cumplen penas de entre tres meses y cuatro años pueden ser candidatos a su liberación anticipada, salvo aquéllos que hubieren cometido delitos sexuales, que esperan deportación, o que hayan violado las condiciones de la libertad anticipada en ocasiones anteriores. En este contexto, la utilización del monitoreo telemático como forma de control de la libertad anticipada constituye el ámbito de menor aplicación en estos países, con un 14\% comparado con el resto de sus aplicaciones en el sistema de justicia. ${ }^{76}$

Similar utilización a la anterior admite España. Así, el Reglamento Penitenciario de 1996 establece que los internos sometidos a régimen de semilibertad, pueden sustituir la permanencia durante ocho horas o la pernocta en el centro penitenciario, por la permanencia o pernocta en su domicilio con control telemático y/u otras medidas de control. $^{77}$

Una tercera aplicación dentro de éste modelo, la encontramos asociada al otorgamiento de la libertad condicional. Esta aplicación es bastante utilizada en el caso de Estados Unidos, donde el control a través del monitoreo telemático es una de las condiciones que pueden ser impuestas a aquéllos que deseen optar a la libertad condicional (parole). Un ejemplo específico, lo encontramos en el Estado de California, donde dependiendo de los perfiles, se utiliza el sistema de radio frecuencia o de rastreo satelital, para controlar a los libertos condicionales. Este último sistema, generalmente se utiliza para la supervisión de libertos que presenten alto riesgo de reincidencia. ${ }^{78}$

Como señala Nellis, parte de la retórica utilizada por los gobiernos para justificar su introducción en sede penitenciaria, no sólo apunta a reconocer que el uso del monitoreo telemático constituye un instrumento de manejo de la cantidad de internos, sino que también enfatiza la noción de que constituye una forma de estructurar y graduar el proceso de liberación de los condenados. ${ }^{79}$

\footnotetext{
${ }^{75}$ JHSA, Electronic (radio frequency) and GPS, cit. nota ${ }^{\circ} 69$.

${ }^{76}$ BOOTHER, “An overview of electronic monitoring”, cit. nota ${ }^{\circ} 66$.

${ }^{77}$ GONZÁLEZ, El control telemático en el sistema penal, cit. nota $\mathrm{n}^{\circ} 38$.

78 Información extraída del Departamento de Correcciones y Rehabilitación del Estado de California. Disponible en http://www.cdcr.ca.gov/Parole/Electronic_Monitoring_Unit/index.html [visitado el 12.04.2013].

${ }^{79}$ NELLIS, "Electronic monitoring: towards integration", cit. nota $n^{\circ} 65$.
} 
1.6.4. Para el control de medidas de seguridad post delictuales.

El monitoreo telemático también es considerado por algunas legislaciones como una forma de control de la imposición de medidas de seguridad post delictual. Esta tendencia se ha concentrado en varios de los estados de Estados Unidos, focalizando su aplicación en el caso de ofensores que hayan cumplido condena por la comisión de ciertos delitos sexuales. Uno de los casos de utilización más extenso, lo encontramos en el estado de Florida, que a partir de la dictación de la denominada "Ley de Jessica" (Jessica Lundsford Act) ${ }^{80}$ en 2005 , introdujo una serie de enmiendas a la legislación existente, tendientes a endurecer las penas en el caso de infractores que hayan cometidos estos delitos, establecer la obligación periódica de registro en las "listas de ofensores sexuales" (sex offenders list), y regular severas sanciones en caso de incumplimiento del deber de registro. Además, se aprovisionó al estado, con los fondos necesarios para la introducción del monitoreo telemático en la supervisión de estos infractores. ${ }^{81}$

En concreto, esta legislación regula la utilización de GPS en el caso de mayores de 18 años, que hubieren sido condenados por algún delito sexual perpetrado contra menores de 15, que tuvieren condenas previas por delitos violentos o sexuales, y que fueren sentenciados a una libertad vigilada o una liberación anticipada. ${ }^{82}$ Además, requiere la utilización del monitoreo telemático por el resto de su vida, si es que el infractor ha sido condenado por haber cometido algunos de los siguientes delitos: secuestrar o privar de libertad a menores de trece años; atraer o tentar a un menor; o agredir lasciva, lujuriosa o sexualmente. Así, los convictos por cualquiera de estos delitos, deben ser supervisados electrónicamente hasta su muerte, junto con ser compelidos a pagar otras multas que mandata la ley. ${ }^{83}$ Además, como señalan Cohen y Jeglic, otros estados de dicho país han seguido el ejemplo del estado descrito, con cerca de una docena que presenta legislación similar. ${ }^{84}$

\section{Futura aplicación en Chile del monitoreo telemático.}

El monitoreo telemático está regulado entre los artículos 23 bis y 23 octies del título III de la Ley $\mathrm{N}^{\circ} 18.216$, modificada por la $\mathrm{N}^{\circ} 20.603$, cuya publicación data del 27 de junio de 2012. Si bien, a la fecha de elaboración del presente artículo se encuentra publicado su cuerpo normativo, la vigencia de sus normas, y especialmente lo relativo a la implementación del monitoreo telemático, han sido supeditados en virtud del artículo 8

\footnotetext{
${ }^{80}$ Esta legislación adoptó la denominación de la "Ley de Jessica", tras el caso de una niña de 9 años que fue violada y asesinada, por un sujeto que se encontraba registrado en la lista de ofensores sexuales, pero que se mudó sin notificar a las autoridades, tras lo cual cometió delito.

${ }^{81}$ BALES, William; MANN, Karen, BLOMBERG, Thomas; GAES, Gerry; BARRICK, Kele; DHUNGANA, Karla; McMANUS, Brian, A Quantitative and Qualitative Assessment of Electronic Monitoring, Washington: National Criminal Justice Reference Service, 2010. Disponible en http://www.criminologycenter.fsu.edu/p/pdf/EM\%20Evaluation\%20Final\%20Report\%20for\%20NIJ.pdf [visitado el 12.04.2013]. La traducción es de la autora.

${ }^{82}$ BALES et al., A Quantitative and Qualitative Assessment, cit. nota n ${ }^{\circ} 81$, p. 25.

${ }^{83}$ BALES et al., A Quantitative and Qualitative Assessment, cit. nota ${ }^{\circ} 81$.

${ }^{84}$ COHEN, Michelle; JEGLIC, Elizabeth, "Sex Offender Legislation in the United States: What Do We Know?", International Journal of Offender Therapy and Comparative Criminology, 2007, 51 (4), pp. 369383.
} 
MORALES, Ana María. "Vigilancia en la modernidad tardía:

El monitoreo telemático de infractores".

transitorio del mencionado cuerpo legal, a la publicación en el Diario Oficial de las modificaciones al Reglamento de la Ley $\mathrm{N}^{\circ} 18.216$, contenido en el Decreto Supremo $\mathrm{N}^{\circ} 1.120$ de 1984. Adicionalmente, el mismo artículo contiene algunas normas asociadas a la gradualidad en la implementación de este sistema, dependiendo de la pena sustitutiva que se trate.

Fuera de esta regulación normativa, el monitoreo telemático sólo ha sido testeado en materia penal en nuestro país, en un pequeña experiencia piloto implementada el año 2009 por la Fiscalía Metropolitana Oriente, para el control de medidas cautelares decretadas en casos de delincuencia económica y violencia intrafamiliar, aplicándose sólo a una cantidad reducida de casos. Más allá de dicha experiencia, una vez que entre gradualmente en vigencia la Ley $\mathrm{N}^{\circ} 20.603$, el país contará por primera vez con la implementación del monitoreo telemático, contando con un cuerpo normativo de respaldo.

En ese contexto, entrando al análisis de la regulación al respecto, encontramos que el inciso primero del artículo 23 bis define el monitoreo telemático como "toda supervisión por medios tecnológicos de las penas establecidas por esta ley".

El concepto entregado por la ley es más acotado que el que ofrece la criminología comparada, en la medida que se refiere sólo al control exclusivo de las penas sustitutivas contenidas en esta ley, y por lo tanto, su implementación no podría aplicarse para el control de otras sanciones contenidas en otros cuerpos normativos (por ejemplo la Ley $\mathrm{N}^{\circ} 19.327$ de violencia en los estadios o la Ley $\mathrm{N}^{\circ} 20.066$ de violencia intrafamiliar), sino se regula de manera expresa. Lo mismo ocurre en caso de que se pretenda su utilización para el control de las medidas cautelares, siendo necesaria una regulación específica que la norme.

La definición normativa, sin embargo, carece de conceptualizaciones asociadas al control y ubicación a distancia del infractor. En ese sentido, la noción entregada por la ley supone, no sólo la tecnología de localización, sino también cualquier supervisión tecnológica. Así, por ejemplo, si se decidiera controlar una de estas penas a través de CCTV, entonces su utilización estaría comprendida en el concepto.

Sin embargo, para efectos de su adecuado entendimiento, resulta necesario complementar lo dispuesto en la Ley $\mathrm{N}^{\circ} 20.603$, con las regulaciones contenidas en el "Reglamento de monitoreo telemático de condenados a penas sustitutivas a las penas privativas o restrictivas de la libertad" (en adelante RMT), aprobado por Decreto Supremo N`515 del 3 de agosto de 2012. En efecto, el artículo 3 de este cuerpo normativo contiene una definición más acabada del monitoreo telemático, distinguiendo entre el "sistema de monitoreo" y el "dispositivo o mecanismo de monitoreo telemático", en sus numerarles 3 y 8.

2. "Dispositivo o mecanismo de Monitoreo Telemático: Aparato(s) que, en conjunto con el sistema de monitoreo, permite localizar a una persona determinada."

8. "Sistema de monitoreo: Aquel destinado a permitir la localización del condenado, dentro de las zonas de cobertura disponible en los sistemas de comunicaciones utilizados, y con levantamiento cartográfico previamente ingresado, que cuenta con la capacidad para detectar si se incumplen las restricciones de 
Polít. crim. Vol. 8, № 16 (Diciembre 2013), Art. 3, pp. 408-471.

[http://www.politicacriminal.cl/Vol_08/n_16/Vol8N16A3.pdf]

movilidad establecidas por una resolución judicial, para el cumplimiento de la pena impuesta dentro del territorio nacional".

Asimismo, en el artículo 1 del reglamento se establece de manera clara, cuál es el objetivo perseguido con su implementación

"El monitoreo telemático, definido en el artículo 23 bis de la ley $\mathrm{N}^{\mathrm{o}} 18.216$, tiene por objeto supervisar, a través de medios tecnológicos, el cumplimiento de la obligación de un condenado de permanecer en un determinado lugar, durante cierta cantidad de horas o de no aproximarse a una persona o lugar determinado".

Como es posible observar, este conjunto de normas hace referencia a varios de los aspectos revisados en la experiencia comparada, matizados con las exigencias legales nacionales. Así, dentro de los objetivos, encontramos la supervisión de condenados, y si bien no se hace una referencia general a la "supervisión en la comunidad", como se observa en la definición de Renzema, ${ }^{85}$ sí se establece claramente que ésta se refiere a la localización en un lugar determinado -en referencia a la existencia de un área de inclusión- o al control de la prohibición de acercamiento a determinadas personas o lugares -en referencia a la existencia de un área de exclusión-. En ese contexto, y al encontrarse bastante más acotados los objetivos de supervisión en el sistema nacional, no sería posible a partir de las definiciones entregadas, incluir la detección de sustancias prohibidas en el cuerpo, el monitoreo de funciones fisiológicas, o el uso de alcohol ignition interlocks, como parte de las funciones del monitoreo telemático. Esto pues el artículo 23 bis de la ley $\mathrm{N}^{\circ} 20.603$ hace explícita referencia a su utilización para el control de las penas establecidas en dicho cuerpo legal, y en particular, como veremos, para llevar a cabo el control de la reclusión parcial, la libertad vigilada intensiva y los casos de pena mixta.

\subsection{Penas sustitutivas que pueden ser controladas a través del monitoreo telemático.}

La ley $\mathrm{N}^{\circ} 20.603$, en sus artículos 23 bis y 23 bis A, establece las penas sustitutivas y los supuestos bajo los cuales procede la supervisión a través del monitoreo telemático. En ese contexto, y de acuerdo a lo analizado en la experiencia comparada, la regulación nacional se centra en el modelo front door, encargándose a la judicatura, la función de decretar su aplicación.

\subsubsection{Reclusión parcial.}

La reclusión parcial, establecida en la Ley $\mathrm{N}^{\circ} 20.603$, vino a reemplazar la reclusión nocturna regulada en la Ley $\mathrm{N}^{\circ} 18.216$, que permitía el encierro en establecimientos especiales de Gendarmería de Chile entre las 22:00 y las 06:00 hrs., por un período definido por el tribunal.

La nueva forma de reclusión establecida en el artículo 6 de la Ley $\mathrm{N}^{\circ} 20.603$, establece modalidades diferidas de cumplimiento horario, permitiendo la reclusión del condenado, ya sea de manera diurna (encierro durante un lapso de ocho horas diarias y continuas, las que

\footnotetext{
${ }^{85}$ RENZEMA, “Electronic Monitoring's Impact on Reoffending”, cit. nota ${ }^{\circ} 26$.
} 
MORALES, Ana María. "Vigilancia en la modernidad tardía:

El monitoreo telemático de infractores".

se fijarán entre las ocho y las veintidós horas), nocturna (encierro entre las veintidós horas de cada día hasta las seis horas del día siguiente) o de fin de semana (entre las veintidós horas del día viernes y las seis horas del día lunes siguiente). Otra de las modificaciones, en consonancia con lo antes expuesto, apuntó a establecer preferentemente, que esta pena debe ser cumplida en el domicilio del condenado, mediante el control telemático de la reclusión. Por otro lado, el artículo 7 establece que para los efectos de esta ley, se entenderá por domicilio la residencia regular que el condenado utilice para fines habitacionales, descartándose que esta pena pueda cumplirse en el lugar donde el sujeto ejerza habitualmente su profesión u oficio.

Entre los argumentos esgrimidos para justificar la modificación a la reclusión nocturna, encontramos su elevado índice de reincidencia, la inflexibilidad de los horarios para decretarla, y principalmente las posibilidades de contagio criminógeno, considerando que más del $40 \%$ de las reclusiones se cumplen en recintos carcelarios destinados a albergar a la población común y no en recintos especiales. $^{86}$

Los requisitos que debe cumplir el condenado para poder ser objeto de la sustitución de la pena privativa de la libertad por reclusión parcial, son básicamente los mismos regulados antes de la reforma a la ley; estos es, que la pena en concreto no supere los tres años de privación o restricción de la libertad, junto con la primariedad delictiva o la hipótesis de reincidencia cuando, sumadas las penas, no superaren los dos años de privación de la libertad. Sin embargo, con la Ley $\mathrm{N}^{\circ} 20.603$ se restringió la cantidad de condenas anteriores a computar, a aquéllas que se hubieren cumplido dentro de los cinco años anteriores en caso de los simples delitos y a los diez años en el caso de los crímenes. Además, se restringió a dos la cantidad de reclusiones parciales de las que podía ser objeto el infractor en el mismo período señalado. Finalmente, se agregaron ciertas exigencias en relación a los antecedentes laborales, educaciones o de otras naturalezas, que pudieren justificar su imposición.

El artículo 23 bis utiliza el verbo "podrá", de lo que se desprende que es facultativo para el juez disponer la supervisión de esta pena a través del control telemático. Lo anterior implica, que la reclusión parcial, puede ser cumplida en el domicilio del condenado de igual forma, sin ser monitoreada telemáticamente, por ejemplo a través de controles de delegados o policías.

De acuerdo a lo informado por el Ejecutivo al Congreso Nacional, el control de esta pena, al suponer exclusivamente una monitorización en el domicilio y en determinados horarios, se efectuará a través del sistema de radio frecuencia. ${ }^{87}$

\footnotetext{
86 BIBLIOTECA DEL CONGRESO NACIONAL (BCN), Historia de Ley $\mathrm{N}^{\circ}$ 20.603. Disponible en http://www.bcn.cl [visitado el 12.04.2013].

${ }^{87}$ BCN, Historia de Ley $\mathrm{N}^{\circ} 20.603$, cit. nota $\mathrm{n}^{\circ} 86$, p. 262.
} 
Polít. crim. Vol. 8, No 16 (Diciembre 2013), Art. 3, pp. 408-471.

[http://www.politicacriminal.cl/Vol_08/n_16/Vol8N16A3.pdf]

2.1.2. Libertad vigilada intensiva, tratándose de algunos delitos cometidos en contexto de violencia intrafamiliar y delitos contra la indemnidad sexual.

La libertad vigilada intensiva es una sanción nueva en nuestra legislación, pero tiene su fuente en la libertad vigilada que se reguló el año 1983, en los artículos 14 al 23 de la Ley $\mathrm{N}^{\circ}$ 18.216. Sin perjuicio de lo anterior, según ya se expuso, esa "intensidad" tiene como antecedente la experiencia de Estados Unidos, país que a partir de los años 80, y en la búsqueda de sanciones intermedias, estableció los programas de supervisión intensiva, que entre otras medidas supusieron intensificar la instancias de supervisión. ${ }^{88}$

No todos los casos de libertad vigilada intensiva conllevan la aplicación del monitoreo telemático, sino sólo aquéllos contemplados en la letra b) del artículo 15 bis de la Ley $\mathrm{N}^{\circ}$ 20.603. La citada norma, se refiere a determinados delitos cometidos en el contexto de violencia intrafamiliar, o en los que se atentare contra la indemnidad sexual, respecto de los cuales sería procedente la monitorización telemática. Fuera de precisar su aplicación sólo en esas familias de delitos, la norma exige para su procedencia, que la pena impuesta al condenado, sea superior a 540 días y no exceda los cinco años, y que el sujeto no cuente con antecedentes penales previos, dentro de los cinco años, en el caso de los simples delitos y dentro de los diez años, en los crímenes, por los cuales se hubiere cumplido una condena.

Finalmente, se requiere la existencia de antecedentes que permitan suponer que una intervención individualizada pudiera ser efectiva para la reinserción social del sujeto. De esta forma, con la citada regulación, se buscó ampliar la utilización de la libertad vigilada para el caso de aquellos delitos que representan una especial preocupación para el legislador, considerando que antes sólo podía ser decretada en el caso que la pena impuesta fuere superior a dos años y no excediere de los cinco años.

En concreto, los delitos regulados en el Código Penal, respecto de los cuales procede el control de la libertad vigilada a través del monitoreo telemático son los siguientes:

- Delitos cometidos en contexto de violencia intrafamiliar

- Amenazas (artículos 296 y 297)

- Parricidio (artículo 390)

- Homicidio simple y calificado (artículo 391)

- Castración (artículo 395)

- Otras mutilaciones (artículo 396)

- Lesiones graves y menos graves (artículos 397, 398 y 399)

- Delitos contra la indemnidad sexual

- Estupro (artículo 363)

- Abuso sexual agravado por la introducción de objetos (artículo 365 bis)

- Abuso sexual (artículo 366)

- Abuso sexual respecto de persona menor de 14 años (artículo 366 bis y 366 quáter)

${ }^{88}$ PETERSILIA, “A decade of experimenting with intermediate sanctions”, cit. nota $\mathrm{n}^{\circ} 7$. 
MORALES, Ana María. "Vigilancia en la modernidad tardía:

El monitoreo telemático de infractores".

- Participación en la producción de material pornográfico en que hayan sido utilizados menores de 18 años (artículo 366 quinquies)

- Facilitación o promoción de la prostitución de menores de edad (artículo 367)

- Facilitación o promoción de la entrada o salida del país para el ejercicio de la prostitución (artículo 367 bis)

- Obtención de servicios sexuales de menor de 18 años y mayor de 14 años (artículo 367 ter)

- Tráfico de personas (artículo 411 bis)

El inciso tercero del artículo 23 bis establece que la utilización del monitoreo telemático en el caso de los delitos señalados -en que los condenados además cumplieren con los requisitos de acceso asociados a los márgenes penales de aplicación y primariedad delictiva-, constituye una facultad del tribunal, quien puede decretar la libertad vigilada intensiva para estos casos, con o sin monitorización telemática, para lo cual deberá sopesar la gravedad del ilícito y la vulnerabilidad de la víctima. De esta forma, aun en los casos del artículo 15 bis b), el tribunal deberá en base a los antecedentes aportados, determinar si resulta necesaria la aplicación del monitoreo telemático.

Por otro lado, el artículo 17 ter establece que en caso de imponerse la libertad vigilada intensiva deberá decretarse, además, una o más de las siguientes condiciones: prohibición de acudir a determinados lugares; prohibición de aproximarse a la víctima, o a sus familiares u otras personas que determine el tribunal, o de comunicarse con ellos; obligación de mantenerse en el domicilio o lugar que determine el juez, durante un lapso máximo de ocho horas diarias, las que deberán ser continuas; y obligación de cumplir programas formativos, laborales, culturales, de educación vial, sexual, de tratamiento de la violencia, u otros similares. Estas condiciones específicas de la libertad vigilada intensiva, constituyen sin duda una de las fórmulas con las cuales el legislador buscó imprimir el carácter "intensivo" de esta libertad vigilada, de manera de distinguirla de la libertad vigilada simple.

Al formar parte de las condiciones de la libertad vigilada intensiva, se entiende que éstas podrán ser supervisadas de igual forma a través del monitoreo telemático. Así pues, en estos casos, la función de dicha tecnología de control no se restringe a la supervisión domiciliaria del sujeto en los lapsos que determinare el juez, sino que también importan una supervisión constante, de manera de controlar el cumplimiento de las condiciones específicas impuestas.

Como se desprende de lo expuesto, la regulación de la libertad vigilada para estos delitos y su combinación con la aplicación del monitoreo telemático, van en consonancia con lo observado en la experiencia internacional, en particular con su aplicación en determinados delitos como es el caso de los cometidos en el contexto de violencia intrafamiliar y de algunos delitos sexuales. Así, como analizamos anteriormente, en el caso de la primera familia de delitos, existen experiencias en Estados Unidos y España, asociadas al control de las medidas de alejamiento del agresor, en el contexto de la violencia doméstica. Por otro lado, en el caso de los ofensores sexuales, y particularmente en el caso de Estados Unidos, 
Polít. crim. Vol. 8, № 16 (Diciembre 2013), Art. 3, pp. 408-471.

[http://www.politicacriminal.cl/Vol_08/n_16/Vol8N16A3.pdf]

se ha aplicado la monitorización, centrándose más bien en los casos de libertad condicional y en medidas de seguridad post delictual.

Desde otra perspectiva, para el control telemático de los infractores que hayan cometido los citados delitos, y respecto de los cuales se hubiere decretado la libertad vigilada intensiva, de acuerdo a lo informado por el Ejecutivo al Congreso, será utilizado el rastreo satelital o GPS como tecnología de supervisión. ${ }^{89}$

Por otro lado, al igual que lo expuesto en relación a los tipos de tecnologías disponibles, el inciso cuarto del artículo 23 bis establece la posibilidad que la víctima porte un dispositivo de control para su protección, recogiendo la tecnología del monitoreo telemático "bilateral". En estos casos, la libertad vigilada intensiva debe ir acompañada de la condición establecida en la letra b) del artículo 17 ter, estos es, la prohibición de aproximarse a la víctima, sus familiares u otras personas que determine el tribunal, toda vez que el monitoreo telemático bilateral no sería útil para controlar las demás condiciones del artículo 17 ter, que no incluyen a la víctima o a sus familiares como especial objeto de protección.

\subsubsection{Libertad vigilada intensiva por aplicación de la pena mixta.}

La pena mixta, establecida en el artículo 33, es un mecanismo que permite la interrupción de la pena privativa de libertad, originalmente impuesta, reemplazándola por el régimen de libertad vigilada intensiva. Para que ésta pueda ser decretada, debe tratarse de condenados a penas de hasta cinco años y un día; que no registren otra condena por crimen o simple delito al momento de ser discutida su interrupción y que hubieren cumplido al menos un tercio de la pena de manera efectiva. Además, es necesario que poseyere un comportamiento calificado como "muy bueno" o "bueno" en los tres bimestres anteriores, de conformidad con lo dispuesto en el artículo 21 del Reglamento de la Libertad Condicional.

Esta norma, inspirada en el artículo 19 de la Ley $\mathrm{N}^{\circ} 20.084$, establece la posibilidad de combinar una pena privativa de la libertad con una pena sustitutiva. Si bien, el legislador le denomina pena mixta, lo cierto es que más que ser una combinación de sanciones, supone la materialización del régimen progresivo que inspira el cumplimiento de éstas. Así, el artículo 93 del Reglamento de Establecimientos Penitenciarios señala que las actividades y acciones de la institución penitenciaria tendrán como referente el carácter progresivo del proceso de reinserción social del interno, y en su programación deberán atender a las necesidades específicas de cada persona a quien se dirigen. Esta regulación especial, por ende, participa de los mismos fundamentos que justifican instituciones como la libertad condicional, basados en los fines de prevención especial positiva, siendo además un instrumento que permite disminuir los efectos de la extrema dureza de las penas y evitar los efectos desocializadores que conllevan la privación de libertad. ${ }^{90}$

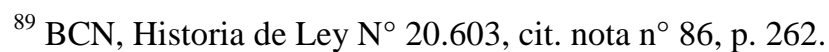

90 Véase, por todos, MORALES, Ana María, "Redescubriendo la Libertad Condicional", Revista Razonamiento Penal N² (2012), pp. 179-201.
} 
MORALES, Ana María. "Vigilancia en la modernidad tardía:

El monitoreo telemático de infractores".

En ese contexto, esta norma debiera operar en momentos tempranos de la ejecución penal, de manera de no traslaparse con la libertad condicional que conforme el numeral 1 del artículo 2 del DL N³21 puede ser solicitada, salvo excepciones, cumplida la mitad de la condena. Así, en el caso de la nueva regulación, la pena mixta puede ser solicitada habiendo cumplido un tercio de la misma. Además, en este caso, se imponen restricciones respecto de los reincidentes y de la pena en concreto. Por otro lado, también existen diferencias en relación al ente encargado de decidir su otorgamiento, pues en el caso de la pena mixta regulada en la Ley $\mathrm{N}^{\circ} 20.603$, corresponde al juez de garantía decidir acerca de su procedencia, en base a los antecedentes proporcionados por Gendarmería de Chile.

En estos casos, a diferencia de las demás hipótesis de procedencia de libertad vigilada, se trata de infractores que han cumplido una parte de la pena privativa de la libertad, que pueden optar a un régimen ambulatorio supervisado, el cual les permite acceder a la oferta programática propia de la libertad vigilada intensiva. En ese sentido, debiera operar como un fuerte estímulo para su utilización, la posibilidad de que opten a ser supervisados tanto por un delegado como por el sistema de monitoreo telemático.

En el caso de la pena mixta, se estableció como obligatorio el control a través del monitoreo telemático por el saldo de la sanción que se cumpliere en libertad vigilada intensiva, de conformidad a lo dispuesto en el artículo 23 bis A. El proyecto originalmente presentado por el Ejecutivo proponía que en estos casos fuera facultativa para el juez la imposición de este mecanismo, para de esta forma, permitir la introducción de análisis relativos a la necesariedad de la medida de supervisión. Sin embargo, el Congreso decidió eliminar la discrecionalidad judicial y establecer la utilización del monitoreo telemático durante todo el saldo de la pena, sin posibilidad de atenuar su imposición mediante el uso de las normas de reemplazo contenidas en el artículo. Como veremos en los próximos párrafos, ésta constituye sin duda uno de los aspectos criticables del proyecto.

Finalmente, respecto de la tecnología que se utilizará para el control telemático de la pena mixta, de acuerdo a lo informado por el Ejecutivo al Congreso, en estos casos será utilizado el rastreo satelital o GPS. ${ }^{91}$

\subsection{Algunas cuestiones prácticas en relación a la aplicación del monitoreo telemático a las penas sustitutivas.}

\subsubsection{Informe de factibilidad técnica.}

Para la imposición del monitoreo telemático, el legislador exige que se cuente con un informe de factibilidad técnica favorable.

El informe de factibilidad técnica es un

“documento elaborado por Gendarmería de Chile, por el que se informa al tribunal, si se cuenta con las condiciones técnicas adecuadas para monitorear al condenado y/o a la víctima, según se requiera en la solicitud del tribunal, considerando: zonas de

${ }^{91}$ BCN, Historia de Ley $\mathrm{N}^{\circ}$ 20.603, cit. nota $\mathrm{n}^{\circ}$ 86, p. 262. 
Polít. crim. Vol. 8, № 16 (Diciembre 2013), Art. 3, pp. 408-471.

[http://www.politicacriminal.cl/Vol_08/n_16/Vol8N16A3.pdf]

inclusión; zonas de exclusión (tratándose de la libertad vigilada intensiva); la duración de la medida; la cobertura del sistema de telecomunicaciones, entre otras", 92

y su objetivo es entregar al juez la información necesaria para decidir sobre la aplicación de la monitorización, considerando especialmente la posibilidad que se generen "fallas de cobertura" o no se cuente con una línea telefónica para poder utilizar el sistema de radio frecuencia.

Sobre el particular, es necesario precisar que durante el debate parlamentario hubo cuestionamientos de algunos académicos en relación a la existencia de problemas de legalidad, al sujetar la facultad judicial de imponer el monitoreo telemático a un informe de factibilidad de una institución de la Administración, como es Gendarmería de Chile. ${ }^{93}$ Sin perjuicio de esto, es necesario precisar, cómo se argumentó durante el debate parlamentario, que en el evento de que el informe de factibilidad fuese negativo, esto no debiese en ningún caso entenderse como un obstáculo para imponer la pena de reclusión parcial o de libertad vigilada intensiva, impuesto por el tribunal en la sentencia. Aquello se establece claramente en el artículo 7, a propósito de la reclusión parcial, al señalar éste que "En tal caso, entendido como excepcional, se podrán decretar otros mecanismos de control similares, en la forma que determine el tribunal." Si bien, esta posibilidad no se establece de manera expresa dentro de la libertad vigilada intensiva, sí se desprende del inciso final del artículo 23 bis, que señala claramente que el tribunal considerará el informe de factibilidad técnica "para efectos de la imposición de esta medida de control" y no de la pena.

\subsection{2. Órgano encargado de administrar el sistema.}

De acuerdo al artículo 23 quater de la ley, la responsabilidad en la administración del sistema de monitoreo telemático quedará radicada en Gendarmería de Chile. En concreto, de acuerdo a lo establecido en el artículo 4 del reglamento, corresponderá al Departamento de Monitoreo Telemático, dependiente de la Subdirección Técnica de la institución, efectuar dicho seguimiento, a través de los medios tecnológicos disponibles.

Si perjuicio de lo anterior, el mismo artículo establece que la institución a cargo podrá contratar servicios externos para estos efectos, de conformidad a la ley $\mathrm{N}^{\circ} 19.886$, de Bases sobre Contratos Administrativos de Suministro y Prestación de Servicios.

En la experiencia comparada existen diversas alternativas, en relación a las responsabilidades que pueden asumir los privados en la aplicación del monitoreo telemático. Así, por ejemplo, Inglaterra y Gales presenta el mayor involucramiento del sector privado en áreas como: el suministro de equipamiento, la operación del centro de monitoreo telemático, la instalación del equipo en el infractor, la orientación respecto de su

\footnotetext{
${ }^{92}$ MINISTERIO DE JUSTICIA, Material de capacitación. Nueva Ley $N^{\circ} 18.216$, Santiago: Ministerio de Justicia, Inédito, p. 111.

${ }^{93}$ Véase, por todos, la intervención del Profesor Guzmán en el debate parlamentario en BCN, Historia de Ley $\mathrm{N}^{\circ} 20.603$, cit. nota $\mathrm{n}^{\circ} 86$, p. 83.
} 
MORALES, Ana María. "Vigilancia en la modernidad tardía:

El monitoreo telemático de infractores".

uso, la respuesta a violaciones, y el inicio del procedimiento frente a incumplimientos. ${ }^{94}$ Similar situación también se presenta en algunos estados de Estados Unidos, como es el caso de Florida. ${ }^{95}$ Sin embargo, otros países han preferido conservar la labor asociada al control telemático de los infractores, entregándoles a los privados sólo la función de proveer los equipos. Esta distinción no es baladí, considerando el tráfico de información sensible a la cual se puede tener acceso, junto con eventuales cuestionamientos asociados a la delegación de funciones eminentemente estatales, en lo que dice relación con la determinación administrativa de los incumplimientos, que sin duda pueden acarrear consecuencias penales de gravedad.

En ese contexto, la regulación nacional del monitoreo telemático es más cautelosa, pues sólo entrega al ámbito privado lo que dice relación con la provisión de la tecnología, cediendo a Gendarmería la función de administrarlo y controlarlo. Así, el artículo 4 del reglamento señala "la Sección de Monitoreo Telemático será la encargada de efectuar todas aquellas actividades relacionadas con la supervisión, a través de los medios tecnológicos disponibles del cumplimiento de las penas". En la misma línea, al definir la expresión "operadores del sistema de monitoreo telemático" en el numeral 6 del artículo 3 del mismo cuerpo normativo, se precisa que corresponden a

"funcionarios de Gendarmería de Chile encargados de realizar el seguimiento mediante este sistema de control y de comunicarse con el condenado y/o las instituciones que correspondan, en caso de generación de las advertencias a las que se refiere el artículo 19 del presente reglamento".

\subsubsection{Duración del control telemático.}

El inciso $6^{\circ}$ del artículo 23 bis dispone que el mecanismo de monitoreo telemático "se aplicará por un plazo igual al de la duración de la pena sustitutiva que se impusiere". Sin embargo, el inciso final del mismo artículo regula la posibilidad de que cese el control a través de este mecanismo, no obstante continúe la ejecución de la sanción, al establecer

"a solicitud del condenado, el tribunal podrá citar a una audiencia a fin de resolver acerca de la mantención, modificación o cesación de esta medida. En este caso, podrá ordenar la modificación o cesación de la medida cuando hubieren variado las circunstancias consideradas al momento de imponer esta supervisión".

En ese contexto, si cesaren las circunstancias que motivaron la orden de monitoreo, el condenado podrá solicitar que se siga ejecutando la sanción sustitutiva sin necesidad de su monitorización telemática. Esto es aplicable, en caso que se hubiere decretado respecto del condenado, una reclusión parcial o una libertad vigilada en las hipótesis de la letra b) del artículo 15 bis, sin embargo no es aplicable en el caso de una libertad vigilada intensiva, como consecuencia de la aplicación de la pena mixta. Esto, pues en dichos casos, el artículo 23 bis A ordena la monitorización telemática durante todo el período de la libertad vigilada intensiva.

\footnotetext{
${ }^{94}$ BOOTHER, "An overview of electronic monitoring", cit. nota ${ }^{\circ} 66$.

${ }^{95}$ ALBRECHT, Electronic Monitoring in Europe, cit. nota ${ }^{\circ} 29$.
} 
Polít. crim. Vol. 8, № 16 (Diciembre 2013), Art. 3, pp. 408-471.

[http://www.politicacriminal.cl/Vol_08/n_16/Vol8N16A3.pdf]

Sin duda, la regulación nacional en relación a la duración del control a través de monitoreo telemático, merece ser objeto de críticas. En primer lugar, la exigencia de que este sistema de control sea utilizado durante toda la ejecución de la sanción sustitutiva, respecto de la cual se decretare, supone efectuar exigencias de proporcionalidad que son propias de la ejecución de las penas y no de medidas de control, como es el caso del monitoreo telemático. Además, esta norma resulta contradictoria con la lógica contenida en el inciso segundo del artículo 23 bis que estable que el juez "podrá" decretar la utilización el monitoreo telemático para controlar la reclusión parcial y la libertad vigilada intensiva. En ese sentido, parece absurdo que el tribunal sólo cuente al inicio y no durante toda la ejecución de la condena, con la posibilidad de revocar dicha medida de control de oficio, si de los antecedentes aportados por Gendarmería pareciere no justificarse su mantenimiento, o que pudiere decretarlo por períodos inferiores del establecido para la pena sustitutiva.

Asimismo, bajo la lógica anterior, aun resulta más reprochable la regulación del legislador a propósito de la pena mixta, pues con la normativa aprobada, pudiere un penado condenando a cinco años y un día de pena privativa de la libertad, al que se le hubiere concedido la pena mixta, estar más de tres años con control telemático. Esto sin duda no se encuentra en sintonía con la experiencia comparada, en la que en general se regulan períodos máximos de seis meses para la reclusión domiciliaria monitorizada telemáticamente, como ocurre en el caso de Inglaterra y Gales, ${ }^{96}$ o Canadá, ${ }^{97}$ o hasta 12 meses, como es el caso de Holanda. ${ }^{98}$ De esta forma, en general no se aconseja una larga monitorización, pues las personas sólo suelen tolerar períodos de entre 90 y 120 días de dicho tipo de control, ${ }^{99}$ luego de lo cual perdería su efecto disuasivo y eventualmente podrían aumentar éste las posibilidades de incumplimiento, aun cuando esta hipótesis no ha sido testeada empíricamente al no existir experiencias internacionales que contemplen períodos de monitorización como el regulado en la Ley №20.603.

Por otro lado, lo que resulta aun más problemático, es que no se establezca criterios asociados a la necesidad o no de control telemático, y que, por lo tanto, pueda ser utilizado en condenados, que posiblemente dejarán de cometer delitos, estén o no con supervisión telemática, como parece ser el caso de los candidatos a pena mixta. Así, el perfil de candidatos de este tipo de sanción, que sean primerizos condenados por delitos de mediana gravedad, y que cuenten con buena conducta, hace suponer en muchos casos que la monitorización no será necesaria, y que el monitoreo electrónico no cumplirá más efectos que los de prevención especial negativa.

96 NELLIS, Mike, "Surveillance and Confinement: Explaining and understanding the experience of electronically monitored curfews", European Journal of Probation, 2009, 1 (1), pp. 41-65. Cfr.: BOOTHER, "An overview of electronic monitoring", cit. nota $\mathrm{n}^{\circ} 66$.

${ }^{97}$ BONTA, James; ROONEY, Jennifer; WALLACE-CAPRETTA, Suzanne, Electronic Monitoring in Canada, Solicitor General Canada, 1999. Disponible en http://www.publicsafety.gc.ca/cnt/rsrcs/pblctns/lctrnc-mntrng-cnd/lctrnc-mntrng-cnd-eng.pdf [visitado el 12.04.2013].

${ }^{98}$ BEIJERSE, Jolande uit; VAN SWAANINGEN, Rene, "Non-custodial sanctions", en: BOONE, Miranda; MOERINGS, Martin, Dutch Prisons, Meppel; BJu Legal Publishers, 2007. Cit: GONZÁLEZ, El control telemático en el sistema penal, cit. nota $\mathrm{n}^{\circ} 38$.

${ }^{99}$ ESCOBAR, Gonzalo, "Los monitores electrónicos (ipuede ser el control electrónico una alternativa a la cárcel?), en: LARRAURI/ CID, “Uso expansionista de la prisión”, cit. nota n 1. 
MORALES, Ana María. "Vigilancia en la modernidad tardía:

El monitoreo telemático de infractores".

Si bien, en nuestro país no existe en la administración penitenciaria criterios actuarialistas de clasificación de acuerdo al riesgo de reincidencia de los sujetos, los requisitos exigidos para optar a la pena mixta, hacen suponer que no estamos frente a condenados que podrían ser clasificados de alto riesgo, sino a sujetos de riesgo bajo o moderado, que perfectamente pueden ser supervisados por un delegado u otro control administrativo, sin necesidad de monitorización. En ese contexto, la solución del legislador no sólo acarrea problemas asociados a los criterios de costo-eficiencia de la medida de control, sino también resulta ser contraria a la experiencia internacional, que aconseja la supervisión en la comunidad con medidas menos invasivas en el caso de los infractores de bajo riesgo, ${ }^{100}$ toda vez que la utilización del monitoreo telemático es concebida como la más punitiva, considerando las restricciones a la libertad que impone. ${ }^{101}$

Considerando lo señalado, y tomando en cuenta que la judicatura no contará con información relativa a la necesariedad de la imposición del monitoreo telemático, correspondería que la defensa aportase los antecedentes adecuados para evitar este sistema de control, en aquellos casos que parecieren no justificar su uso.

\section{Mitos y realidades existentes en torno a la aplicación del monitoreo telemático.}

A continuación se analizará una serie de supuestos que han formado parte de la discusión asociada a la introducción del monitoreo telemático en las distintas legislaciones. Así, si bien este mecanismo de control ha sido utilizado por la experiencia anglosajona desde los años 80, la utilidad del mismo en relación a los objetivos asociados a la reducción de la población recluida, de entregar una alternativa costo-eficiente al encarcelamiento u otros programas en la comunidad, y a la reducción de la reincidencia de los sujetos a control, entre otros fines, ha sido objeto de un debate considerable. A esto, se suman, algunos cuestionamientos que ha abordado la literatura en relación a la aplicación de este mecanismo de control, respecto de determinados delitos y ofensores, de los efectos en los infractores y sus familias, de la afectación de la garantía constitucional a la privacidad, y de la creación de una sociedad vigilante.

De esta forma, como se verá en las próximas páginas, su implementación en otras legislaciones ha estado rodeada de mitos, que se buscan rebatir en las próximas páginas. Considerando lo anterior, su propósito fundamental es el de sistematizar la literatura y evidencia criminológica acerca de los aspectos antes precisados, de manera de aportar a futuros debates que se susciten en su aplicación en nuestro país. En ese contexto, el interés del presente artículo es entregar una visión que supere los debates meramente axiológicos, con el objeto de debatir empíricamente acerca de sus consecuencias.

\footnotetext{
${ }^{100}$ DEMICHELE/PAYNE, Offender supervision, cit. nota $\mathrm{n}^{\circ} 32$.

101 THE MAGISTRATES' ASSOCIATION, "Sentencing Policy and Practice Committee. Curfew orders with electronic monitoring (tagging)", Policy Paper, 2010. Disponible en http://www.magistratesassociation.org.uk/dox/consultations/1285770521_56-curfew-orderspolicy.pdf?PHPSESSID=eqmccuoidnqd4sqaes8gj4o5r3 [visitado el 12.04.2013].
} 
Polít. crim. Vol. 8, № 16 (Diciembre 2013), Art. 3, pp. 408-471.

[http://www.politicacriminal.cl/Vol_08/n_16/Vol8N16A3.pdf]

\section{1. ¿Permite reducir la cantidad de personas recluidas o tiene efectos de expansión de la red de control penal (netwidening)?}

Como se expuso anteriormente, la búsqueda de sanciones intermedias y de mecanismos de control más intensos, como el monitoreo telemático, tuvo en su antesala el incremento desproporcionado de la población carcelaria, principalmente en Estados Unidos, y la búsqueda de alternativas que permitieran racionalizar el uso de la pena privativa. En ese contexto, uno de los efectos esperados con la introducción del monitoreo telemático en las distintas legislaciones, estuvo asociado a la posibilidad de reducir la cantidad de personas encarceladas. ${ }^{102}$ Sin embargo, en la actualidad, la literatura internacional muestra incertidumbre en torno al cumplimiento de dicho objetivo. Como señala Boother,

"aunque el argumento de que el aumento del uso del ME [monitoreo electrónico] ha reducido la población penitenciaria puede ser tentador... existe poca evidencia al respecto. La población penitenciaria ha aumentado y también el uso del ME [monitoreo electrónico]". 103

En esa línea, se ha planteado que la introducción de este mecanismo de control, no ha logrado reducir la cantidad de población recluida, sino que lo que, por el contrario, ha expandido la red de control penal o netwidening. ${ }^{104}$

La frase "expansión de la red", corresponde a una traducción de la palabra en inglés "netwidening", y tiene su fundamento, como se señaló anteriormente, en la tesis expuesta entre otros por Cohen, ${ }^{105}$ quien argumentó que la introducción de sanciones en la comunidad ha implicado el surgimiento de nuevas formas de control social, en las que el control al interior de la institución cerrada da paso a la existencia de redes de supervigilancia dentro de la ciudad. En tal sentido, las sanciones en la comunidad, no habrían logrado reemplazar la cárcel como respuesta, sino que habrían supuesto el expandir el sistema penal a áreas tradicionalmente ajenas a éste, y por ende, ampliar el control social formal sobre personas tradicionalmente ajenas al mismo.

En el ámbito criminológico, la expresión "netwidening", no cuenta con significado unívoco, concibiéndose una naturaleza dual a la expresión. ${ }^{106}$ Esto sería atribuible a la distinción efectuada por Tonry y Lynch, ${ }^{107}$ quienes diferencian entre los efectos del netwidening en la implementación de las sanciones intermedias entre los "front-end programs" y los "back-end programs", dando lugar a "front-end netwidening" y "back-end

102 HARTJEN, Clayton; RHINE, Edward (Eds.), Correctional theory and practice, Chicago: Nelson-Hall, 1992. Cit.: BOTTOS, Shauna, An overview of Electronic Monitoring in Corrections: The issues and Implications, Research Brand Correctional Service Canada, 2007. Disponible en http://www.cscscc.gc.ca/research/r182-eng.shtml [visitado el 12.04.2013].

${ }^{103}$ BOOTHER, "An overview of electronic monitoring", cit. nota no 66, p. 42.

${ }^{104}$ BONTA et al., Electronic Monitoring in Canada, cit. nota ${ }^{\circ} 97$.

${ }^{105}$ COHEN, "The punitive city", cit. nota ${ }^{\circ} 3$.

${ }^{106}$ PADGETT, Kathy; BALES, William; BLOMBERG, Thomas, "Under Surveillance: An Empirical Test Effectiveness and Consequences of Electronic Monitoring", Criminology and Public Policy 5 (2006), pp. 6191.

${ }^{107}$ TONRY, Michael; LYNCH, Mary, "Intermediate sanctions", en: TONRY, Michael (Ed.), Crime and Justice: A Review of Research, Chicago: University of Chicago Press, 1995, pp. 99-144. 
MORALES, Ana María. "Vigilancia en la modernidad tardía:

El monitoreo telemático de infractores".

netwidening". ${ }^{108}$ El primer tipo de netwidening estaría asociado al uso de sanciones intermedias más intensas en infractores que de igual forma no hubieren recibido una pena privativa de la libertad, imponiendo una sanción en casos que tradicionalmente no son castigados o estableciendo penas más severas de las que tradicionalmente son objeto. El segundo tipo de netwidening, se asociaría al aumento de las probabilidades de recibir una pena privativa de la libertad, como consecuencia de la existencia de mayores violaciones técnicas, entre aquellos infractores que son objeto de mayor vigilancia. De esta forma, este tipo de netwidening se manifestaría en un aumento del encarcelamiento como consecuencia de una mayor supervisión, y del aumento de las posibilidades de detección de los incumplimientos o quebrantamientos -en nuestro lenguaje jurídico-.

En ambos casos, las consecuencias suponen más individuos sujetos a sanciones penales, y la necesidad de que exista más personal asociado a su control. ${ }^{109}$

En ese contexto, poder evaluar el efecto del netwidening en relación al monitoreo telemático, no constituye una tarea fácil, y la mayoría de las conclusiones en relación a sus efectos, se han construido en base a estudios cualitativos, y a las percepciones de los encargados de la política pública y de los operadores de los programas. ${ }^{110}$

En el caso concreto del "front-end netwidening", las afirmaciones entorno a la expansión de la red de control penal, se asocian a la aplicación del monitoreo a infractores de bajo riesgo. Esto, debido a que los rigurosos criterios de selección para su aplicación detectados en ciertas jurisdicciones, han hecho que en definitiva los mejores candidatos -con menores probabilidades de reincidir-, sean usualmente sujetos a supervisión mediante monitoreo telemático, los que podrían funcionar igualmente bien -es decir, sin reincidir- en la comunidad sin este mecanismo de control. ${ }^{111}$ En esa línea, en un estudio de evaluación de tres programas en Canadá, desarrollado por Bonta y sus colaboradores, ${ }^{112}$ los autores pudieron constatar la existencia de netwidening en uno de los programas. Esto, debido a que no se pudo establecer diferencias entre los sujetos que eran derivados por la judicatura a libertad vigilada intensiva (intensive probation) y aquéllos que lo eran a libertad vigilada con monitoreo electrónico, presentado similares niveles de riesgo y de reincidencia.

De esta forma, los autores sugieren que los infractores derivados a monitoreo electrónico, podrían haber sido controlados efectivamente en la comunidad, sólo con la libertad vigilada intensiva, y sin la supervisión adicional a través del control telemático. Por otro lado, Padgett y sus colaboradores, ${ }^{113}$ en un estudio cuasi experimental de evaluación del este sistema, desarrollado en Florida, Estados Unidos, buscaron distinguir entre aquellos delitos "violentos" y "no violentos", como una medición de la seriedad de la ofensa, y la aplicación de este dispositivo de control. Sus resultados indicaron que aquellos sujetos a los cuales se había sentenciado a reclusión domiciliaria supervisada con el monitoreo

\footnotetext{
${ }^{108}$ PADGETT et al., "Under Surveillance”, cit. nota ${ }^{\circ} 106$.

${ }^{109}$ BOTTOS, An overview of Electronic Monitoring in Corrections, cit. nota $n^{\circ} 102$.

${ }^{110}$ BOTTOS, An overview of Electronic Monitoring in Corrections, cit. nota $n^{\circ} 102$.

111 BONTA, James; WALLACE-CAPRETTA, Suzanne; ROONEY, Jennifer, "Can electronic monitoring make a difference? An evaluation of three Canadian programs", Crime \& Delinquency 2000, 46 (1), pp.61-75.

112 BONTA/WALLACE-CAPRETTA/ROONEY, "Can electronic monitoring make a difference?", cit. nota $\mathrm{n}^{\circ} 111$.

${ }^{113}$ PADGETT et. al., "Under Surveillance”, cit. nota $n^{\circ} 106$.
} 
telemático, tendieron a ser condenados por delitos más violentos que aquéllos sentenciados a una pena en libertad sin monitoreo telemático, desechando la tesis del "front-end netwidening".

En relación al "back-end netwidening", los resultados de las investigaciones también han sido en general contradictorios. Así, en un estudio sobre la aplicación del monitoreo telemático en la supervisión de medidas cautelares ambulatorias, se encontraron mayores tasas de violaciones técnicas, en los sujetos que habían sido liberados en la comunidad con monitoreo telemático, respecto de aquéllos que fueron dejados en libertad sin dicho mecanismo de control. ${ }^{114}$ Por otro lado, en el estudio de Bonta y colaboradores, ${ }^{115}$ los autores no encontraron efecto alguno del monitoreo telemático, en la existencia de mayores violaciones técnicas; mientras que en el estudio desarrollado Padget y sus colaboradores, ${ }^{116}$ se encontró que tanto la radio frecuencia como el rastreo satelital, redujeron significativamente la proporción de violaciones técnicas en aquellos infractores sujetos a monitoreo telemático.

En definitiva, este debate aún está abierto, al encontrarse evidencia mixta respecto de los efectos del netwidening. Sin embargo, como señala Bottos, ${ }^{117}$ considerando las implicancias en la política pública de estos efectos, lo mejor parece ser reservar el monitoreo telemático para infractores cuyo riesgo de reincidencia sea moderado o alto, de manera que éste opere realmente como una alternativa al encarcelamiento.

En el caso chileno, de la regulación de la aplicación del monitoreo telemático contenida en la Ley $\mathrm{N}^{\circ} 20.603$, es posible desprender un efecto de netwidening en su utilización para los casos de libertad intensiva, en los delitos cometidos en el contexto de violencia intrafamiliar y en aquéllos que atentan contra la indemnidad sexual. Esto se debería a que los supuestos regulados en el artículo 15 Bis, corresponden a casos que previo a esta reforma correspondían a la órbita de la aplicación de la remisión condicional, reclusión parcial o de la libertad vigilada, dependiendo del quantum de la pena. Por lo tanto, en la práctica con la modificación, habría un tratamiento más severo en estos supuestos, al pasar a ser candidatos de la libertad vigilada intensiva junto con la posibilidad de imponer el monitoreo telemático como forma de control, bajo la lógica del "front-door netwidening". Esta situación se ve agudizada por la inexistencia de filtros en el uso del monitoreo telemático, asociados al riesgo de los sujetos con los que pudiere cooperar la administración penitenciaria, con ocasión del informe de factibilidad técnica que debe emitir, en la decisión judicial sobre la aplicación de dicho mecanismo de control. Así, es posible avizorar la aplicación del monitoreo telemático por la judicatura a todo tipo de infractores, independiente de si este mecanismo resultase adecuado para el control de determinados perfiles.

\footnotetext{
${ }^{114}$ COOPRIDER, Keith; KERBY, Judith, "Practical application of electronic monitoring at the pretrial stage". Federal Probation 54 (1990), pp. 28-35.

${ }^{115}$ BONTA et al., "Can electronic monitoring make a difference?, cit. nota $\mathrm{n}^{\circ} 111$.

${ }^{116}$ PADGETT et al., "Under Surveillance", cit. nota $n^{\circ} 106$.

${ }^{117}$ BOTTOS, An overview of Electronic Monitoring in Corrections, cit. nota $n^{\circ} 102$.
} 
MORALES, Ana María. "Vigilancia en la modernidad tardía:

El monitoreo telemático de infractores".

De manera inversa, la aplicación del monitoreo telemático en la reclusión parcial o en la libertad vigilada intensiva, como consecuencia de aplicación de una pena mixta, hace vaticinar la existencia de positivos efectos de disminución de la población recluida. Esto pues, la regulación del monitoreo telemático para el control de dichas penas, supone la utilización del mismo en un universo de infractores que con anterioridad a la reforma hubieren sido candidatos al cumplimiento de una pena en recintos penitenciarios, como consecuencia de la reclusión nocturna o de la pena privativa de la libertad. En ese contexto, una eventual preocupación en relación al netwidening, podría asociarse a una posible alza en los quebrantamientos, o a cambios en el juzgamiento por parte de la judicatura, que frente a la incorporación de la pena mixta, pudieren tender a condenar a más sujetos a penas privativas de la libertad hasta el límite permitido por la pena mixta. Esto, con el objeto de que los sujetos sean recluidos por un período acotado, y luego les sea concedida la libertad vigilada intensiva con monitoreo telemático permanente.

\section{2. ¿Tiene efectos en la reducción de la reincidencia?}

La medición de la reincidencia constituye la forma habitual de medir la eficacia del sistema penitenciario y también de determinados programas a los cuales son derivados aquellas personas sujetas a control penal. ${ }^{118}$

Existen varios estudios que, a nivel comparado, han buscado evaluar los efectos del monitoreo telemático en la reducción de la reincidencia delictual. No obstante que no debiera atribuírsele consecuencias asociadas a la prevención especial positiva, toda vez que no tiene la naturaleza de sanción, existen varias razones para estimar que esta herramienta de control sí podría tener un efecto en la reincidencia. La más común es que la amenaza de la detección inmediata de la comisión de nuevos delitos, operaría como disuasivo. Otros han argumentado que la condición de reclusión domiciliaria que usualmente es supervisada a través de este sistema, supondría un mayor desarrollo de oportunidades prosociales, además de una oportunidad para que el infractor aprenda la autodisciplina. La más plausible, de acuerdo a Bonta y sus colaboradores, es que el monitoreo telemático evita los efectos negativos del encarcelamiento. ${ }^{119}$

Si bien, a lo largo de casi tres décadas de implementación en algunos países, se han realizado varios estudios de evaluación, aún se cuenta con información limitada respecto de la efectividad de esta medida de control, considerando las limitaciones metodológicas de varias de las investigaciones llevadas a cabo. ${ }^{120}$ Algunos de los estudios han buscado evaluar modelos de front door, mientras que otras han evaluado modelos de back door. Por otro lado, en términos de la metodología de evaluación, la mayoría de los estudios realizados son de tipo cuasi experimental, y sólo unos pocos han podido llevarse a cabo

\footnotetext{
${ }^{118}$ MORALES, Ana María; MUÑOZ, Nicolás; WELSCH, Gherman; FÁBREGA, Jorge, La Reincidencia en el Sistema Penitenciario Chileno, Fundación Paz Ciudadana, 2012. Disponible en http://www.pazciudadana.cl/wp-content/uploads/2013/07/2013-03-21_reincidencia-en-el-sistemapenitenciario-chileno.pdf [visitado el 12.04.2013].

${ }^{119}$ BONTA/WALLACE-CAPRETTA/ROONEY, "Can electronic monitoring make a difference?, cit. nota $\mathrm{n}^{\circ}$ 111.

${ }^{120}$ BOTTOS, An overview of Electronic Monitoring in Corrections, cit. nota $\mathrm{n}^{\circ} 102$.
} 
Polít. crim. Vol. 8, No 16 (Diciembre 2013), Art. 3, pp. 408-471.

[http://www.politicacriminal.cl/Vol_08/n_16/Vol8N16A3.pdf]

experimentalmente, mientras que los más influyentes pero escasos, han efectuado revisiones en base a meta-análisis. A continuación se expondrá sintéticamente algunos de sus resultados.

En relación al modelo de front door, encontramos un estudio relativamente reciente, desarrollado en Suiza por Killias y sus colaboradores. ${ }^{121} \mathrm{Su}$ virtud frente a otros estudios de evaluación, es que utilizó una metodología de tipo experimental, en base a un experimento controlado de 240 sujetos asignados aleatoriamente a servicios comunitarios o monitoreo telemático. En él se buscó establecer mediciones en relación a la reincidencia, junto a otras materias como el auto reporte sobre la comisión de nuevos delitos y otras medidas de integración social como el matrimonio, presupuesto y las deudas de los infractores. Los hallazgos del estudio arrojaron que los infractores a quienes se les asignó el monitoreo telemático y completaron exitosamente su sanción, reincidieron menos que aquellos asignados a servicios comunitarios, aunque la diferencia fue marginal $(\mathrm{p}<0.10)$.

También, en la línea de la investigación anterior, Bonta y sus colaboradores ${ }^{122}$ desarrollaron un estudio de evaluación en la región canadiense de British Columbia, que tenía al año 2000, el mayor programa de monitoreo telemático en ese país. Así, en base a una evaluación de tipo cuasi experimental, se conformaron tres grupos: uno conformado por condenados en la comunidad que fueron supervisados a través del monitoreo telemático, y los grupos de control, conformado por internos liberados, y por condenados a probation. Los resultados arrojaron una reincidencia menor en el caso de los condenados con monitorización (26,7\%), frente a la detectada en los casos de internos $(37,9 \%)$, y de los sujetos a probation $(33,3 \%)$. Sin embargo, adicionalmente los autores efectuaron el ejercicio de controlar de acuerdo al riesgo de reincidencia de los sujetos analizados, determinado previamente a través de un cuestionario. Su objetivo consintió, en determinar si las diferencias en la reincidencia, podían ser atribuibles exclusivamente al efecto de la exposición al tratamiento, o si en definitiva, se explicarían por la existencia de distintos niveles de riesgo en los grupos. Los resultados arrojaron que cuando el riesgo de reincidencia fue considerado en el análisis, aquellos sujetos a monitorización, ya no mostraron menor reincidencia que la existente en los grupos de comparación.

En relación al modelo de back door, es necesario hacer referencia a un estudio realizado en Suecia, en que se buscó evaluar cuasi experimentalmente, un programa de liberación temprana de personas recluidas, introducido en $2001 .^{123}$ El grupo de tratamiento estuvo conformado por internos condenados a penas superiores a dos años, a los que se les ofreció ser liberados con monitorización, cuatro meses antes de tenar la posibilidad de acceder a la libertad condicional (normalmente cuando se hubieren cumplido 2/3 de la sentencia). El grupo de control estuvo conformado por un grupo pareado de internos liberados sin

121 KILLIAS, Martin; GILlIÉRON; Gwladys; KISSLING, Izumi; VILLETTAZ, Patrice, "Community Service Versus Electronic Monitoring-what works better? Results of a Randomized Trial”, British Journal of Criminology 50 (2010), pp.1155-1170.

122 BONTA/WALLACE-CAPRETTA/ROONEY, "Can electronic monitoring make a difference?, cit. nota $\mathrm{n}^{\circ}$ 111.

123 MARKLUND, Frederik; HOLMBERG, Stina, "Effects of early release from prison using electronic tagging in Sweden”, Journal of Experimental Criminology, 2009, 5 (1), pp. 41-61. 
MORALES, Ana María. "Vigilancia en la modernidad tardía:

El monitoreo telemático de infractores".

monitoreo telemático. Los resultados de la evaluación mostraron una reincidencia menor en el caso de los liberados anticipadamente con monitoreo telemático (26\%) frente al grupo de comparación (38\%). La diferencia entre grupos fue estadísticamente significativa ( $\mathrm{p}<$ $0.01)$.

También, en la línea del modelo de back door, un estudio realizado en el estado de Georgia, Estados Unidos, buscó evaluar cuasi experimentalmente la aplicación del monitoreo telemático en libertos condicionales que hubieren cometido delitos violentos. ${ }^{124}$ El grupo de tratamiento estuvo conformado por toda la población sentenciada por delitos violentos y que haya sido liberada condicionalmente, sujeta a control telemático entre 1995 y 1996. Mientras, el grupo de control estuvo conformado por infractores condenados también por delitos violentos, y que hubieren sido liberados condicionalmente entre 1994 y 1995, sin control telemático. Los resultados de la evaluación no arrojaron diferencias en la reincidencia entre ambos grupos. Sin embargo, se pudo observar que aquéllos liberados condicionalmente con monitorización, permanecieron en la comunidad más tiempo, es decir, tardaron más en reincidir que los libertos que no fueron objeto de control telemático.

Desde otra perspectiva de evaluación, los estudios de meta-análisis más importantes realizados en la materia, son los de Renzema ${ }^{125}$ y el de Renzema y Mayo-Wilson. ${ }^{126}$ El primero de ellos consiste en una investigación que aún no ha sido terminada, y respecto de la cual existen dudas, pues como argumenta Albrecht, ${ }^{127}$ el estudio fue retirado del registro de The Campbell Collaboration. ${ }^{128}$ En éste, se revisó 2.659 artículos, de los cuales 125 correspondieron a evaluaciones del monitoreo electrónico. Finalmente sólo 14 de éstos lograron cumplir con los criterios de selección, considerando 2.664 individuos que participaron en programas de monitoreo. Los resultados del meta-análisis, no reportaron ningún efecto positivo de la disminución de la reincidencia con el uso de éste mecanismo de control.

El meta-análisis más robusto en la materia, ha sido el realizado por Renzema y MayoWilson, ${ }^{129}$ que buscó determinar el efecto del monitoreo telemático en la reducción de la reincidencia en infractores de riesgo moderado a alto. En dicha investigación, se revisaron todos aquellos estudios que tuvieran un grupo de control, entre 1986 y 2002, determinando una muestra de 154 investigaciones que incluyeran evaluaciones de impacto. De éstos, sólo tres estudios lograron completar los criterios de inclusión de los autores: el de Finn y

\footnotetext{
${ }^{124}$ FINN, Mary; MUIRHEAD-STEVES, Suzanne, "The Effectiveness of Electronic Monitoring with Violent Male Parolees', Justice Quarterly 19 (2002), pp. 293-312.

${ }^{125}$ RENZEMA, Electronic Monitoring's Impact on Reoffending, cit. nota $\mathrm{n}^{\circ} 26$.

${ }^{126}$ RENZEMA/ MAYO-WILSON, “Can electronic monitoring reduce crime”, cit. nota n 27.

127 ALBRECHT, Hans-Joerg, “Electronic Monitoring, Resettlement and Recidivism”, Presentación en power point efectuada en la Séptima conferencia en monitoreo electrónico, organizado por la Organización Europea de Probación (CEP), $2011 . \quad$ Disponible en http://www.cepprobation.org/uploaded_files/EM2011_Day_1.5_Resettlement_Recidivism_by_HansJoerg_Albrecht.pdf [visitado el 12.04.2013].

${ }^{128}$ The Campbell Collaboration es una es una red internacional de investigadores, que produce revisiones sistemáticas sobre los efectos de las intervenciones sociales. Para mayor información véase http://www.campbellcollaboration.org/

${ }^{129}$ RENZEMA/ MAYO-WILSON, "Can electronic monitoring reduce crime”, cit. nota n ${ }^{\circ} 27$.
} 
Polit. crim. Vol. 8, № 16 (Diciembre 2013), Art. 3, pp. 408-471.

[http://www.politicacriminal.cl/Vol_08/n_16/Vol8N16A3.pdf]

Muirhead-Steves, ${ }^{130}$ el de Sugg, Moore y Howard $^{131}$ y de Bonta, Wallace-Capretta y Rooney. ${ }^{132}$ Del análisis de los tres estudios se concluyó que el monitoreo telemático no reveló un impacto en la reducción de las tasas de reincidencia entre los períodos observados entre uno y tres años, frente a otros programas de diversión del sistema.

A nivel latinoamericano, encontramos una reciente investigación realizada por Di Tella y Schargrodsky en Buenos Aires. ${ }^{133}$ En ella, compararon a individuos cuyo último período de supervisión fue monitoreado telemáticamente, con un grupo integrado por sujetos que, en paralelo, hubiesen permanecido en reclusión. En ambos casos, se trataba de sujetos en prisión preventiva, por lo que si bien resulta complejo medir la reincidencia en grupos respecto de los cuales uno no podría esperar efectos preventivos especiales positivos, lo cierto es que el sistema de persecución mixto de Argentina, hace que en la práctica el cumplimiento de la pena se verifique generalmente bajo el cumplimiento de dicha medida cautelar. En ese contexto, los resultados del estudio mostraron que la reincidencia de aquéllos controlados telemáticamente era $9 \%$ más baja, que en el caso de quienes finalizaron su paso por el sistema penal recluidos.

En definitiva, la literatura relativa a la efectividad del monitoreo telemático en la reducción de la reincidencia ha producido resultados disímiles. ${ }^{134}$ En ese contexto, las mayores críticas apuntan a que varias de las investigaciones realizadas se han enfocado en infractores que tienen un bajo riesgo de cometer nuevos delitos, independientemente del monitoreo. De ahí a que no se pueda estimar con claridad si el efecto es atribuible a la utilización de dicho sistema de supervisión. ${ }^{135}$

Considerando los resultados de la evidencia hasta la fecha, como recomiendan Renzema y Mayo-Wilson, ${ }^{136}$ si el monitoreo telemático seguirá siendo la alternativa de los gobiernos frente a las crisis presupuestarias, el hacinamiento carcelario o la búsqueda de aumento de la supervisión de los infractores, entonces debe acompañarse de otros programas que han mostrado efectividad en la reducción de las conductas infractoras, si es que además se quiere tener algún efecto en la reincidencia.

Finalmente, considerando la evidencia internacional, la futura situación en Chile parece estar en parte en consonancia con lo afirmado anteriormente, considerando que el monitoreo telemático decretado en conjunto con la libertad vigilada intensiva, ya sea como pena sustitutiva o como consecuencia de una pena mixta, siempre irá adosada a la supervisión de un delegado. Esto supondrá algún tipo de intervención tendiente a abordar la

\footnotetext{
${ }^{130}$ FINN/MUIRHEAD-STEVES, “The Effectiveness of Electronic Monitoring”, cit. nota n 124 .

131 SUGG, Darren; MOORE, Louise; HOWARD, Philip, "Electronic monitoring and offending behavior: reconviction results for the second year of trials of curfew orders ", Research finding, $\mathrm{N}^{\circ} 41$, London: Home Office research, development and statistics Directorate, 2001.

${ }^{132}$ BONTA/WALLACE-CAPRETTA/ROONEY, "Can electronic monitoring make a difference?, cit. nota $\mathrm{n}^{\circ}$ 111.

133 DI TELLA, Rafael; SCHARGRODSKY, Ernesto, "Criminal Recidivism after Prison and Electronic Monitoring”, Journal of Political Economy, 2013, 121(1), 28-73.

${ }^{134}$ BOTTOS, An overview of Electronic Monitoring in Corrections, cit. nota $n^{\circ} 102$.

${ }^{135}$ BONTA et al., Electronic Monitoring in Canada, cit. nota $n^{\circ} 97$.

${ }^{136}$ RENZEMA/ MAYO-WILSON, "Can electronic monitoring reduce crime”, cit. nota n 27.
} 
MORALES, Ana María. "Vigilancia en la modernidad tardía:

El monitoreo telemático de infractores".

conducta infractora, y puede por lo tanto esperarse efectos positivos en la reducción de la reincidencia, particularmente si la oferta en programas esta adecuadamente estructurada y articulada. Sin embargo, ése no es el caso en la reclusión parcial, que sólo supone la supervisión realizada mediante el control telemático. En ese contexto, será necesario desarrollar desde un comienzo evaluaciones que permitan hacer un seguimiento adecuado y determinar los efectos en estos casos.

\section{3. ¿Es una alternativa costo-eficiente?}

Uno de los argumentos utilizados por los distintos gobiernos, para justificar la introducción del monitoreo telemático, dice relación con los menores costos para el Estado que implicaría su implementación.

En ese sentido, es necesario tener presente que los resultados del análisis de costoeficiencia, dependen en primer lugar del tipo de mecanismo de control o sanción que se utilice como comparación. Así, si bien existe bastante información empírica respecto de los menores costos que presentaría el monitoreo telemático al compararse con la cárcel, esto no sería tan claro, si se coteja con el costo de otros programas en la comunidad. ${ }^{137}$ Tampoco se presentaría tal supuesto, si, como recomienda la literatura, el monitoreo telemático se acompaña con programas de intervención en la comunidad.

En segundo término, los mayores ahorros para el Estado también dependen de la modalidad de implementación, cuestión que debe necesariamente vincularse con la discusión relativa al netwidening. Así, si el monitoreo telemático se introduce para controlar a infractores que antes eran objeto de una medida de diversión del sistema penal, entonces no se producirá un ahorro de recursos, pues lo que habrá es un nuevo mecanismo de control, frente a nuevos supuestos de punición.

En tercer término, la discusión acerca de si es más costo-eficiente, también debe vincularse con las mayores posibilidades de reinserción y de evitar nuevos pasos por el sistema penal. Así, mientras más contribuya a la disminución de la reincidencia, mayores ahorros fiscales se producirán a largo plazo.

En síntesis, si bien el monitoreo telemático puede resultar menos oneroso que la cárcel, esto sólo se observará con claridad, si la monitorización no es acompañada de un programa en la comunidad -lo que a su vez es desaconsejado por la literatura-, y si es utilizada en supuestos que previo a su introducción hubieren ameritado la imposición de una pena de cárcel.

En el caso nacional, el uso del monitoreo telemático, al confrontarse con los costos de los recintos carcelarios, sin duda representará una fuente de ahorro de recursos importante. De esta forma, de acuerdo a información proporcionada por el Ministerio de Justicia, en el caso del control por radio frecuencia de la reclusión parcial, el gasto diario por penado sería de $\$ 2.450$ por día, a lo que habría que sumarle $\$ 15.000$ por interno a pagar por la instalación y

${ }^{137}$ ALBRECHT, Electronic Monitoring in Europe, cit. nota ${ }^{\circ} 29$. 
Polít. crim. Vol. 8, № 16 (Diciembre 2013), Art. 3, pp. 408-471.

[http://www.politicacriminal.cl/Vol_08/n_16/Vol8N16A3.pdf]

desinstalación del dispositivo. En el caso del control de la libertad vigilada intensiva controlada mediante GPS, el costo diario por penado sería de $\$ 3.500$, sumado a $\$ 30.000$, correspondientes a la instalación y desinstalación. ${ }^{138}$

En el caso de los recintos penitenciarios, es preciso distinguir entre aquéllos operados por el Estado y los recintos concesionados. En el caso de los primeros, el costo diario por interno sería de \$10.634, mientras que en los segundos, ascendería a $\$ 13.929 .{ }^{139}$ En ese contexto, en todos los casos en que el monitoreo telemático se implemente en lugar de la cárcel, se producirá efectivamente un ahorro. Éste es, sin duda, el caso de su aplicación para el control de la reclusión parcial, e incluso, como veremos, para la libertad asistida como consecuencia de la aplicación de una pena mixta.

Sin embargo, si lo comparamos con otro tipo de supervisión en la comunidad, no se producen necesariamente dichos ahorros. Así, si bien no se tiene claridad respecto de los costos asociados al control de los condenados en libertad vigilada asistida, una aproximación básica a aquéllos expresados durante la tramitación legislativa de la ley, podría permitir estimar el costo diario de la libertad vigilada en $\$ 691$ pesos. ${ }^{140}$ De esta forma, una libertad asistida intensiva considerando el monitoreo, podría ascender a \$4.191 diarios, lo que sin duda es más costoso que el sólo control mediante libertad vigilada, contemplado bajo la vigencia de la antigua ley $\mathrm{N}^{\circ} 18.216$, y al cual podían acceder los penados actualmente contemplados en los supuestos de la letra b) del artículo 15 bis.

Sin embargo, es difícil efectuar estimaciones si se considera la participación del penado en la comunidad a través de programas especializados. Así por ejemplo, si el sujeto presenta un consumo problemático de drogas, podría ser derivado a un programa ambulatorio intensivo, cuyo valor alcanzaría los $\$ 7.291$ diarios. ${ }^{141}$ En estos casos, resulta necesario tener una oferta especializada, que sin duda será más onerosa, que la intervención sólo en base a la libertad vigilada o el monitoreo telemático en conjunto con la libertad vigilada intensiva.

En ese contexto, si bien resulta adecuado afirmar que el monitoreo telemático es menos costoso que la cárcel, en el caso de la supervisión en la comunidad, todo dependerá como se articule el sistema y las prestaciones especializadas de acuerdo a las necesidades de los

\footnotetext{
${ }^{138}$ Información obtenida por la autora, en base a comunicación por correo electrónico con la División de Reinserción Social de dicha cartera.

${ }^{139}$ Cálculo en base al costo mensual de \$319.011 de las cárceles operadas por el Estado y de \$417.874 en el caso de las cárceles concesionadas, tomando como referencia la presentación efectuada por Ex Ministro de Justicia Teodoro Ribera, denominada "Realidad actual y desafíos del sistema penitenciario chileno", realizada en el seminario "Cárceles concesionadas revitalizando el modelo", organizado por el Instituto Libertad y Desarrollo, en 2012. Disponible en http://www.lyd.com/wp-content/uploads/2012/08/Presentación-LyD.pdf [visitado el 12.04.2013].

${ }^{140}$ Calculo en base a informe financiero de la Ley, que contemplaba para 2011 un costo estimado de $\$ 3.262 .000 .000$ para la contratación de 287 delegados, a una ratio de 45 penados por delegado. Véase, por todos, BCN, Historia de Ley $\mathrm{N}^{\circ}$ 20.603, cit. nota $\mathrm{n}^{\circ}$ 86, p. 263.

141 Calculo en base al estudio de MORALES, Ana María; WELSCH, Gherman; CÁRCAMO, Javiera; MUÑOZ, Nicolás, "Estudio de estimación del presupuesto general para la implementación del programa de Tribunal de Tratamiento de Drogas a nivel nacional, tanto para población adolescente como adulta. Informe Final", Fundación Paz Ciudadana, 2011, p.241. Disponible en http://www.pazciudadana.cl/wpcontent/uploads/2013/07/2011-04-01_estudio-de-estimacion.pdf [visitado el 12.04.2013].
} 
MORALES, Ana María. "Vigilancia en la modernidad tardía:

El monitoreo telemático de infractores".

condenados. Por otro lado, es necesario tener presente que si se decide utilizar en candidatos que antes no eran supervisados adecuadamente, entonces no se producirán ahorros, al menos en el corto plazo. Sin embargo, en el largo plazo, eventualmente sí puede producirse un beneficio en las arcas fiscales, si el monitoreo telemático contribuye a disminuir la reincidencia delictual, aun cuando no se cuenta con evaluaciones nacionales, y los estudios internacionales no permiten efectuar afirmaciones en uno u otro sentido.

\section{4. ¿Es aplicable a todo tipo de delincuencia?}

En la experiencia comparada se observa una amplia utilización del monitoreo telemático, en distintos tipos de delincuencia. Así, este sistema, ha sido utilizado de manera indistinta respecto de imputados o condenados por distintos tipos penales, prefiriéndose para efectos de la selección de los perfiles, más que el tipo de delito cometido, el riesgo de reincidencia del sujeto que será monitorizado. ${ }^{142}$

Sin perjuicio de lo señalado, existen algunas investigaciones a nivel internacional que han buscado evaluar la aplicación en determinados tipos delictuales -fundamentalmente en el caso de violencia intrafamiliar, delitos sexuales y manejo en estado de ebriedad-, junto con evaluar su aplicación en determinados perfiles de infractores, como aquéllos que presentan consumo problemático de drogas, o quienes pertenecen un rango etario determinado. A continuación se analizará algunas de sus aplicaciones.

Como se observó anteriormente, en el caso de la violencia intrafamiliar, el monitoreo telemático ha sido utilizado en algunos estados de Estados Unidos, y también en distintas comunidades de España, con el objeto de monitorear el cumplimiento de restricciones asociadas a una medida cautelar o a la ejecución de una pena. También, su uso se ha prestado para efectos del resguardo de víctimas específicas, en particular en relación a las medidas de alejamiento que se pueden imponer al agresor como medidas de protección de éstas. En el caso concreto del primero de los países, las investigaciones cualitativas realizadas por Erez e Ibarra, ${ }^{143}$ relativas a su aplicación para controlar el cumplimiento de medidas cautelares, muestran resultados positivos en relación a la posibilidad de otorgar mayor seguridad a las víctimas, especialmente dentro de las 24 horas posteriores a la liberación del supuesto agresor, espacio de tiempo que parecer ser especialmente vulnerable para ésta. ${ }^{144}$

Así, sus investigaciones reportan que el monitoreo telemático, cuando es usado bilateralmente tanto por el victimario como por la víctima, les ha permitido a éstas conectarse con sus redes familiares y sociales, y entregar un mecanismo de apoyo, a personas que usualmente están alejadas. ${ }^{145}$ Sin embargo, se debe tener presente que estos efectos positivos se han registrado sólo respecto de las víctimas, y que no existen investigaciones que se hayan centrado sobre sus efectos en los agresores, los que seguramente, a fin de intervenir su conducta violenta, deberán ser derivados a programas

\footnotetext{
${ }^{142}$ DEMICHELE/ PAYNE, Offender supervision, cit. nota $\mathrm{n}^{\circ} 32$.

${ }^{143}$ EREZ/IBARRA, "Making Your Home a Shelter", cit. nota $n^{\circ} 57$.

${ }^{144}$ DEMICHELE/ PAYNE, Offender supervision, cit. nota $\mathrm{n}^{\circ} 32$.

${ }^{145}$ EREZ/IBARRA, "Making Your Home a Shelter", cit. nota n ${ }^{\circ} 57$
} 
Polít. crim. Vol. 8, № 16 (Diciembre 2013), Art. 3, pp. 408-471.

[http://www.politicacriminal.cl/Vol_08/n_16/Vol8N16A3.pdf]

especializados en abordaje de la violencia intrafamiliar. Asimismo, también es necesario tener presente que si bien la tecnología entrega mayor protección a las víctimas, como se analizó anteriormente, ésta no es infalible, pudiendo eventualmente entregar una falsa sensación de seguridad en ellas. ${ }^{146}$

En el caso de los delitos sexuales, y como se analizó anteriormente, en Estados Unidos, ha habido una amplia utilización del monitoreo telemático en el caso de infractores que han sido condenados por dichos tipos penales, particularmente como una medida de seguridad post delictual. En estos casos, más allá de las situaciones contingentes que han inspirado medidas legislativas, como la observada en dicho país, es necesario tener en cuenta que a pesar de las creencias populares, este tipo de infractores presenta en general bajos porcentajes de reincidencia, ${ }^{147}$ cuestión también observada a nivel nacional. ${ }^{148}$ Por otro lado, en relación a la aplicación de esta medida de control, actualmente hay pocas investigaciones que hayan evaluado su efectividad. Así, encontramos un estudio recientemente realizado por Gies y sus colaboradores, en el cual testearon la reincidencia de un grupo de ofensores de este tipo de alto riego liberados condicionalmente con GPS, frente al grupo de control conformado por sujetos de similar perfil, que fueron liberados condicionalmente con la supervisión ordinaria a través de los parole officers (delegados de libertad condicional. Lo resultados arrojaron un reincidencia significativamente menor en el caso de los sujetos a supervisión con monitorización. ${ }^{149}$ Sin embargo, como precisan Button y sus colaboradores, ${ }^{150}$ este tipo de infractores generalmente tienen conductas sexuales proscritas por la legislación, las que difícilmente serán alteradas por la sola imposición de un mecanismo de control en el sujeto. En ese contexto, la literatura internacional sugiere que el monitoreo telemático debe ser sólo una parte de una intervención más integral que comprenda distintas estrategias para supervisar a estos infractores en la comunidad, y que suponga la existencia de programas especiales para el abordaje de estas conductas. ${ }^{151}$

También se observa en la experiencia comparada, su utilización en el caso de condenados por delitos de manejo estado de ebriedad. En particular, el monitoreo telemático ha sido utilizado en algunos estados de Estados Unidos, para este tipo de infractores, que han sido sentenciados a reclusión domiciliaria, a libertad vigilada junto con reclusión domiciliaria, o como parte de una sentencia mixta. ${ }^{152}$ En algunos casos, la medida de reclusión supervisada a través del monitoreo telemático tiene como condición el testeo contante de la cantidad de

\footnotetext{
${ }^{146}$ EREZ/IBARRA, "Making Your Home a Shelter", cit. nota $n^{\circ} 57$.

${ }^{147}$ DEMICHELE/ PAYNE, Offender supervision, cit. nota $\mathrm{n}^{\circ} 32$.

${ }^{148}$ MORALES et al., La Reincidencia en el Sistema Penitenciario Chileno, cit. nota $n^{\circ} 118$.

149 GIES, Stephen; GAINEY, Randy; COHEN, Marcia; HEALY, Eoin; DUPLANTIER, Dan; YEIDE, Martha; BEKELMAN, Alan; BOBNIS, Amanda; HOPPS, Michael, Monitoring High-Risk Sex Offenders With GPS Technology: An Evaluation of the California Supervision Program, Final Report, Office of Research and Evaluation National Institute of Justice, Washington DC, 2012. Disponible en https://www.ncjrs.gov/pdffiles1/nij/grants/238481.pdf [visitado el 12.04.2013].

${ }^{150}$ BUTTON, Deeanna; DeMICHELE, Matthew; PAYNE, Brian, "Using Electronic Monitoring to Supervise Sex Offenders. Legislative Patterns and Implications for Community Corrections Officers", Criminal Justice Policy Review, 2009, 20 (4), pp. 414-436.

${ }^{151}$ DEMICHELE/ PAYNE, Offender supervision, cit. nota $\mathrm{n}^{\circ} 32$.

${ }^{152}$ BARTON, Shannon; ROY, Sudipto, "Convicted Drunk Drivers in an Electronic Monitoring Program: A preliminary study”, International Journal of Criminal Justice Sciences, 2008, 3 (1), pp. 28-43.
} 
MORALES, Ana María. "Vigilancia en la modernidad tardía:

El monitoreo telemático de infractores".

alcohol en el organismo del sujeto, para lo cual se utiliza tecnología como la descrita anteriormente, relativa a la detección de alcohol a distancia. Adicionalmente, se contempla la utilización de alcohol ignition interlocks, que como se señaló, implica la instalación en el automóvil de un dispositivo de bloqueo de uso frente a la presencia de consumo de alcohol por parte del conductor. En particular, aun es escasa la evidencia sobre la efectividad del monitoreo telemático en el caso de infractores por este delito. Sin embargo, en un estudio cuantitativo realizado en el Estado de Pensilvania, relativo a la aplicación del monitoreo en este tipo de infractores, se pudo evaluar la efectividad de esta medida en relación a nuevos consumos de drogas y alcohol. El grupo de tratamiento estuvo conformado por aquellos condenados por manejo en estado de ebriedad a reclusión domiciliaria, controlada a través de monitoreo telemático, y como grupo de control a aquéllos que ingresaron a una jail. ${ }^{153}$ Dentro de los hallazgos, se encontró que el uso de monitoreo electrónico no aumenta las posibilidades de éxito relacionado con el consumo posterior de drogas o alcohol. Así, aquéllos que fueron sentenciados a reclusión domiciliaria con monitoreo electrónico, si bien presentaron un menor consumo que el grupo de control, las diferencias entre ambos no fueron estadísticamente significativas. ${ }^{154} \mathrm{~A}$ su vez, en otro estudio desarrollado en California, en que se buscó evaluar la aplicación del sistema del alcohol ignition interlocks en condenados por estos delitos, los hallazgos mostraron que ésta incide en una reducción de nuevos eventos asociados al manejo en estado de ebriedad, en el caso de reincidentes por estos delitos. Sin embargo, el mismo estudio demostró la inefectividad de estos dispositivos para el caso de los primerizos que hubieren cometido el delito de manejo en estado de ebriedad. $^{155}$ De cualquier forma, aún son muy incipientes los estudios sobre el funcionamiento de esta medida de control, en dicho tipo de infractores, como para dimensionar eventuales beneficios asociados a su incorporación.

En el caso de condenados que presentaren consumo problemático de drogas, en la experiencia internacional es posible observar la existencia de una evaluación de antigua data, que buscó determinar los efectos del monitoreo telemático en condenados por cualquier delito, que hubieren presentado consumo problemático, en el estado de Los Ángeles en Estados Unidos. En ese estudio fueron comparados los archivos de un grupo de infractores con consumo problemático de drogas condenados a libertad vigilada, con otro de condenados a libertad vigilada junto con reclusión domiciliaria controlada a través de monitoreo telemático. Los resultados arrojaron menores tasas de revocaciones y de violaciones de reglas - como no asistir a un testeo de drogas o encontrarse con consumo al momento del testeo-, en el caso de aquellos sujetos que fueron monitorizados

\footnotetext{
153 Que corresponden instalaciones de cumplimiento de reclusiones de corta duración, a las cuales son derivados aquellos condenados por delitos menores (misdemeanor) o personas que sean acusadas de delitos graves que se encuentren a la espera de juicio.

${ }^{154}$ COURTRIGHT, Kevin; BERG, Bruce; MUTCHNICK, Robert, "Rehabilitation in the New Machine? Exploring Drug and Alcohol Use and Variables Related to Success Among DUI Offenders Under Electronic Monitoring-Some Preliminary Outcome Results”, International Journal of Offender Therapy and Comparative Criminology, 2000, 44(3), pp. 293-311.

155 DEYOUNG, David; TASHIMA, Helen; MASTEN, Scott, An evaluation of the effectiveness of ignition interlock in California, California: California Department of Motor Vehicles, 2004. Disponible en https://www.dmv.ca.gov/about/profile/rd/210_ignition_interlock_report.pdf [visitado el 12.04.2013].
} 
Polít. crim. Vol. 8, No 16 (Diciembre 2013), Art. 3, pp. 408-471.

[http://www.politicacriminal.cl/Vol_08/n_16/Vol8N16A3.pdf]

electrónicamente en conjunto con la el cumplimiento de la libertad vigilada. ${ }^{156}$ Sin embargo, al igual que en los casos anteriores, considerando la escasa evidencia, no es posible determinar los efectos en este tipo de infractores, tomando en cuenta además la antigüedad del estudio analizado.

En países como Estados Unidos, e Inglaterra y Gales, además se presentan aplicaciones del monitoreo electrónico en infractores juveniles. Así, por ejemplo, en el caso de estos últimos, puede ser impuesto como una sentencia comunitaria en sí, como uno de varios requerimientos de una sanción comunitaria, como una condición para la liberación bajo fianza, o como una de las condiciones asociadas a la liberación temprana en penas privativas de la libertad. ${ }^{157} \mathrm{Al}$ igual que en los casos anteriores, aún son pocos los estudios que ha podido medir la efectividad de la utilización del monitoreo electrónico en jóvenes, no encontrándose en la evidencia internacional evaluaciones robustas en la materia. Considerando dicho contexto, es necesario tener presente que la utilización de este mecanismo de control en jóvenes, conlleva ciertas consideraciones adicionales, que no necesariamente se presentan tratándose de la aplicación para adultos. De esta forma, han surgido ciertos cuestionamientos relativos a la necesidad de combinar adecuadamente este mecanismo de control con la educación del joven, y de cómo vincular a los padres y a la familia a la ejecución de sanciones que conlleven este dispositivo. En esa línea, uno de los aspectos que parece concitar consensos, es que la situación de vulnerabilidad en la que se encuentra la mayoría de los jóvenes infractores, hace necesaria la intervención y el apoyo de profesionales del ámbito psicosocial, por lo que la reclusión con monitoreo telemático, siempre debe incluirse en programas de apoyo integral. ${ }^{158}$

Por último, también encontramos en la regulación comparada, la aplicación del monitoreo telemático a sospechosos de haber cometido un delito terrorista. En efecto, tal es el caso Inglaterra y Gales, y de Australia. En los primeros - que han concentrado la atención de la escasa literatura que se ha referido a esta aplicación-su utilización en éste ámbito data de la dictación del Prevention of terrorism Act de 2005, legislación aprobada luego del atentado ocurrido en el sistema de trasporte el mismo año en Londres. Esta regulación, contenía las denominadas "control orders" (órdenes de control) que podían ser impuestas a cualquier sujeto respecto del cual existiere razonable sospecha de su involucramiento en actos terroristas y que junto con restricciones a las comunicaciones y a los contactos del sujeto, regulaba la posibilidad de imponer una reclusión domiciliaria, monitoreada

\footnotetext{
${ }^{156}$ GLASER, Daniel; WATTS, Ronald, "Electronic Monitoring of Drug Offenders on Probation", Judicature, 1992, 76 (3).

${ }^{157}$ WYMAN, Mary; WALKER, Sue, "Young People - The Opportunities and Challenges of Tagging", presentación en power point en la Conferencia en Monitoreo Electrónico, organizado por la Organización Europea de Probation (CEP), realizada entre el 7 y el 9 de Mayo de 2009, en Holanda. Disponible en http://www.cep-probation.org/default.asp?page_id=116\&news_item=191 [visitado el 12.04.2013].

${ }_{158}$ NELLIS, Mike; TORRES, Nuria, "Electronic Monitoring and Probation: Offender rehabilitation and the reduction of Prison population", Conference Report, $7^{\text {th }}$ European Electronic Monitoring Conference, 5 al 7 de Mayo, Portugal, 2011. Disponible en http://www.cep-probation.org/default.asp?page_id=157\&map_id=85 [visitado el 12.04.2013].
} 
MORALES, Ana María. "Vigilancia en la modernidad tardía:

El monitoreo telemático de infractores".

electrónicamente mediante radio frecuencia. ${ }^{159}$ Esta legislación, fue duramente criticada por la doctrina, ${ }^{160}$ entre otros aspectos, por atribuirle una naturaleza civil a medidas que arrastraban consecuencias penales, como ocurre con las restricciones a la libertad ambulatoria, las que podían tener una duración indefinida. Asimismo, recibió bastantes críticas de la sociedad civil, al considerarse que vulneraba el artículo 5 de la Convención Europea de Derechos Humanos, el que permitía la detención fuera del contexto de un proceso penal sólo en casos de guerra o de situación de emergencia pública que constituyeran una amenaza a la vida de la nación. A consecuencia de lo anterior, esta legislación fue recientemente derogada, considerando la entrada en vigencia del Terrorism Prevention and Investigation Measures Act de 2011, pero que sin embargo, no obstante los cuestionamientos efectuados, aún mantiene como medida el arresto domiciliario indefinido y otras restricciones a la libertad en base a sospechas y a información secreta de inteligencia. 161

En síntesis, la evidencia internacional en la materia aún es incipiente, y no ha mostrado resultados concluyentes en términos de la aplicación en determinados tipos o perfiles de delincuencia. En ese contexto, considerando que la regulación nacional, no obstante ser aplicable exclusivamente a mayores de 18 años, sí hace distinciones en base a la tipología de delitos, es necesario que a futuro se realicen investigaciones que permitan establecer sus efectos a propósito de los delitos cometidos en el ámbito intrafamiliar y los de índole sexual. Esto pues, como señalan las investigaciones en esta materia, y si bien en el caso de los delitos de violencia doméstica existen algunas investigaciones que han reportado efectos positivos en las víctimas, aún no se cuenta con estudios que aborden específicamente sus efectos en los agresores, situación similar a la que se presenta respecto de los ofensores sexuales.

\section{5. ¿Tiene efectos indeseados en los infractores y sus familias?}

El debate en torno al uso del monitoreo electrónico también se ha centrado en los efectos que éste pudiere tener en la vida del infractor y sus familias. Los estudios que han buscado indagar acerca de los efectos en ellos, han abordado fundamentalmente el potencial de "estigma" y vergüenza asociada al porte del monitoreo telemático, el desistimiento, y los efectos colaterales en sus relaciones de trabajo y familiares.

Las concepciones vinculadas con el potencial estigmatizarte del monitoreo electrónico, se relacionan a las tesis del etiquetamiento, y en particular con la tesis del estigma y de la "identidad deteriorada" expuesta por Goffman en 1965, con el objeto de retratar la situación de aquellos individuos que no son socialmente aceptados. ${ }^{162}$ En ese contexto, algunos

\footnotetext{
${ }^{159}$ NELLIS, Mike, "Electronic monitoring and the creation of control orders for terrorist suspects in Britain", en: ABBAS, Tahir (Ed.), Islamic political radicalism, Edimburgo: Edinburgh University Press, 2007, pp. 263-278.

${ }^{160}$ Véase, por todos, ZENDER, Lucia, "Preventive Justice or Pre-punishment? The case of control orders", Current Legal Problems, 2007, 60 (1), pp.174-203.

${ }^{161}$ Véase, por todos, lo expuesto por Liberty Org. Disponible en www.liberty-human-rights.org.uk/index.php [visitado el 12.04.2013].

162 GOFFMAN, Erving, Stigma: Notes on the Management of Spoiled Identity, Nueva York: Simon \& Schuster, 1963.
} 
Polít. crim. Vol. 8, № 16 (Diciembre 2013), Art. 3, pp. 408-471.

[http://www.politicacriminal.cl/Vol_08/n_16/Vol8N16A3.pdf]

autores han argumentado respecto del monitoreo telemático que "ninguna otra sanción en la comunidad [...] tiene el potencial de revelar que otra persona es un infractor", lo que de cierta forma "deteriora" en palabras de Goffman la identidad que de otra forma quisiera proyectar éste, ya sea en público o en situaciones más íntimas. ${ }^{163}$

En efecto, cuando recién fueron implementados estos programas, algunos estudios cualitativos lograron recoger dicha visión, argumentando que más de la mitad de los infractores sujetos a monitoreo electrónico, experimentaban alguna forma de estigma, y se sentían avergonzados de portarlos, buscando desesperadamente camuflarlos. ${ }^{164}$ Considerando lo anterior, algunos gobiernos, especialmente los europeos, han obligado a los fabricantes a diseñar dispositivos cada vez más pequeños, que no sean fácilmente visibles. Sin embargo, en algunos estados de Estados Unidos es ese aspecto el que ellos buscan destacar, utilizando dispositivos que son visiblemente estigmatizadores. ${ }^{165}$

Por otro lado, las posibilidades de estigma que representa el monitoreo, especialmente en los jóvenes, es un tema relevante, no sólo por las repercusiones en sus relaciones comunitarias, sino también porque este mecanismo de control eventualmente podría ser visibilizado por los pertenecientes a dicho rango etario, como una suerte de "trofeo", adquiriendo con esto - parafraseando a Merton- ${ }^{166}$ el "estatus maestro" de delincuente. Así, por ejemplo, el Consorcio para la Reforma Penal (Penal Reform Consortium), ha sugerido que el monitoreo es "unívocamente estigmatizante" en el caso de los jóvenes, pues ellos "deberán asistir al colegio con un brazalete atado a su muñeca o tobillo, que los marquen como infractores", advirtiendo que los jóvenes "indudablemente van a jactarse de su brazalete, y lo usarán como una medalla de honor, adoptado una imagen "dura" difícil de superar". 167

En la misma línea, algunos estudios han reportado efectos asociados a un sentimiento de vergüenza de los infractores, la que de modo como la plantea Braithwaite, ${ }^{168}$ no siempre tendría un componente negativo, pudiendo tener un elemento reintegrador. Esto ha llevado a que algunos autores argumenten que en este caso, la vergüenza sería reintegrativa, al evitar el contagio criminógeno de la cárcel, al entregar más control que la probation, y al permitir el mantenimiento de los lazos familiares y del trabajo. ${ }^{169}$ En ese contexto, si bien no existen investigaciones centradas en lo anterior, Gainey y Payne argumentan a partir de

\footnotetext{
${ }^{163}$ NELLIS, "Surveillance and Confinement", cit. nota ${ }^{\circ}$ 96, p. 50.

${ }^{164}$ MAIR, George; NEE, Claire, Curfew orders with electronic monitoring: the trials and their result, Home office Research Study 163, London Home Office, 1990.

${ }^{165}$ NELLIS, Mike, "Surveillance, stigma and spatial constraint" en: NELLIS et al., Electronically Monitored Punishment, cit. nota $\mathrm{n}^{\circ} 25$.

${ }^{166}$ MERTON, Robert, Social Theory and Social Structure, Nueva York: The Free Press, 1968.

167 PENAL AFFAIR CONSORTIUM, The electronic monitoring of offenders, Londres: Penal Affair Consortium, 1997. Cit.: NELLIS, "Surveillance, stigma and spatial constraint", cit. nota $\mathrm{n}^{\circ}$ 166, p. 203. La traducción es de la autora.

${ }^{168}$ BRAITHWAITE, John, Crime, Shame and Reintegration, Cambridge: Cambridge University Press, 1989.

${ }^{169}$ SHERMAN, Lawrence, "Defiance, deterrence, and irrelevance: A theory of criminal sanction", Journal of Research in Crime and Delinquency, 30 (1993), pp. 445-473. Cit.: GAINEY, Randy; PAYNE, Brian "Understanding the experience of house arrest with electronic monitoring: An analysis of quantitative and qualitative data", International Journal of Offender Therapy and Comparative Criminology, 2000, 44 (1), pp. 84-96.
} 
MORALES, Ana María. "Vigilancia en la modernidad tardía:

El monitoreo telemático de infractores".

un estudio cuantitativo y cualitativo, orientado a conocer las experiencias de los infractores sujetos a monitorización, que las mujeres y las personas casadas presentan mayores tendencias a experimentar vergüenza, y que a su vez, son más propensas a reincidir. ${ }^{170}$

Desde otra óptica, en base a la misma investigación, los autores encontraron que la mayoría de los infractores no consideran el monitoreo electrónico como "terriblemente punitivo", 171 pero tampoco lo ven como una aplicación benévola. Además, la mayoría de los entrevistados, percibieron el monitoreo telemático como menos restrictivo que la cárcel.

Por otro lado, en un estudio exploratorio desarrollado en el año 2000 en Inglaterra, Hucklesby, ${ }^{172}$ buscó indagar acerca de las experiencias de aquéllos que se encontraban sujetos a monitorización, mediante 78 entrevistas practicadas a sujetos condenados a reclusión en sus domicilios con monitoreo electrónico. Uno de los aspectos investigados, tuvo relación con sus intenciones de cometer nuevos delitos a futuro, estableciendo un grupo de "persistentes", y otro de "desistentes", en consonancia con las corrientes criminológicas contemporáneas basadas en el paradigma del desistimiento, representado entre otros por Maruna, Farrall, Calverley, McNeill y Bottoms y sus colaboradores. ${ }^{173}$

El grupo de "persistentes", es decir de aquellos infractores que no tenían planes de cesar en su conducta infractora, representaron cerca de un tercio de los entrevistados. Una de las tesis principales de este grupo para continuar cometiendo delitos apuntó a que la reclusión domiciliaria monitoreada telemáticamente no tenía un efecto disuasivo, que los infractores no podían evitar meterse en problemas, o que pretendían retornar a su estilo de vida anterior. $^{174}$

Los “desistentes", es decir, aquéllos que se encontraban embarcados en un proyecto de cese en su actividad delictual, comprendieron a dos tercios de los entrevistados. Uno de los argumentos centrales esgrimidos por este grupo, fue el del temor de ir a la cárcel. Otros entrevistados, narraron que las restricciones asociadas a los períodos de reclusión, "les habría enseñado una lección", ${ }^{175}$ y que habrían decidido abandonar la carrera delictiva, cambiando sus estilos de vida, de manera que sus compromisos laborales y familiares tuvieran prioridad en sus vidas. En ese contexto, a partir de sus relatos, Hucklesby sostiene

\footnotetext{
${ }^{170}$ GAINEY/PAYNE, "Understanding the experience of house arrest", cit. nota ${ }^{\circ} 169$.

${ }^{171}$ GAINEY/PAYNE, "Understanding the experience of house arrest", cit. nota n ${ }^{\circ}$ 169, p. 94. La traducción es de la autora.

${ }^{172}$ HUCKLESBY, Anthea, "Vehicles of desistance?: The impact of electronically monitored curfew orders", Criminology and Criminal Justice, 2008, 8 (1), pp. 51-71.; HUCKLESBY, Anthea, "Insider's views. Offender's and staff's experiences of electronically monitored curfews", en: NELLIS et al., Electronically Monitored Punishment, cit. nota $\mathrm{n}^{\circ} 24$.

${ }^{173}$ Véase, por todos, MARUNA, Shad, Making good: How ex convicts Reform and Rebuild Their Lives, Washington DC: American Psychological Association Books, 2001; FARRAL, Stephen; CALVERLEY, Adam, Understanding Desistance from Crime, Maidenhead: Open University Press, 2006; McNEILL, Fergus, "A desistance paradigm for offender management", Criminology and Criminal Justice, 2006, 6 (1), pp. 39-62; BOTTOMS, Anthony; SHAPLAND, Joanna; COSTELLO, Andrew, HOLMES, Deborah; MUIR, Grant "Towards Desistance: Theoretical Underpinnings for an Empirical Study", The Howard Journal of Criminal Justice, 2004, 43 (4), pp. 368-389.

${ }^{174}$ HUCKLESBY, "Insider's views", cit. nota n ${ }^{\circ} 172$.

${ }^{175}$ HUCKLESBY, “Insider's views”, cit. nota n 172, p. 235.
} 
Polít. crim. Vol. 8, № 16 (Diciembre 2013), Art. 3, pp. 408-471.

[http://www.politicacriminal.cl/Vol_08/n_16/Vol8N16A3.pdf]

que la sanción de reclusión en el domicilio con monitoreo electrónico, puede ser "efectiva en apoyar el proceso de desistencia de aquellos infractores que están pensando o que activamente están tratando de cesar su actividad delictual". ${ }^{176}$

Por otro lado, en base a la misma investigación, la autora pudo establecer que la reclusión en el domicilio, controlada mediante el monitoreo telemático, tuvo un rol importante en la desarticulación de ciertos hábitos y en la desvinculación de los ambientes y pares criminógenos, reduciendo el "capital antisocial". Además, argumenta una mejora en los niveles de "capital prosocial", incentivando a los infractores a conectarse con las influencias vinculadas a la desistencia, como la familia y el trabajo. ${ }^{177}$

En relación al trabajo, en base al mismo estudio, se estableció que aquéllos que se encontraban trabajando al momento de ser condenados a reclusión con monitorización, la mayoría reportó que ésta afectó negativamente su trabajo, al no contar con horarios flexibles de cumplimiento, no poder hacerse cargo de turnos, y contar con antecedentes penales, lo que además habría tenido consecuencias financieras. ${ }^{178}$

Tratándose de los efectos en las familias, algunos autores han señalado que aquéllos que residen conjuntamente con el infractor, muchas veces se ven indirectamente castigados, como consecuencia de la vigilancia constante. De esta forma, verían afectadas sus posibilidades de utilizar la línea telefónica del hogar, y muchas veces sufrirían los efectos sociales colaterales asociados a la visibilidad del equipamiento usado en el cuerpo por el infractor y en el hogar. A esto, además debe sumarse la creación de un ambiente familiar más estresante y el estigma de vivir con un infractor. ${ }^{179}$ Sin embargo, tanto los condenados como la familia parecen valorar el que a través de este sistema, ellos puedan seguir contribuyendo a las responsabilidades familiares. ${ }^{180}$ En ese contexto, como plantean Mair y Mortimer, aquellos infractores que tienen familia, consideran que el apoyo de ésta es una cuestión central para cumplir adecuadamente con el monitoreo telemático. ${ }^{181}$

Una vez que este sistema entre en funcionamiento en nuestro país, eventualmente se generarían algunos de los efectos indeseados mencionados, los que podrían ser mitigados con una adecuada implementación y utilización del sistema. El primero dice relación con la posibilidad de estigmatización que, sin duda, puede verse menguada, en la medida que se exija por los encargados de implementar el monitoreo telemático, a la o las empresas proveedoras de los dispositivos, facilitar tecnologías que procuren ser de tamaño pequeño, y ojalá poco visibles. El segundo aspecto dice relación con la aplicación por parte de la judicatura, de los distintos períodos de reclusión parcial previstos por la ley $\mathrm{N}^{\circ} 20.603$, y su adecuación a las necesidades y perfil delictual de los infractores. Así, como se analizó anteriormente, el artículo 7 de la citada norma legal, dispone tres modalidades de reclusión:

\footnotetext{
${ }^{176}$ HUCKLESBY, “Insider's views”, cit. nota n 172, p. 235. La traducción es de la autora.

${ }^{177}$ HUCKLESBY, "Vehicles of desistance", cit. nota $n^{\circ} 172$, p. 66. La traducción es de la autora.

${ }^{178}$ HUCKLESBY, "Insider's views", cit. nota $\mathrm{n}^{\circ} 172$.

${ }^{179}$ MARTINOVIC, The punitiveness of electronically monitored, cit. nota $\mathrm{n}^{\circ} 28$.

${ }^{180}$ BOTTOS, An overview of Electronic Monitoring in Corrections, cit. nota $\mathrm{n}^{\circ} 102$.

181 MAIR, Gorge; MORTIMER, Ed, Curfew orders with Electronic Monitoring, Home Office Research Studies no. 163, London: Home Office, 1996.
} 
MORALES, Ana María. "Vigilancia en la modernidad tardía:

El monitoreo telemático de infractores".

diurna, nocturna, y de fin de semana, entre las que puede optar el juez, para lo cual deberá tener presente los antecedentes laborales, educacionales o de otra naturaleza que justificaren la reclusión domiciliaria, de conformidad con lo dispuesto en la letra c) del artículo 8.

En ese sentido, y en consonancia con lo antes expresado, especialmente en relación a los efectos en el trabajo, la judicatura deberá procurar con la imposición de esta pena, optar por el régimen de reclusión, que permita, en lo posible, que el infractor abandone su actividad delictual, considerando las particularidades relativas a los horarios más frecuentes de comisión de los ilícitos. Sin embargo, otro de los aspectos que se deberá tener presente es el de buscar alternativas de aplicación que no afecten la continuidad del trabajo y los estudios, en caso que el condenado se encuentre realizando alguna de dichas actividades. Esto es importante, considerando el potencial que tiene el trabajo y el estudio -como vía para acceder al primero-, para fomentar la desistencia de la actividad criminal en los infractores.

\section{6. ¿Vulnera derechos fundamentales de los sujetos a control?}

La implementación de estas tecnologías ha llevado a diversos autores a redefinir el espacio tradicional privado del "hogar como mi castillo" a el "hogar es mi prisión", 182 argumentando la debilitación del domicilio. Por otro lado, la introducción de tecnologías como el rastreo satelital ha empujado a otros autores, a concebir esta aplicación en el ámbito penitenciario, como la construcción de una "celda virtual y móvil", ${ }^{83}$ una "prisión sin rejas", ${ }^{184}$ o a una versión moderna de los antiguos grilletes con bola a través de las denominaciones de "electronic ball and chain", 185 haciendo alusión a la "high tech" o alta tecnología utilizada como estrategia para lidiar con los infractores. ${ }^{186}$

Las denominaciones antedichas, vinculan necesariamente la utilización del monitoreo telemático con eventuales afectaciones al derecho a la intimidad, a la inviolabilidad del hogar, al secreto de las comunicaciones, a la libre circulación, a la libertad personal y a la protección de datos, generando de acuerdo a algunos autores, una peligrosa intromisión en la esfera privada del sujeto. ${ }^{187}$ Asimismo, también hay cuestionamientos en relación a que la aplicación del monitoreo telemático, podría implicar el uso de un castigo cruel e inhumano, ${ }^{188}$ y por lo tanto proscrito por los instrumentos internacionales de derechos humanos.

\footnotetext{
${ }^{182}$ IGLÉSIAS, Miguel Ángel; PÉREZ, Juan Antonio, "La pena de localización permanente y su seguimiento con medios de control electrónicos", Anuario de Derecho Constitucional Latinoamericano, 2006, p.1096. Disponible en http://www.juridicas.unam.mx/publica/librev/rev/dconstla/cont/2006.2/pr/pr21.pdf [visitado el 12.04.2013].

${ }^{183}$ IGLÉSIAS/PÉREZ, “La pena de localización permanente", cit. nota n 182.

${ }^{184}$ NELLIS, "Out of this World", cit. nota ${ }^{\circ} 23$. La traducción es de la autora.

185 GIBBS, Anita; KING, Denise, "The electronic Ball and Chain? The Operation and Impact of Home Detention with Electronic Monitoring in New Zealand", The Australian and New Zealand Journal of Criminology, 2003, 36 (1), pp. 1-17.

${ }^{186}$ NELLIS, "Out of this World", cit. nota ${ }^{\circ} 23$.

${ }^{187}$ IGLÉSIAS/PÉREZ, "La pena de localización permanente", cit. nota n ${ }^{\circ} 182$.

188 JHSA, Electronic monitoring, 2000. Disponible en http://www.johnhoward.ab.ca/pub/A3.htm [visitado el 12.04.2013].
} 
Cuando los primeros programas de monitoreo telemático fueron implementados en Estados Unidos, efectivamente, uno de los primeros cuestionamientos apuntó a que mediante la utilización de este tipo de tecnología, pudieran ser puestos en peligro algunos de estos derechos. También, surgieron preocupaciones en relación a la garantía establecida en la cuarta enmienda de la Constitución de dicho país, que otorga protección a los ciudadanos frente a intrusiones físicas de las que pudieran ser objeto en su hogar por parte de la autoridad. ${ }^{189}$ Sin embargo, actualmente la constitucionalidad del monitoreo electrónico es un tema aceptado en dicho país, no siendo foco de debate. ${ }^{190}$ En ese sentido, algunos de los argumentos legales esgrimidos para aprobar su utilización, apuntan a que especialmente los condenados a penas como la probation -que constituyen los mayores usuarios de monitoreo electrónico en dicho país-, no gozarían de los mismos derechos que los ciudadanos ordinarios, sino que de "derechos disminuidos" (diminished rights), pudiendo ser objeto de ciertas afectaciones a sus derechos fundamentales. También se argumentó en este contexto, que considerando que la probation es un privilegio y no un derecho, los jueces pueden ejercer un importante grado de discreción en orden a determinar sus condiciones, una de las cuales correspondía a la aplicación del monitoreo telemático. ${ }^{191}$ Así, algunos autores han argumentado que "las cortes han permitido las restricciones a los derechos establecidos en la cuarta enmienda, cuando esas restricciones son necesarias para alcanzar los objetivos de la probation", 192

En este mismo tema, algunos autores de España, también dan cuenta de lo resuelto por la jurisprudencia de dicho país, no directamente en relación al uso del monitoreo telemático, sino que en materia de afectación del derecho a la intimidad. En concreto, González ${ }^{193}$ sostiene que la instalación de dispositivos de monitorización mediante radio frecuencia y GPS, efectivamente lesionan el derecho a la intimidad y también el honor de la persona, al permitirse la visibilización del dispositivo, y la divulgación de su condición de penada. Sin embargo, argumenta que la monitorización electrónica puede enmarcarse dentro de la norma fundamental, en la medida que el Tribunal Constitucional Español admite ciertas afecciones a la intimidad, si se cumplen determinados requisitos recogidos en la jurisprudencia. ${ }^{194}$ Así, para poder ser legítima la afectación a la intimidad, ésta debe "preverse legalmente, tener una finalidad legítima, adoptarse de forma motivada por la autoridad judicial o administrativa, habilitada legalmente para ello, y respetar los límites de la proporcionalidad". 195

Por otro lado, en relación a la prohibición de castigos crueles e inhumanos, la jurisprudencia de otros países ha entendido que este método de control no coincidiría con

\footnotetext{
189 AMSTRONG, Troy; REINER, Gary; PHILLIPS, Joel, Electronic monitoring programs: an overview, EMT Group Inc., 1987. Disponible en http://www1.spa.american.edu/justice/documents/3335.pdf [visitado el 12.04.2013].

${ }^{190}$ JHSA, Electronic monitoring, cit. nota ${ }^{\circ} 188$.

${ }_{191}$ AMSTRONG et al. Electronic monitoring programs, cit. nota $\mathrm{N}^{\circ} 189$, p. 9.

192 HOUK, Julie, "Electronic Monitoring of Probationers: A Step Towards Big Brother", Golden Gate University Law review, 14 (2), 1984, p. 441. Cit: AMSTRONG et al., Electronic monitoring programs, cit. nota $\mathrm{n}^{\circ} 189$, p. 9. La traducción es de la autora.

193 GONZÁLEZ, "El control telemático en el sistema penal”, cit. nota $n^{\circ} 38$.

${ }^{194}$ Véase, por todos, la STC 207/1990, FJ $6^{\circ}$.

195 GONZÁLEZ, "El control telemático en el sistema penal", cit. nota n 38, p.8.
} 
MORALES, Ana María. "Vigilancia en la modernidad tardía:

El monitoreo telemático de infractores".

los estándares contemplados en los instrumentos internacionales que definen cuándo se está frente a un castigo de tales características. De esta forma, el monitoreo electrónico "comparado con el encarcelamiento, es visto como menos restrictivo y más humano". 196

En otros países, como Canadá, para evitar problemas de orden constitucional, se ha optado por exigir el consentimiento del infractor para efectos de la aplicación del monitoreo telemático, el cual a fin de ser efectivo, debe ser entregado sin coerciones y de manera completamente informada. ${ }^{197}$

En el caso nacional, la regulación contenida en la Ley $\mathrm{N}^{\circ} 20.603$, hace vaticinar la existencia de posibles debates, en relación a eventuales afectaciones al derecho a la intimidad, en la medida que la regulación de la norma, sólo exige el consentimiento de la víctima, para efectos de la aplicación del monitoreo bilateral, como lo dispone el inciso cuarto del artículo 23 Bis. En ese sentido, resulta llamativo, que esta temática no haya sido objeto de debate parlamentario, considerando sus importantes consecuencias, no obstante que se puedan aventurar soluciones similares a la observada en la jurisprudencia comparada, considerando las prerrogativas que le asiste a la judicatura en orden a decretar la pena sustitutiva y, en concreto, la aplicación del monitoreo telemático como mecanismo de control.

Otro aspecto vinculado con este debate relativo a la afectación de derechos fundamentales, hace referencia a una eventual vulneración del derecho a no autoincriminarse, ${ }^{198}$ lo que necesariamente debe ser ligado con el uso de la información obtenida mediante el monitoreo electrónico para posteriores fines investigativos, distintos de los orientados a la ejecución misma de la sanción para lo cual es utilizado. Sin duda, que este aspecto es especialmente sensible en caso de la utilización del rastreo satelital, toda vez que mediante el mismo se puede obtener la exacta localización de la persona en un período de tiempo. En ese contexto, resulta necesario que las legislaciones en la materia regulen de manera cautelosa quiénes pueden acceder a dicha información, y bajo qué supuestos, y que sean castigados aquellos accesos y usos de la información del infractor, que estén fuera de las hipótesis previstas por el legislador.

En el caso de la legislación nacional, la normativa en la Ley $\mathrm{N}^{\circ} 20.603$, relativa al uso de la información proporcionada por monitoreo telemático, pudiere presentar algunos aspectos problemáticos, en la medida que el artículo 23 quinquies, autoriza a los físcales del Ministerio Público a acceder a la información relativa a la aplicación del monitoreo telemático, en el marco de investigaciones en que el sujeto monitorizado aparezca como imputado. Sin embargo, esta situación puede verse superada toda vez que la norma exige que el juez de garantía efectúe previamente una ponderación de valores entre las necesidades de investigación y la afectación del derecho a no autoincriminarse, al someterlo a las reglas de autorización judicial previa contenidas en los artículos 9 y 236 del Código procesal penal.

\footnotetext{
196 JHSA, Electronic monitoring, cit. nota ${ }^{\circ} 188$, p. 12. La traducción es de la autora.

${ }^{197}$ JHSA, Electronic monitoring, cit. nota ${ }^{\circ} 188$.

${ }^{198}$ IGLÉSIAS/PÉREZ, “La pena de localización permanente”, cit. nota n 182.
} 
Adicionalmente en relación a este último derecho, es necesario tener presente, que de conformidad con lo dispuesto en el artículo 23 quinquies, una vez que hubieren trascurrido dos años desde el cumplimiento de la condena, Gendarmería de Chile deberá proceder a la destrucción de la información proporcionada por el sistema. Si bien, resulta adecuada la regulación relativa a la destrucción de la información, hubiere sido deseable que el plazo fuese contado desde el cese del monitoreo, considerando lo extenso del plazo en que se puede hacer uso de la información. Así, podrán llegar a existir casos de hasta 7 años en que se mantendrá la información, de manera independiente de si el sujeto estuvo 6 meses o durante todo el tiempo de duración de la pena controlado telemáticamente.

También, en esta línea de análisis encontramos algunos cuestionamientos a la afectación del principio de igualdad en la aplicación de las penas, en la medida que el monitoreo telemático puede conllevar efectos discriminatorios, al exigir para su aplicación, la existencia de ciertos supuestos que no todos los ciudadanos están en condiciones de cumplir, como son al menos la exigencia de domicilio estable y de una conexión telefónica. Asimismo, esta crítica se genera aun con más fuerza, respecto de aquellas legislaciones en que se exige que el infractor colabore con los costes de instalación y funcionamiento, como sucede con las de algunos estados de Estados Unidos. ${ }^{199}$

En Chile, también es posible visualizar eventuales afectaciones al principio de igualdad, en el caso que el condenado no cuente con un domicilio estable y la existencia de una conexión telefónica. Sin embargo, al establecerse en el inciso segundo del artículo 23 Bis como una facultad discrecional del tribunal, el decretar la utilización del monitoreo telemático para el control de la reclusión parcial y la libertad vigilada intensiva en los supuestos de la letra b) del artículo 15 bis, se entregan herramientas a la judicatura para poder dar una adecuada respuesta en caso de presentarse situaciones como las indicadas. De esta forma, al ser facultativo para el tribunal decretar su uso, el no contar con domicilio estable y conexión telefónica, no debiera ser impedimento para poder decretar algunas de esas penas sustitutivas. Por lo demás, el propio inciso segundo del artículo 7, establece para el caso particular de la reclusión nocturna, la posibilidad que se decreten excepcionalmente otros medios de control similares.

Finalmente, en relación a la situación observada en otros países, que exigen que el infractor concurra al financiamiento del monitoreo, es preciso recordar que una de las indicaciones ingresadas por el Ejecutivo en agosto de 2010, precisamente apuntaron a prever dicha posibilidad, contemplando la existencia de un arancel que permitía determinar la gratuidad o copago del mecanismo de monitoreo. ${ }^{200}$ Finalmente, el Ejecutivo reculó, y decidió retirar

\footnotetext{
${ }^{199}$ IGLÉSIAS/PÉREZ, “La pena de localización permanente”, cit. nota n 182.

${ }^{200}$ De esta forma, el artículo 23 septies del proyecto establecía que "La instalación, mantención y utilización de los dispositivos de control telemático de que trata esta ley, serán siempre gratuitas para los sujetos afectos al sistema de monitoreo telemático.

Excepcionalmente, se podrá cobrar, total o parcialmente, por la utilización del dispositivo de control telemático a los sujetos afectos al sistema de monitoreo que dispongan de recursos para financiarlo privadamente. Para estos efectos, se considerará, al menos, su nivel de ingresos, capacidad de pago y el número de personas del grupo familiar que de ellos dependa, en conformidad al reglamento al que hace referencia el artículo siguiente. $\mathrm{BCN}$, Historia de Ley $\mathrm{N}^{\circ} 20.603$, cit. nota $\mathrm{n}^{\circ} 86$, p. 34.
} 
MORALES, Ana María. "Vigilancia en la modernidad tardía:

El monitoreo telemático de infractores".

la indicación respectiva al copago un año después. En ese sentido, es preciso reconocer que cualquier solución a que se llegue, a este respecto, será siempre basada en argumentos axiológicos y vinculados a la concepción político-económica de la relación individuoEstado. En ese contexto, considerando el monopolio estatal del castigo, y básicamente considerando los mismos argumentos por los cuales se entiende que el sujeto condenado a la cárcel no debe hacer pago de su estadía en ella, es que la gratuidad aparece como una condición necesaria en estos casos.

\section{7. ¿Fomenta la existencia de una sociedad vigilante?}

Lilly $^{201}$ ha sugerido que el monitoreo telemático debe ser analizado considerando el contexto cultural en que se ha generado y en el marco del desarrollo más amplio de tecnologías de vigilancia. En esa línea, Haggerty y Ericson ${ }^{202}$ han planteado que el surgimiento y la convergencia de un conjunto de métodos de vigilancia (surveillant assemblage), vienen a nutrir a la existencia de redes integradas de información computarizada, con el cual se pueden supervigilar electrónicamente los movimientos de los ciudadanos, consumidores, empleados y otras categorías del mundo contemporáneo. Así, el monitoreo telemático sería una técnica de vigilancia más, que se agrega a la red existente, en búsqueda de información relativa al comportamiento de las personas, y que forma parte de los métodos de vigilancia ya integrados al trabajo, a la vida diaria -bajo el formato de cajeros, tarjetas inteligentes, tarjetas de membresía para acceder a determinados bienes y servicio-, y a la monitorización de los espacios públicos y privados, a través de circuitos cerrados de televisión (CCTV). ${ }^{203}$ En dicho marco, argumentan los mismo autores, que la información obtenida a través de los distintos métodos de vigilancia, es dirigida a diferentes lugares de acopio y escrutinio de la información, que incluyen entre otras, a centros forenses, instituciones estadísticas, estaciones de policía, instituciones financieras y corporativas, y sedes militares, que la utilizan con el objeto de desarrollar estrategias económicas, de gobernanza o de control. ${ }^{204}$

Desde esa perspectiva, los argumentos asociados al fomento del vigilantismo, necesariamente deben vincularse con los aportes teóricos de Foucault ${ }^{205}$ y el análisis del panóptico, en la medida que puede entregar una adecuada metáfora para entender los objetivos detrás de los sistemas de vigilancia de los individuos. Así, es preciso recordar que uno de los aspectos del disciplinamiento a través del panóptico, está constituido por la observación y vigilancia constante de los prisioneros, desarrollada con el objeto de trasformar o "normalizar" al individuo. Sin embargo, el panóptico no sólo fue planteado como un reflejo del modelamiento al interior de la prisión, sino también como un reflejo de las técnicas de poder y disciplinamiento también ejercidas en otros espacios, como la fábrica, los hospitales, la escuela y la milicia. Así, en todos estos lugares se desarrollarían

Siempre que procediere el cobro por la utilización del sistema de monitoreo telemático, se deberá informar al condenado de dicha circunstancia en forma previa a la instalación del correspondiente dispositivo."

${ }^{201}$ LILLY, J. Robert, “Tagging reviewed”, Howard Journal of Criminal Justice 29, 1990, pp. 229-245.

${ }^{202}$ HAGGERTY, Kevin; ERICSON, Richard, "The surveillant assemblage", British Journal of Sociology, 2000, 51(4), pp. 605-622.

${ }^{203}$ NELLIS, "Out of this World", cit. nota ${ }^{\circ} 23$.

${ }^{204}$ HAGGERTY/ERICSON, "The surveillant assemblage", cit. nota ${ }^{\circ} 202$.

${ }^{205}$ FOUCAULT, Michel, Vigilar y Castigar, Madrid: Siglo XXI, 2005. 
estrategias panópticas que buscan ejercer un control social. Esto formaría parte de lo que Foucault denomina "archipiélago carcelario", 206 donde todo sujeto es normalizable, expandiéndose el control de éste, desde la escuela al lugar de trabajo, y a la vida cotidiana.

Por otro lado, también es posible vincular esta línea argumentativa a lo expuesto por Orwell en su obra "1984", donde también buscó retratar el vigilantismo a través de la imagen del "Big Brother" (Gran Hermano), donde los ciudadanos de Oceana, eran constantemente monitorizados a través de una pantalla operada por agentes de un estado totalitario y jerárquico, que usaban la vigilancia, como una forma de mantener el orden y la conformidad.

Si bien, los estudios contemporáneos sobre la vigilancia, continúan tomando como marco teórico las obras de Foucault y de Orwell, como señalan Haggerty y Ericson, en el caso del primero, la vigilancia panóptica es utilizada como estrategia de disciplinamiento del alma, mientras que para el segundo, la vigilancia es utilizada como una forma de mantener el control social jerárquico. La diferencia con los métodos de vigilancia contemporáneos estaría radicada en que a través de éstos, lo que se buscaría es acceder a información sobre patrones de comportamiento, ya sea de consumo -como ocurre con el caso de la información financiera o corporativa- o delictivo - en el caso de la información policial o penitenciaria-, buscando establecer perfiles ex post facto, y reconstruyendo comportamientos, hábitos y acciones de las personas. ${ }^{207}$

En ese contexto, la supervisión de infractores a través del monitoreo telemático, necesariamente debe ser concebida dentro de un sustrato de análisis más estructural, relativo a la vigilancia, del modo en que la concibe Giddens, ${ }^{208}$ esto es, como uno de los principales componentes institucionales de la modernidad tardía. Así, el sociólogo inglés argumenta que, si bien la vigilancia dice relación con la supervisión de las actividades de las poblaciones en cuestión en la esfera política, su importancia no está de ninguna manera limitada a esa arena. De dicha forma, la supervisión puede ser ejercida de manera directa, como en muchas de las instituciones analizadas por Foucault, sean éstas prisiones, escuelas, o lugares de trabajo abiertos, entre otras. Sin embargo, lo más característico de la vigilancia contemporánea, es su carácter indirecto, basándose en el "control de la información”."209

Considerando lo anterior, y buscando responder si el monitoreo telemático fomenta la existencia de una sociedad vigilante, la respuesta, a la luz de las argumentaciones teóricas expuestas, necesariamente debe ser afirmativa. Esto, en la medida que se enmarca dentro del espectro de tecnologías de control de la información contemporáneas, y que busca efectivamente producir información acerca de los individuos con el objeto de controlar su localización, pudiendo incluso obtenerse patrones de movimiento en el caso de la utilización del rastreo satelital. Si bien es cierto lo anterior, resulta necesario comprender que la monitorización de infractores, se inserta en un marco amplio de la vigilancia propia de la sociedad contemporánea, y que supone el acceso y control de información en varias

\footnotetext{
${ }^{206}$ FOUCAULT, Vigilar y Castigar, cit. nota ${ }^{\circ} 205$, p. 303.

${ }^{207}$ HAGGERTY/ERICSON, "The surveillant assemblage”, cit. nota $n^{\circ} 202$.

${ }^{208}$ GIDDENS, Anthony, The Consequences of Modernity, Cambridge: Polity Press, 1990.

${ }^{209}$ GIDDENS, The Consequences of Modernity, cit. nota $\mathrm{n}^{\circ} 208, \mathrm{p} .58$.
} 
MORALES, Ana María. "Vigilancia en la modernidad tardía:

El monitoreo telemático de infractores".

esferas de la vida cotidiana. Es así, como en nuestro país, diariamente nos vemos expuestos a instancias de vigilancia, a través de la utilización de las cámaras de CCTV, el uso del GPS para el rastreo de vehículos, o la absorción de la información relativa a nuestros hábitos de consumo por parte de la industria privada.

\section{Conclusiones}

El presente ensayo buscó -en primer término- entregar un marco conceptual para efectos de entender el surgimiento del monitoreo telemático en las distintas legislaciones. Es así, como éste fue concebido bajo el alero de las denominadas "sanciones intermedias", creadas con el objetivo de contar con respuestas sancionatorias, que no gozaran ni de la visión de benignidad asociada a la probation ni de la dureza propia de las penas de cárcel. En ese contexto, se precisó que el monitoreo telemático no busca servir como sanción en sí mismo, sino que corresponde a un mecanismo de control o una tecnología que usualmente va adosado a otras sanciones como las reclusiones domiciliarias y a la imposición de condiciones de alejamiento. De esta forma, se analizó su implementación en el ámbito de la justicia penal, particularmente su utilización para el control de medidas cautelares, de sanciones en la comunidad, de permisos de salida de los recintos penitenciarios, para el control de la libertad condicional, y también para algunos usos asociados al control de medidas de seguridad post delictual.

En segundo término, se revisaron algunos aspectos relativos a su futura implementación en nuestro país, a partir de la dictación de la Ley $\mathrm{N}^{\circ} 20.603$, analizándose su regulación para el control de la reclusión parcial, la libertad vigilada intensiva en las hipótesis de condenados por algunos delitos contra la indemnidad sexual y de violencia intrafamiliar, y su aplicación a la libertad vigilada intensiva como consecuencia de la dictación de una pena mixta.

En particular, fue posible establecer consonancias entre la regulación normativa y aquélla observada en la experiencia comparada, en relación a la aplicación del monitoreo telemático para controlar las penas sustitutivas antes señaladas, particularmente en el caso de los delitos cometidos en el contexto intrafamiliar y los delitos sexuales. Así, una cuestión relevada por la literatura criminológica, es la importancia que estos casos siempre vayan acompañados de algún tipo de intervención psicosocial que aborde la conducta infractora, como efectivamente parece desprenderse de la regulación de estos supuestos, en combinación con la libertad vigilada intensiva. Sin embargo, también se presentan algunos aspectos problemáticos en la regulación nacional del monitoreo telemático, y que dicen relación con la duración del mismo, la obligatoriedad de su utilización en los casos de pena mixta, y la inexistencia de criterios que permitan decidir a la judicatura respecto de la necesidad de imponer tal control, especialmente en los casos en que se observen bajas probabilidades de que el condenado reincida. Esta cuestión resulta, sin duda, relevante desde la perspectiva del uso eficiente de los recursos del Estado y de la evitación de eventuales efectos indeseados en los infractores y sus familias.

En tercer término, uno de los propósitos del presente ensayo, fue analizar la evidencia e investigaciones comparadas, en relación al cumplimiento de algunos de los objetivos asociados a la implementación de esta política pública, junto con plantear, también en base 
a la literatura internacional, algunos debates suscitados a propósito de su aplicación para el control penal de determinadas medidas y sanciones. Es así, como en primer lugar, se analizó los efectos del monitoreo telemático en relación al propósito asociado a la reducción de la cantidad de personas recluidas y se pudo establecer, que ese fin generalmente no se habría cumplido. En ese contexto, se analizó lo planteado por algunos autores, que han argumentado que lo que eventualmente se habría producido con su implementación es el fenómeno de ampliación de la red de control penal o netwidening. Sin embargo, se pudo también observar que la evidencia criminológica ha entregado resultados contradictorios, no pudiéndose establecer con firmeza a partir de dichos hallazgos la generación de esos efectos. No obstante lo anterior, y como una forma precisamente de evitarlos, es que se recomienda su aplicación a infractores con altas o moderadas probabilidades de reincidir, de manera que éste ópere realmente como una alternativa al encarcelamiento. Asimismo, y en base al análisis de su futura implementación en la legislación nacional, fue posible anticipar efectos tanto de reducción de la cantidad de personas recluidas - en el caso del uso para el control de la reclusión parcial, como en la libertad vigilada intensiva decretada como consecuencia de la aplicación de una pena mixta-, como de netwidening - en el caso de su aplicación a los condenados por ciertos delitos sexuales y de violencia intrafamiliar, respecto de los cuales se hubiere decretado una libertad vigilada intensiva-.

Otro de los objetivos tradicionalmente invocados para fomentar la aplicación del monitoreo telemático, se relaciona con sus eventuales efectos en la reducción de la reincidencia. En relación a este punto, es necesario tener presente que si bien el monitoreo telemático no constituye una sanción, y por lo tanto no correspondería esperar consecuencias asociadas a la prevención especial, sí se ha argumentado por la literatura comparada la generación de efectos positivos en esa materia, asociados al efecto disuasivo de la amenaza de detección inmediata, al desarrollo de oportunidades prosociales, y especialmente a la idea de que la monitorización evitaría los efectos negativos del encarcelamiento. Sin embargo, los resultados de los estudios internacionales son mixtos, no existiendo evidencia concluyente que permita afirmar los efectos positivos en esta materia, tanto para los modelos de front door como para los modelos de back door.

Desde otra perspectiva, también se encuentra con su implementación, una demanda asociada a la generación de una alternativa costo-eficiente. En ese contexto, se logró establecer que los efectos en la reducción de costos, dependerán en gran medida del diseño legal que se adopte para su introducción, vinculando al debate asociado al netwidening. Así, si el monitoreo telemático es utilizado "en vez" de la cárcel, entonces es posible esperar ciertos ahorros directos por el Estado. Sin embargo, para todos aquellos casos en que el monitoreo telemático entre a "competir" en su ámbito de aplicación con otras alternativas al encarcelamiento, resulta más complejo visualizar esos ahorros.

También se observó que uno de los aspectos debatidos por la literatura internacional dice relación con su aplicación a distintos tipos de delincuencia. En concreto, a partir de la revisión efectuada, se pudo establecer que el monitoreo telemático ha sido aplicado en una diversidad de infractores, aun cuando no se ha podido establecer su conveniencia para todos los perfiles. Es así, como se ha recomendado por algunos expertos, que más que el tipo de 
MORALES, Ana María. "Vigilancia en la modernidad tardía:

El monitoreo telemático de infractores".

delito, resulta necesario tener presentes las probabilidades de reincidencia de la persona sujeta a monitorización, junto con hacerse cargo de las complejidades que podrían presentarse en caso de aplicarse en jóvenes.

Además, se buscó indagar sobre los efectos del monitoreo telemático, tanto en los infractores como en sus familias, observándose en base a las escasas investigaciones existentes a nivel internacional en la materia, ciertos efectos en los infractores tanto negativos como positivos. Dentro de los negativos, encontraríamos experiencias asociadas al estigma y vergüenza, que estarían presentes en la experiencia vital de los sujetos monitorizados, y que en el caso de los jóvenes, debiera ser abordada con aun mayor precaución. También, se registrarían algunos efectos en relación al trabajo, al no contar los infractores con la flexibilidad horaria necesaria. Por otro lado, los efectos positivos, estarían asociados a una suerte de apoyo al proceso de desistencia de aquellos infractores que están buscando cesar en su actividad delictual, lo que se explicaría por la posibilidad que otorga la reclusión en el domicilio, de desvincularse de ambientes y pares criminógenos, junto con aumentar el capital prosocial, al incentivar a los infractores a conectarse con las influencias vinculadas a la desistencia como la familia y el trabajo. Asimismo, también desde la perspectiva familiar, se valoraría positivamente que el sujeto a monitorización pudiere seguir contribuyendo a las responsabilidades en su hogar, y donde el apoyo de sus seres cercanos parece ser esencial para poder cumplir adecuadamente con los requerimientos propios de la reclusión.

En la literatura comparada también encontramos algunos argumentos que apuntan a que la introducción de este tipo de tecnologías fomentaría el vigilantismo, siendo caracterizadas dentro de las técnicas de supervisión contemporánea. En ese sentido, se argumentó que el monitoreo telemático debe, necesariamente, enmarcarse en análisis más estructurales, concibiéndose a éste como uno de los componentes institucionales de la modernidad tardía, asociada a la búsqueda constante del control de la información. Así también, y vinculadas con el debate anterior, se analizó las eventuales consecuencias que pudiera tener el uso de ésta tecnología en la afectación de la esfera privada, y en particular respecto del derecho a la intimidad, la inviolabilidad del hogar, el secreto de las comunicaciones, la libre circulación, la libertad personal y la protección de datos personales. Sobre este punto, se observó que en la jurisprudencia comparada, si bien se reconoce la afectación de derechos con su imposición, se ha entendido que algunos de ellos, como el derecho a la intimidad, pueden ser objeto de ciertas afectaciones si se cumplen determinados requisitos, entendiendo que los sujetos a monitoreo telemático tendrían "derechos disminuidos". También en relación a este debate, se plantearon ciertos cuestionamientos a la regulación nacional en relación al derecho a no auto incriminarse, considerando las posibilidades asociadas al uso de información obtenida con el monitoreo.

Finalmente, y a modo de síntesis, es posible afirmar que la evidencia e investigaciones internacionales, arrojan tanto aspectos positivos como negativos, en relación al monitoreo telemático en otras legislaciones, no obstante que la información en varios de las temáticas indagadas aún es incipiente como para efectuar afirmaciones categóricas, respecto de su aplicación. Sin embargo, como se señaló anteriormente, un punto crucial para su adecuada implementación se relaciona con la generación de una arquitectura normativa que permita 
Polít. crim. Vol. 8, № 16 (Diciembre 2013), Art. 3, pp. 408-471.

[http://www.politicacriminal.cl/Vol_08/n_16/Vol8N16A3.pdf]

hacerse cargo de varios de los aspectos señalados, especialmente en lo relativo a los efectos de expansión de la red de control penal o netwidening, y a su uso en aquellos infractores con mayor probabilidad de reincidencia. En ese marco, si bien la regulación en la Ley $\mathrm{N}^{\circ} 20.603$ resulta adecuada, haciéndose cargo de algunas de estas prevenciones, también presenta algunos aspectos problemáticos que de no ser abordados, podrían afectar el adecuado funcionamiento del sistema.

\section{BIBLIOGRAFÍA}

ALBRECHT, Hans-Joerg, Electronic monitoring in Europe. A summary and assessment of recent developments in the legal framework and implementation of electronic monitoring, Max Planck Institute for Foreign and International Criminal Law, 2005. Disponible en http://www.mpicc.de/shared/data/pdf/albrecht.pdf [visitado el 12.04.2013].

"Imprisonment and alternatives to prisons: Changes and prospects in comparative perspective", Revista Académica, 3 (6), UNAM-Instituto de Investigaciones Jurídicas, 2006.

"Electronic Monitoring, Resettlement and Recidivism", Presentación en power point efectuada en la Séptima conferencia en monitoreo electrónico, organizado por la Organización Europea de Probación (CEP), 2011. Disponible en http://www.cepprobation.org/uploaded_files/EM2011_Day_1.5_Resettlement_Recidi vism_by_Hans-Joerg_Albrecht.pdf [visitado el 12.04.2013].

AMSTRONG, Troy; REINER, Gary; PHILLIPS, Joel, Electronic monitoring programs: an overview, Sacramento: EMT Group Inc., 1987. Disponible en http://www1.spa.american.edu/justice/documents/3335.pdf [visitado el 12.04.2013].

BALES, William; MANN, Karen, BLOMBERG, Thomas.; GAES, Gerry.; BARRICK, Kele; DHUNGANA, Karla; McMANUS, Brian, A Quantitative and Qualitative Assessment of Electronic Monitoring, Washington: National Criminal Justice Reference $\quad$ Service, $2010 . \quad$ Disponible en http://www.criminologycenter.fsu.edu/p/pdf/EM\%20Evaluation\%20Final\%20Report \%20for\%20NIJ.pdf [visitado el 12.04.2013].

BARTON, Shannon; ROY, Sudipto, "Convicted Drunk Drivers in an Electronic Monitoring Program: A preliminary study", International Journal of Criminal Justice Sciences, 2008, 3 (1), pp. 28-43.

BIBLIOTECA DEL CONGRESO NACIONAL, Historia de Ley $N^{\circ} 20.603$. Disponible en http://www.bcn.cl [visitado el 12.04.2013].

BONTA, James; ROONEY, Jennifer; WALLACE-CAPRETTA, Suzanne, Electronic Monitoring in Canada, Solicitor General Canada, 1999. Disponible en http://www.publicsafety.gc.ca/cnt/rsrcs/pblctns/lctrnc-mntrng-cnd/lctrnc-mntrng-cndeng.pdf [visitado el 12.04.2013].

"Can electronic monitoring make a difference? An evaluation of three Canadian programs", Crime \& Delinquency 2000, 46 (1), pp.61-75

BOOTHER, Mark, "An overview of electronic monitoring", presentación efectuada en seminario El uso de tecnologías en el sistema penal: Monitoreo Telemático, realizado por la Fundación Paz Ciudadana, 2011. Inédito. 
MORALES, Ana María. "Vigilancia en la modernidad tardía:

El monitoreo telemático de infractores".

BOTTOS, Shauna, An overview of Electronic Monitoring in Corrections: The issues and Implications, Research Brand Correctional Service Canada, 2007. Disponible en http://www.csc-scc.gc.ca/research/r182-eng.shtml [visitado el 12.04.2013].

BOTTOMS, Anthony; SHAPLAND, Joanna; COSTELLO, Andrew, HOLMES, Deborah; MUIR, Grant, "Towards Desistance: Theoretical Underpinnings for an Empirical Study", The Howard Journal of Criminal Justice, 2004, 43 (4), pp. 368-389.

BRAITHWAITE, John, Crime, Shame and Reintegration, Cambridge: Cambridge University Press, 1989.

BURREL, William y GABLE, Robert, "From B.F. Skinner to Spiderman to Martha Stewart: The Past, Present and Future of electronic monitoring of offenders", Probation and Parole, Current Issues, 2008, pp.101-118.

BUTTON, Deeanna; DeMICHELE, Matthew; PAYNE, Brian, "Using Electronic Monitoring to Supervise Sex Offenders. Legislative Patterns and Implications for Community Corrections Officers”, Criminal Justice Policy Review, 2009, 20 (4), pp. 414-436.

COHEN, Michelle; JEGLIC, Elizabeth, "Sex Offender Legislation in the United States: What Do We Know?", International Journal of Offender Therapy and Comparative Criminology, 2007, 51 (4), pp. 369- 383.

COHEN, Stanley, "The punitive city: Notes on the dispersal of social control", Contemporary Crises, 1979, 3 (4), pp. 339-363.

CONWAY, Peggy "A basic introduction to electronic monitoring: Remote supervision technologies", Journal of Offender Monitoring, 2001, 14 (1\&2), pp. 6-10.

COOPRIDER, Keith; KERBY, Judith, "Practical application of electronic monitoring at the pretrial stage", Federal Probation 54 (1990), pp. 28-35.

COURTRIGHT, Kevin; BERG, Bruce; MUTCHNICK, Robert, "Rehabilitation in the New Machine? Exploring Drug and Alcohol Use and Variables Related to Success Among DUI Offenders Under Electronic Monitoring-Some Preliminary Outcome Results ”, International Journal of Offender Therapy and Comparative Criminology, 2000, 44 (3), pp. 293-311.

CRIMINAL JUSTICE JOINT INSPECTION, Thematic report. It's complicated: The management of electronically monitored curfews, 2012. Disponible en http://www.justice.gov.uk/downloads/publications/inspectoratereports/hmiprobation/joint-thematic/electronic-monitoring-report-2012.pdf [visitado el 12.04.2013].

CROWE, Ann; SYDNEY, Linda, BANCROFT, Pat; LAWRENCE, Beverly, Offenders Supervision with Electronic Technology, Kentucky: American Probation and Parole Association, 2002. Disponible en https://www.ncjrs.gov/pdffiles1/nij/grants/197102.pdf [visitado el 12.04.2013].

DEMICHELE, Matthew y PAYNE, Brian, Offender supervision with Electronic Technology: Community corrections resource, Washington: Bureau of Justice Assistance, Department of Justice, 2009. Disponible en http://www.appanet.org/eweb/docs/appa/pubs/oset_2.pdf [visitado el 12.04.2013].

DEYOUNG, David; TASHIMA, Helen; MASTEN, Scott, An evaluation of the effectiveness of ignition interlock in California, California: California Department of Motor

Vehicles,

2004.

Disponible

en 
Polít. crim. Vol. 8, № 16 (Diciembre 2013), Art. 3, pp. 408-471.

[http://www.politicacriminal.cl/Vol_08/n_16/Vol8N16A3.pdf]

https://www.dmv.ca.gov/about/profile/rd/210_ignition_interlock_report.pdf [visitado el 12.04.2013].

DI TELLA, Rafael; SCHARGRODSKY, Ernesto, "Criminal Recidivism after Prison and Electronic Monitoring”, Journal of Political Economy, University of Chicago, 2013, 121(1), 28-73.

EREZ, Edna; IBARRA, Peter, "Making Your Home a Shelter. Electronic Monitoring and Victim Re-entry in Domestic Violence Cases”, British Journal of Criminology, 2007, 47 (1) pp.100-120.

EREZ, Edna; IBARRA, Peter; BALES, William y GUR, Oren, GPS Monitoring Technologies and Domestic Violence: An Evaluation Study, Washington: National Criminal Justice Reference Service, 2012. Disponible en http://www.ncdsv.org/images/GPSMonitoringTechnologiesAndDVandEvaluationStu dy_6-2012.pdf [visitado el 12.04.2013].

ESCOBAR, Gonzalo, "Los monitores electrónicos (¿puede ser el control electrónico una alternativa a la cárcel?), en: LARRAURI, Elena y CID, José, (Coord.) Las Penas alternativas a la prisión, Barcelona: Bosch, 1997, pp. 197-224.

FARRAL, Stephen; CALVERLEY, Adam, Understanding Desistance from Crime, Maidenhead: Open University Press, 2006.

FINN, Mary; MUIRHEAD-STEVES, Suzanne, "The Effectiveness of Electronic Monitoring with Violent Male Parolees", Justice Quarterly 19 (2002), pp. 293-312.

FOUCAULT, Michel, Vigilar y Castigar, Madrid: Siglo XXI, 2005.

GAINEY, Randy; PAYNE, Brian, "Understanding the experience of house arrest with electronic monitoring: An analysis of quantitative and qualitative data", International Journal of Offender Therapy and Comparative Criminology, 2000, 44 (1), pp. 84-96.

GIES, Stephen; GAINEY, Randy; COHEN, Marcia; HEALY, Eoin; DUPLANTIER, Dan; YEIDE, Martha; BEKELMAN, Alan; BOBNIS, Amanda; Hopps, Michael, Monitoring High- Risk Sex Offenders With GPS Technology: An Evaluation of the California Supervision Program, Final Report, Office of Research and Evaluation National Institute of Justice. Washington DC. 2012. Disponible en https://www.ncjrs.gov/pdffiles1/nij/grants/238481.pdf [visitado el 12.04.2013].

GIBBS, Anita; KING, Denise, "The electronic Ball and Chain? The Operation and Impact of Home Detention with Electronic Monitoring in New Zealand", The Australian and New Zealand Journal of Criminology, 2003, 36 (1), pp. 1-17.

GIDDENS, Anthony, The Consequences of Modernity, Cambridge: Polity Press, 1990.

GLASER, Daniel; WATTS, Ronald, "Electronic Monitoring of Drug Offenders on Probation", Judicature, 1992, 76 (3).

GOFFMAN, Erving, Stigma: Notes on the Management of Spoiled Identity, Nueva York: Simon \& Schuster, 1963.

GONZÁLEZ, Cristina, El control telemático en el sistema penal, tesis doctoral, Universidad de Barcelona, 2008. Disponible en http://ddd.uab.cat/pub/tesis/2008/tdx1120108-151704/cgb1de1.txt [visitado el 12.04.2013].

HAGGERTY, Kevin; ERICSON, Richard, "The surveillant assemblage", British Journal of Sociology, 2000, 51(4), pp. 605-622.

HAVERKAMP, Rita; MAYER, Markus, LÉVY, René, "Electronic monitoring in Europe", European Journal of Crime, Criminal Law and Criminal Justice, 2004, 12(1), pp. 3645. 
MORALES, Ana María. "Vigilancia en la modernidad tardía:

El monitoreo telemático de infractores".

HUCKLESBY, Anthea, "Vehicles of desistance?: The impact of electronically monitored curfew orders", Criminology and Criminal Justice, 2008, 8 (1), pp. 51-71.

"Insider's views. Offender's and staff's experiences of electronically monitored curfews", en: NELLIS Mike; BEYENS, Kristel y KAMINSKY, Dan, Electronically Monitored Punishment. International and critical perspectives, Oxon: Routledge, 2013.

IGLÉSIAS, Miguel Ángel; PÉREZ, Juan Antonio, "La pena de localización permanente y su seguimiento con medios de control electrónicos", Anuario de Derecho Constitucional Latinoamericano, 2006. Disponible en http://www.juridicas.unam.mx/publica/librev/rev/dconstla/cont/2006.2/pr/pr21.pdf [visitado el 12.04.2013].

KILLIAS, Martin; GILLIÉRON; Gwladys; KISSLING, Izumi; VILLETTAZ, Patrice, "Community Service Versus Electronic Monitoring - what works better? Results of a Randomized Trial”, British Journal of Criminology 50 (2010), pp. 1155-1170.

JOHN HOWARD SOCIETY OF ALBERTA, Electronic monitoring, 2000. Disponible en http://www.johnhoward.ab.ca/pub/A3.htm [visitado el 12.04.2013].

"Electronic Monitoring", The Reporter, 2001, 18 (1). Disponible en http://www.johnhoward.ab.ca/newslet/may2001/may01.htm [visitado el 12.04.2013]. Electronic (radio frequency) and GPS monitored community based supervision programs, 2006. Disponible en http://www.johnhoward.ab.ca/pub/pdf/monitorupdate.pdf [visitado el 12.04.2013].

IBARRA, Peter y EREZ, Edna, "Victim-centric Diversion? The electronic monitoring of domestic violence cases", Behavioral Sciences and the Law 23 (2005), pp. 259-276.

LARRAURI, Elena y CID, José, "Uso expansionista de la prisión y políticas reduccionistas”, en: LARRAURI, Elena y CID, José, (Coord.) Las Penas alternativas a la prisión, Barcelona: Bosch, 1997, pp. 11-35.

LARRAURI, Elena, "Las paradojas de importar alternativas a la cárcel en el Derecho Penal español”, Anuario de Derecho Penal y Ciencias Penales 1 (1991), pp. 45-62.

LILLY, J. Robert, “Tagging reviewed”, Howard Journal of Criminal Justice 29 (1990), pp. 229-245.

MAIR, George; NEE, Claire, Curfew orders with electronic monitoring: the trials and their result, Home office Research Study 163, London Home Office, 1990.

MAIR, Gorge; MORTIMER, Ed, Curfew orders with Electronic Monitoring, Home Office Research Studies N 163, London: Home Office, 1996.

MARKLUND, Frederik, HOLMBERG, Stina, "Effects of early release from prison using electronic tagging in Sweden", Journal of Experimental Criminology, 2009, 5 (1), pp. 41-61.

MARTINOVIC, Marietta, "The punitiveness of electronically monitored community based programs". Artículo presentado en la Conferencia de la "Probation and Community Corrections Officers Association Inc.", Perth, Australia, 2002. Disponible en http://www.aic.gov.au/media_library/conferences/probation/martinovic.pdf [visitado el 12.04.2013].

MARUNA, Shad, Making good: How ex convicts Reform and Rebuild Their Lives, Washington DC: American Psychological Association Books, 2001.

McNEILL, Fergus, "A desistance paradigm for offender management", Criminology and Criminal Justice, 2006, 6 (1), pp. 39-62. 
Polít. crim. Vol. 8, № 16 (Diciembre 2013), Art. 3, pp. 408-471.

[http://www.politicacriminal.cl/Vol_08/n_16/Vol8N16A3.pdf]

MERTON, Robert, Social Theory and Social Structure, Nueva York: The Free Press, 1968.

MINISTERIO DE JUSTICIA, Material de capacitación. Nueva Ley $N^{\circ} 18.216$, Santiago: Ministerio de Justicia, Inédito.

MORALES, Ana María, "Redescubriendo la Libertad Condicional”, Revista Razonamiento Penal N² (2012), pp. 179-201.

MORALES, Ana María; MUÑOZ, Nicolás; WELSCH, Gherman; FÁBREGA, Jorge, La Reincidencia en el Sistema Penitenciario Chileno, Fundación Paz Ciudadana, 2012, Disponible en http://www.pazciudadana.cl/wp-content/uploads/2013/07/2013-0321 reincidencia-en-el-sistema-penitenciario-chileno.pdf [visitado el 12.04.2013].

MORALES, Ana María; WELSCH, Gherman; CÁRCAMO, Javiera; MUÑOZ, Nicolás, Estudio de estimación del presupuesto general para la implementación del programa de Tribunal de Tratamiento de Drogas a nivel nacional, tanto para población adolescente como adulta. Informe Final, Fundación Paz Ciudadana, 2011. Disponible en http://www.pazciudadana.cl/wp-content/uploads/2013/07/2011-04-01_estudio-deestimacion.pdf [visitado el 12.04.2013].

MORRIS, Norval y TONRY, Michael, Between Prison and Probation. Intermediate Punishments in a rational Sentencing System, New York: Oxford University Press, 1990.

NELLIS, Mike, "The electronic monitoring of offenders in England and Wales: Recent developments and future prospects", British Journal of Criminology, 1991, 31(2), pp. 165-185.

"Out of this World: The Advent of the Satellite Tracking of Offenders in England and Wales", The Howard Journal of Criminal Justice, 2005, 44(2), pp. 125150.

"Electronic monitoring and the creation of control orders for terrorist suspects in Britain", en: ABBAS, Tahir (Ed.), Islamic political radicalism, Escocia: Edinburgh University Press, 2007, pp. 263-278.

"Surveillance and Confinement: Explaining and understanding the experience of electronically monitored curfews", European Journal of Probation, 2009, 1 (1), pp. 41-65.

"Electronic monitoring: towards integration into offender management?", en: McNEILL, Fergus; RAYNOR, Peter, y TROTTER, Chris, Offender Supervision. New Directions in theory, research and practice, Oxon: Willan, 2010.

"Surveillance, stigma and spatial constraint", en: NELLIS, Mike; BEYENS, Kristel y KAMINSKY, Dan, Electronically Monitored Punishment. International and critical perspectives, Oxon: Routledge, 2013.

NELLIS, Mike; TORRES, Nuria, "Electronic Monitoring and Probation: Offender rehabilitation and the reduction of Prison population", Conference Report, $7^{\text {th }}$ European Electronic Monitoring Conference, 5 al 7 de Mayo, Portugal, 2011. Disponible en http://www.cep-probation.org/default.asp?page_id=157\&map_id=85 [visitado el 12.04.2013].

PADGETT, Kathy; BALES, William; BLOMBERG, Thomas, "Under Surveillance: An Empirical Test Effectiveness and Consequences of Electronic Monitoring", Criminology and Public Policy 5 (2006), pp. 61-91. 
MORALES, Ana María. "Vigilancia en la modernidad tardía:

El monitoreo telemático de infractores".

PAYNE, Brian; DeMICHELE Matthew, "Electronic supervision for sex offenders: Implications for work load, supervision goals, versatility and policy making", Journal of Criminal Justice 28 (2010), pp. 276-281.

PETERSILIA, Joan, "A decade of experimenting with intermediate sanctions: what have we learned?", Journal of the Justice Research and Statistics Association, 1999, 1 (1), pp. 9-22.

When prisoners come home. Parole and Prisoner Reentry, Nueva York: Oxford University Press, 2003

PETERSILIA, Joan; TURNER, Susan; KAHAN, James y PETERSON, Joyce, Granting felons probation: public risks and alternatives, Washington: National Institute of Justice y RAND Corporation, 1985.

RENZEMA, Marc, "State of the art: Part II Programmed contact equipment", Journal of offender monitoring, 1992, 2 (3), pp.18-23.

Electronic Monitoring's Impact on Reoffending, 2003. Disponible en http://www.correcttechllc.com/articles/13.pdf [visitado el 12.04.2013].

RENZEMA, Marc y MAYO-WILSON, Evan, "Can electronic monitoring reduce crime for moderate to high risk offenders?", Journal of Experimental Criminology 1 (2005), pp. 215-237.

RIBERA, Teodoro, presentación denominada "Realidad actual y desafíos del sistema penitenciario chileno", realizada en el seminario Cárceles concesionadas revitalizando el modelo, organizado por el Instituto Libertad y Desarrollo, en 2012. Disponible en http://www.lyd.com/wp-content/uploads/2012/08/PresentaciónLyD.pdf [visitado el 12.04.2013].

SUGG, Darren; MOORE, Louise; HOWARD, Philip, "Electronic monitoring and offending behavior: reconviction results for the second year of trials of curfew orders", Research finding $\mathrm{N}^{\circ} 41$, London: Home Office research, development and statistics Directorate, 2001.

THE MAGISTRATES' ASSOCIATION, "Sentencing Policy and Practice Committee. Curfew orders with electronic monitoring (tagging)", Policy Paper, 2010. Disponible en http://www.magistrates-association.org.uk/dox/consultations/1285770521_56curfew-orders-policy.pdf?PHPSESSID=eqmccuoidnqd4sqaes8gj4o5r3 [visitado el 12.04.2013].

TONRY, Michael; LYNCH, Mary, “Intermediate sanctions”, en: TONRY, Michael (Ed.), Crime and Justice: A Review of Research, Chicago: University of Chicago Press, 1995, pp. 99-144.

VON HIRSCH, Andrew, Censurar y castigar, Madrid: Trotta, 1998.

VON HIRSCH, Andrew; WASIK, Martin, "Non-custodial penalties and the principles of Desert", The Criminal Law Review, 1988, pp.554-572.

WYMAN, Mary y WALKER, Sue, "Young People - The Opportunities and Challenges of Tagging", presentación en power point en la Conferencia en Monitoreo Electrónico, organizado por la Organización Europea de Probation (CEP), realizada entre el 7 y el 9 de Mayo de 2009, en Holanda. Disponible en http://www.cepprobation.org/default.asp?page_id=116\&news_item=191 [visitado el 12.04.2013].

ZENDER, Lucía, "Preventive Justice or Pre-punishment? The case of control orders", Current Legal Problems, 2007, 60 (1), pp. 174-203. 